EDUCATIONAL EXPERIENCES OF INCARCERATED YOUTH:

DOING SCHOOL WHILE DOING TIME

\author{
A dissertation submitted to the faculty of \\ San Francisco State University \\ In partial fulfillment of \\ the Requirements for \\ As \\ the Degree \\ 35 \\ 2016 \\ Doctor of Education \\ EDD \\ In \\ - $\$ 28$ \\ Educational Leadership
}

by

Janine Yvonne Saunders

San Francisco, California

May 2016 
Copyright by

Janine Yvonne Saunders

2016 


\section{CERTIFICATION OF APPROVAL}

I certify that I have read Educational Experiences of Incarcerated Youth: Doing School While Doing Time by Janine Yvonne Saunders, and that in my opinion this work meets the criteria for approving a dissertation submitted in partial fulfillment of the requirements for the degree: Doctor of Education in Educational Leadership at San Francisco State University.

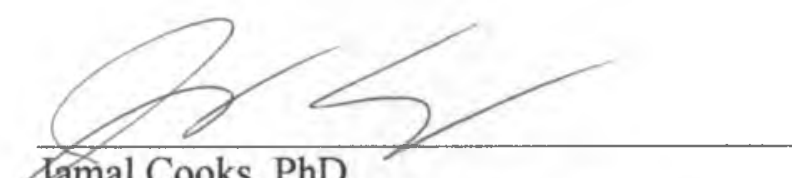

Professor of Secondary Education
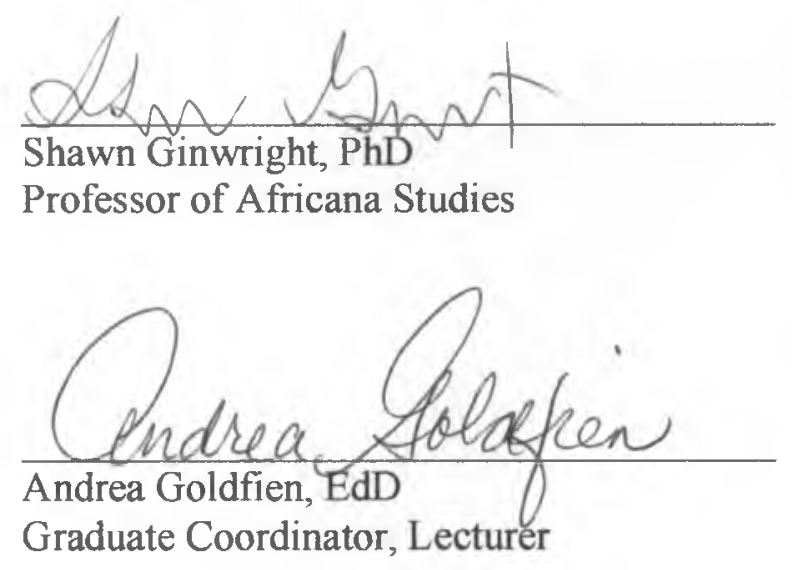


\title{
EDUCATIONAL EXPERIENCES OF INCARCERATED YOUTH: \\ DOING SCHOOL WHILE DOING TIME
}

\author{
Janine Yvonne Saunders \\ San Francisco State University
}

2016

Poor academic outcomes for incarcerated students are well-established in the literature but limited qualitative data are available that describe students' educational experiences. This study deepens our understanding of students' experiences in the school-to-prison pipeline. An exploratory case study design used phenomenological interviews to answer the following questions: How do incarcerated students describe their educational experiences leading up to and during incarceration? How do incarcerated students make meaning of their educational experiences behind bars? Findings emerged across the students' educational trajectory and included positive early school experiences, school disengagement in middle and high school, and academic reengagement in prison school. Recommendations include reimagining the way we educate young people behind bars. The stories of young people, told in their own words, can demonstrate how to disrupt the flow of adolescents through the pipeline and create juvenile justice schools that help all students succeed academically.

I certify that the Abstract is a correct representation of the content of this dissertation.
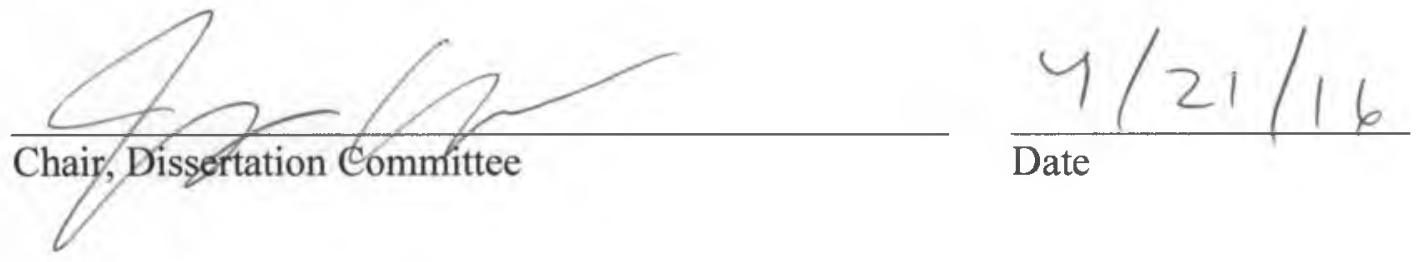

Date 


\section{PREFACE}

With love, I thank my family especially my wife Dionne Teasley.

With appreciation, I thank my dissertation chair and committee members.

With gratitude, I thank my professors, classmates, and study group (EBSG4L).

With humility, I thank other Black women who have told stories and made it possible for me to tell these stories. To Mary Peake, Zora Neale Hurston, Toni Morrison, Audre Lorde, bell hooks, Ava DuVernay, Ella Baker, and those whose names I do not know. \#blackgirlmagic With special thanks to my father and my mother (the first Dr. Saunders). You are my first, my finest, and my wisest teachers. 


\section{ACKNOWLEDGEMENTS}

This dissertation would not have been possible without the young people who so generously shared their time and their truth with me. To Ahmed, Brandon, Travis, Lisa, Shamieka, Jesus, Andrew, Carlos, Sergio, Juan, Angelo, Raymond, Roberto, Andre, Jorge, Raphael, JaMarcus, Dominique, Vanessa, Erykah, Peter, Daniel, DeShawn, James, Michael, Donte, Timothy, and Tyrone. Though your names are pseudonyms, your stories are real. I tried to share them as honestly as you did. You feel me? 


\section{TABLE OF CONTENTS}

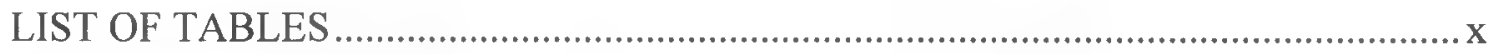

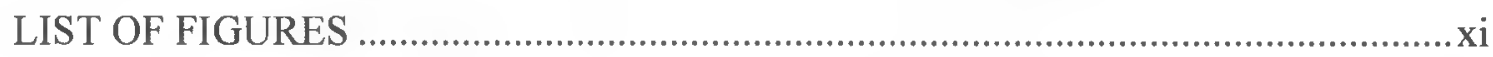

LIST OF APPENDICES ..............................................................................................

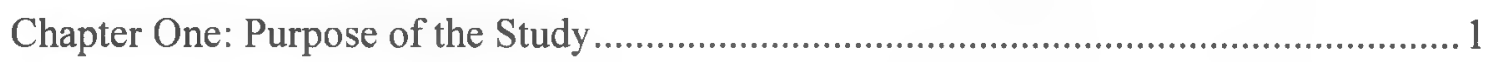

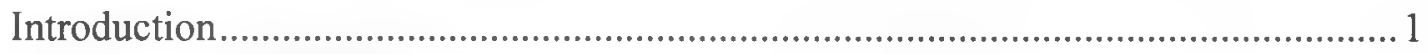

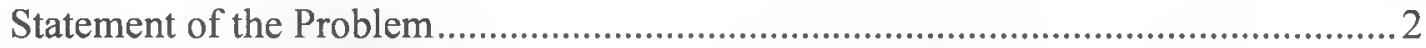

Incarcerated Students Have Poor Academic Outcomes........................................2

Prison Schools Reinforce Existing Educational Inequities...................................

Research Questions and Design............................................................................ 12

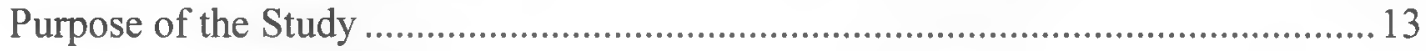

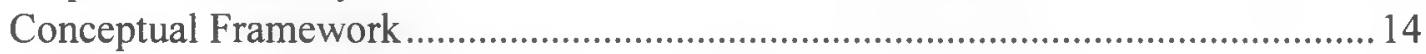

Statement of Delimitations and Scope of Study .................................................. 19

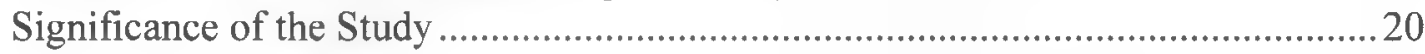

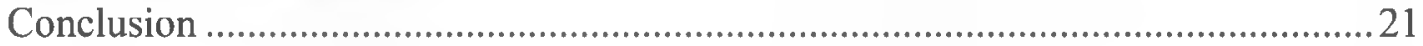

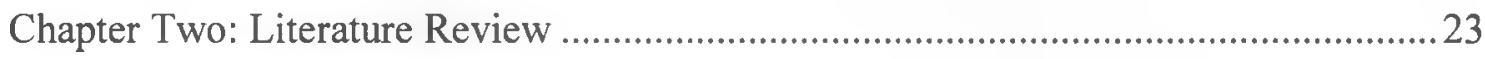

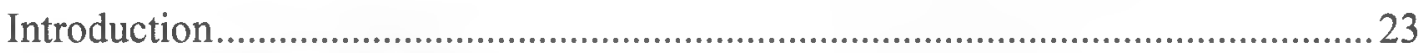

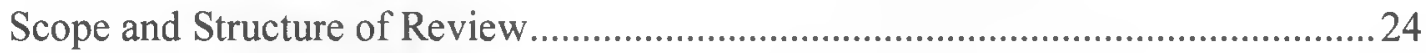

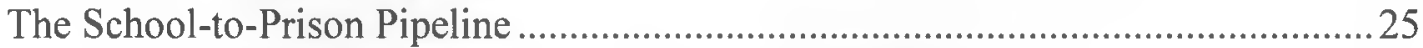

Contributing Factor: Adverse Childhood Experiences ......................................28

Contributing Factor: Neglected Urban Schools .....................................................34

Contributing Factor: Exclusionary School Discipline ……………………............37

Summary of Contributing Factors ................................................................ 40

Protective Factor: Positive Student-Teacher Relationships ..................................41

Protective Factor: Culturally Relevant Pedagogy .................................................45

Summary of Protective Factors..........................................................................50

Prison Schools as Institutions of Social Control....................................................50

The Hidden Curriculum Goes to Prison.............................................................51

Foucault, Power, and Social Control ............................................................54

Summary of Prison Schools as Institutions of Social Control.............................58

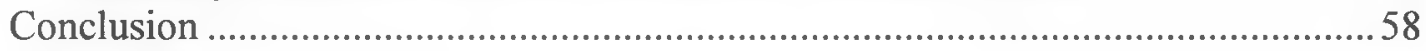

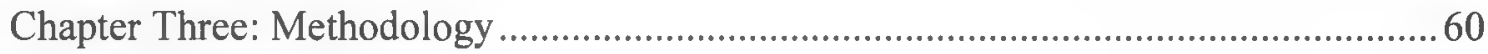

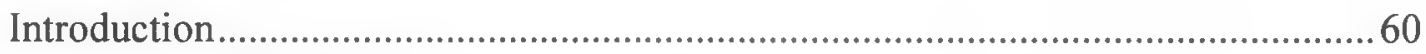

The Role and Perspective of the Researcher.......................................................60 


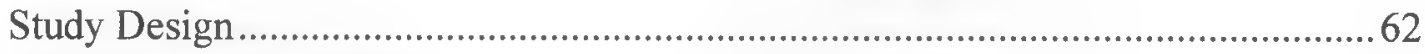

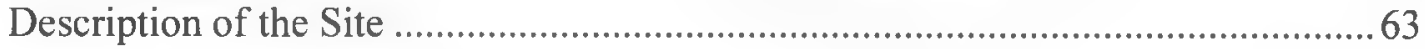

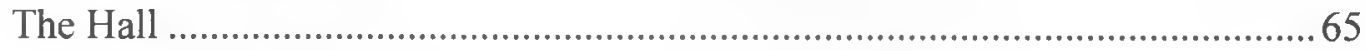

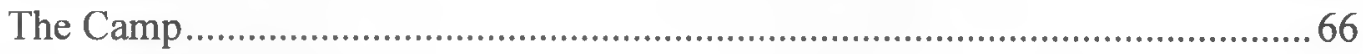

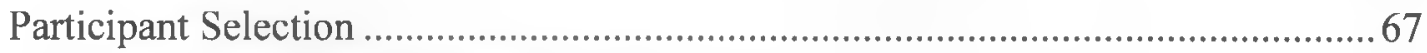

Ethics and Protection of Human Subjects............................................................ 70

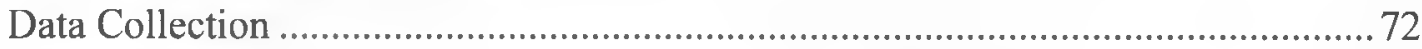

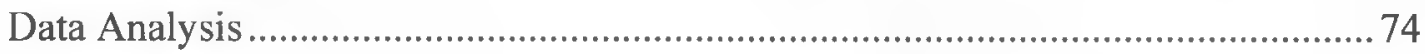

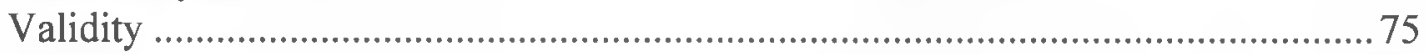

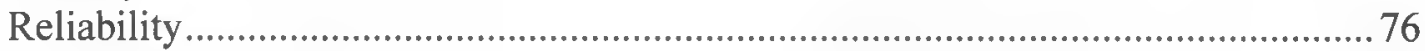

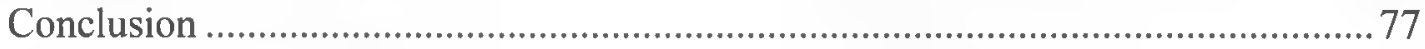

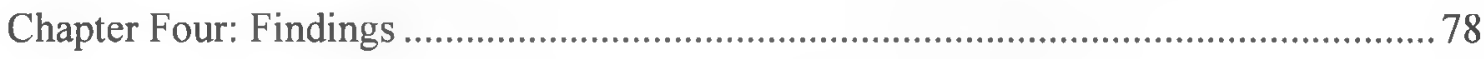

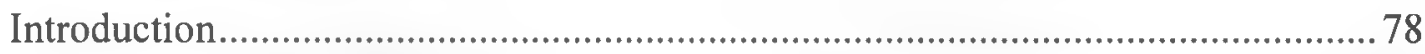

Positive Early School Experiences .......................................................................... 81

Dominique: The Rose That Grew from Concrete...............................................8 82

Positive Teacher Relationships ........................................................................88

Positive Learning Environment .........................................................................94

Family \& Community Influence ......................................................................98

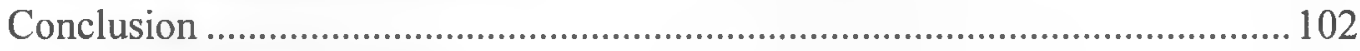

School Disengagment in Middle \& High School ................................................... 103

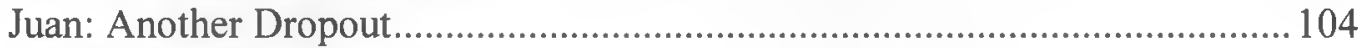

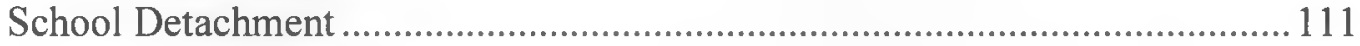

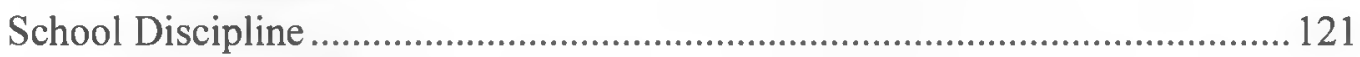

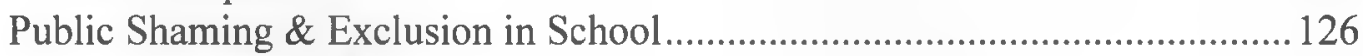

Caught Between School and the Streets .....................................................132

Conclusion ....................................................................................................

Academic Reengagement in Prison School ......................................................... 141

Ahmed: A Wake Up Call ................................................................................ 142

Positive Teacher Relationships......................................................................... 150

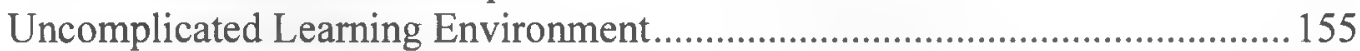

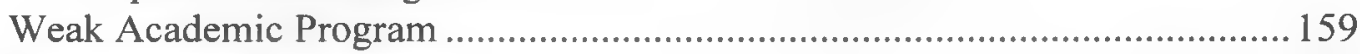

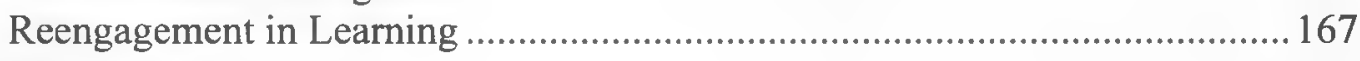

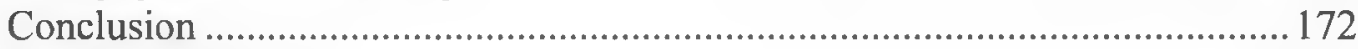

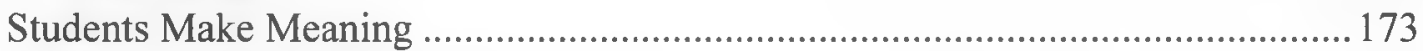

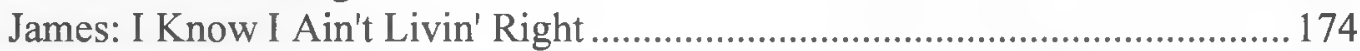

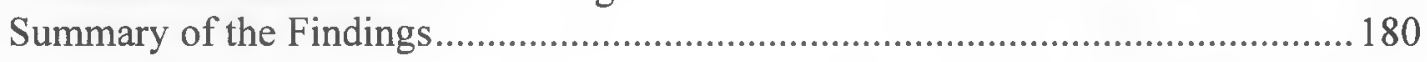

Chapter Five: Discussion and Recommendations........................................................ 183

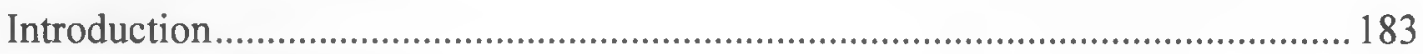

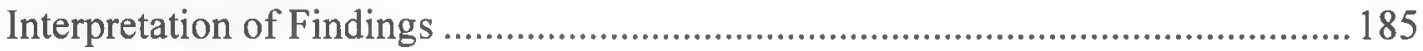


The Importance of Student-Teacher Relationships............................................ 186

The Importance of ACEs on Learning and Engagement ................................... 188

The Impact of Exclusionary School Discipline Policies.................................... 190

Summary of the Findings: Making Meaning ................................................. 192

Implications for Social Justice Leadership .............................................................195

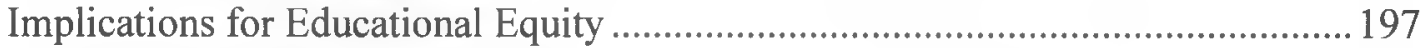

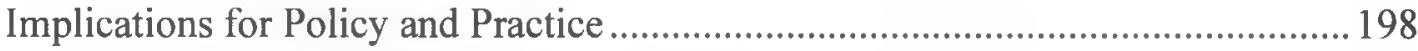

Reduce Exclusionary Discipline Polices ....................................................... 198

Individualized Learning Plans for Incarcerated Students .................................. 199

Recommendations for Further Study ...............................................................202

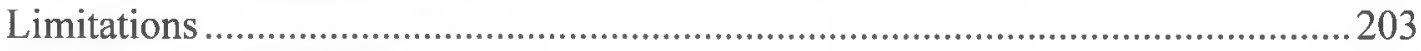

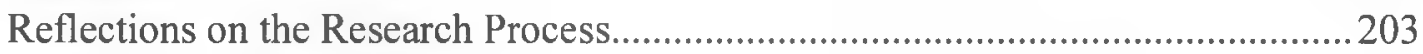

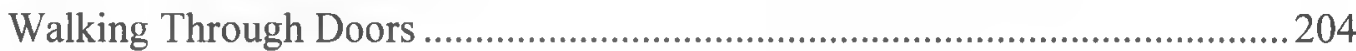

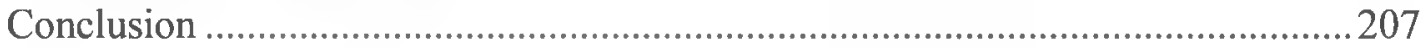

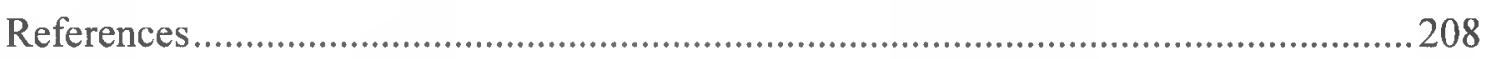

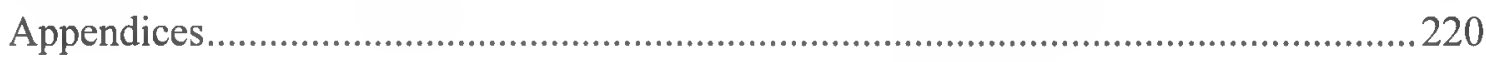




\section{LIST OF TABLES}

Table

1. Summary of Participants
Page 68 


\section{LIST OF FIGURES}

Figure Page

1. Social Purpose of Education ……………........................................................... 16

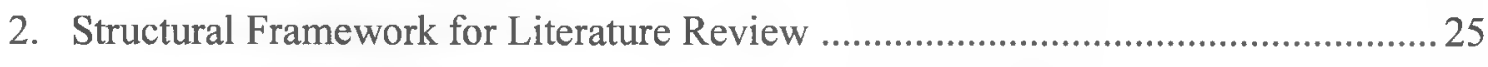

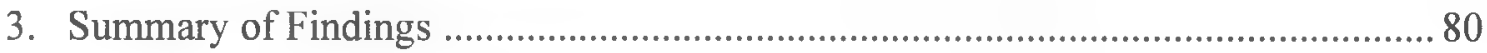




\section{LIST OF APPENDICES}

Appendix Page

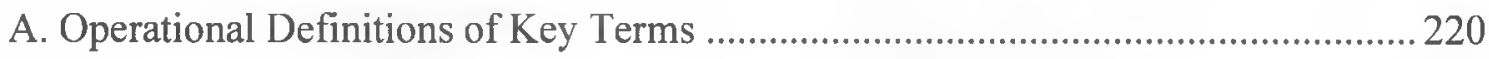

B. San Francisco State University Institutional Review Board Consent ....................... 222

C. Recruitment Letter for Student Interviews ……………............................................ 223

D. Recruitment Letter for Teacher Interviews and Observations ................................. 224

E. Minor Assent/Informed Consent to Participate in Interviews ................................ 225

F. Parent/Guardian Permission for a Minor to Participate in Interviews ..................... 227

G. Teacher Consent to Participate in Interviews and Observations .............................229

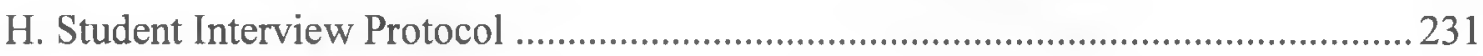

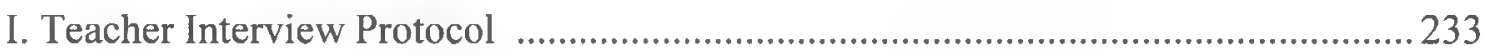




\section{Chapter One: Purpose of the Study \\ Not everything that is faced can be changed, but \\ nothing can be changed until it is faced.}

\section{Introduction}

$\sim$ James Baldwin

In spite of the lowest youth crime rates in 20 years (Holman \& Ziedenberg, 2006), the United States currently incarcerates more children than any other country in the world. More than 1 million youth have contact with court systems in the United States each year (Leone \& Weinberg, 2010). Nearly $14 \%$ of those youth are referred to juvenile detention centers and similar institutions (Office of Juvenile Justice and Delinquency Prevention, 2010). On any given day, nearly 100,000 children in the US attend school behind bars (Justice Policy Institute, 2009). In California, approximately 100,000 youth are arrested annually and $18 \%$ of those youth are placed in a network of county and state juvenile halls and other detention facilities (Harris, 2014).

The educational experiences of incarcerated youth fail to prepare them for future academic success. Incarcerated youth have lower standardized test scores, lower grade point averages, and higher rates of grade retention than their non-incarcerated peers (Baltodano, Harris, \& Rutherford, 2005; Foley, 2001; Tesoro, Thompson, \& Morris, 2014; Wang, Blomberg, \& Li, 2005). Most incarcerated adolescents do not graduate from high school (Balfanz, Spiridakis, Neild, \& Legters, 2003; Foley, 2001) and even fewer attain a postsecondary degree (Balfanz et al., 2003). Federal law and state education codes require that juvenile justice facilities provide an education for 
imprisoned minors (Bell, 2001; Caldwell \& Curtis, 2013). However, few academic standards exist for students being educated behind bars (Bell 2001; Coalition for Juvenile Justice, 2001). The existing literature show that, using nearly any quantitative measure of academic success, the educational needs of incarcerated youth are not being met by the juvenile justice educational system.

\section{Statement of the Problem}

While juvenile prisons are called upon to educate young people, they were not designed for this task. Most educational programs in the juvenile justice system are illequipped to meet the diverse educational challenges that most incarcerated students bring into the prison. The problem statement below discusses some of the most pressing issues in juvenile justice education and how those issues impact student outcomes.

\section{Incarcerated Students Have Poor Academic Outcomes}

Poor academic outcomes for incarcerated students are well-documented in the literature (Baltodano et al., 2005; Foley, 2001; Katsiyannis, Ryan, Zhang, \& Spann, 2008; Tesoro et al., 2014; Wang et al., 2005; Zamora, 2005). Foley (2001) conducted a seminal review of the academic characteristics of incarcerated youth. The researcher reviewed 20 articles describing incarcerated youths' academic characteristics and academic performance across a 25 -year span stretching from 1975 to 2000 . The review demonstrated that the academic achievement of incarcerated youth has consistently 
been found to be one year to several years below expected grade levels. Overall, the author found that all incarcerated students performed below their non-incarcerated peers on standardized assessments; the average student was 15 years old and performed between fifth- and ninth-grade levels (Foley, 2001). In addition to being broad, the findings are unique in their consistency. Without exception all articles reviewed for the study found, using various standardized assessments of academic performance, that incarcerated youth perform significantly lower than their non-incarcerated peers.

Since Foley (2001) was published, additional research has continued to demonstrate low academic achievement among incarcerated youth. A study by Zamora (2005) of 327 male juvenile offenders in Texas compared the grade level of the student with the students' reading and math levels using the Kaufman Test of Educational Achievement (KTEA). While nearly all of the students (86.6\%) were between 7 th and 10th grade, nearly half of the students placed at the elementary reading level (44\%) and elementary math level (48\%). Further, the study found that students who were assessed at intake and again at release made minimal academic progress during their incarceration (Zamora). It is noteworthy that students not only entered the institution below grade level but also failed to make adequate progress during their incarceration. Research by Baltodano and colleagues (2005) also demonstrated poor academic outcomes on standardized assessments for incarcerated youth. Researchers assessed 204 male students in Arizona using the Woodcock-Johnson III Tests of Achievement 
(WJIII) and the Dynamic Indicators of Basic Early Literacy Skills (DIBELS) Oral Reading Fluency (ORF). While the mean age of the students was 16 years old, the students scored at the 8th grade level in reading and the 7th grade level in math. This echoes the findings by both Zamora and Foley that showed all students scoring below grade level.

While both of the studies above examined small samples of male students, Tesoro and colleagues (2014) conducted a large study of both male and female students. Tesoro et al. also found lower achievement for incarcerated students using the Arizona Instrument to Measure Standards (AIMS), a statewide standardized assessment. Participants in the study included 8,996 male and female students arrested at least once between August 2006 and May 2011. The study found that more than half of incarcerated students in the study failed to meet state standards in reading, math, and writing. While none of the research cited above explored the causes of low academic achievement, multiple studies demonstrate that poor performance on standardized assessments is the norm among incarcerated students.

In addition to poor performance on standardized assessments, incarcerated youth also experience higher rates of grade retention and have lower grade point averages than their peers. A large, multi-year study by Wang and colleagues (2005) assessed differences between a statewide sample of 5,187 incarcerated students and 5,187 nonincarcerated students. Researchers found that students who had experienced 
incarceration during the school year were almost twice as likely to be retained in the same grade for failing to meet academic standards. Wang et al. also found that incarcerated students had lower mean grade point averages (1.46 GPA) than their nonincarcerated peers (2.12 GPA). Tesoro et al. (2014), referenced above for research using the AIMS to demonstrate incarcerated students' failure to meet state standards, also found that incarcerated students had lower GPAs than a comparable national sample of their peers. Though the author did not indicate the GPA of non-incarcerated peers, he found that incarcerated students had a mean 1.54 GPA. Tesoro et al. also found that students missed an average of 17 days of school during the year that they were arrested. Though Tesoro et al. and colleagues did not discuss a correlation between low grade point averages and poor attendance, there may be an association between the two factors. However, the research does demonstrate that incarcerated students consistently earn low grades and have lower grade point averages than their non-incarcerated peers.

When considering the low rates of standardized test performance, low grade point averages, and high rates of grade retention, it is not surprising that incarcerated youth have low high school graduation rates. A five-year study of 4,319 students who left school as a result of incarceration was conducted by Balfanz et al. (2003) in a large mid-Atlantic city. Researchers found that most students experienced their first incarceration during ninth grade and focused their analysis on these students. While 
most ninth graders returned to high school within a year of release, almost none succeeded in graduating. Within a year of their return to school, the majority of students had dropped out of high school and less than 15 percent ultimately earned a diploma (Balfanz et al.). Similarly, a study of 10,000 formerly incarcerated youth in Florida found that only $7 \%$ had earned a GED or high school diploma prior to their release (Juvenile Justice Educational Enhancement Program [JJEEP], 2005). Other studies have shown that only $20 \%$ of incarcerated adults have a high school diploma or GED as compared to $75 \%$ of non-incarcerated adults (Coalition for Juvenile Justice, 2001; Foley, 2001; Darling-Hammond, 2010). For many students, earning a diploma during or immediately after incarceration is a challenge. Further, the research demonstrates that across a wide range of indicators, low academic performance among incarcerated students is ubiquitous.

As this problem statement indicates, numerous studies have documented poor academic outcomes for students experiencing incarceration. Using various standardized assessments, the literature show that incarcerated youth have lower academic performance than their non-incarcerated peers. While none of the research cited in this review explored the processes that contribute to low academic achievement among incarcerated students, multiple studies demonstrate that low grade point averages, high rates of grade retention, and low rates of high school graduation are the norm. In spite of the wealth of data demonstrating poor academic performance for incarcerated youth, 
limited data are available that describe the experiences of young people in juvenile justice educational settings (Caldwell \& Curtis, 2013; Foley, 2001). New research is needed to understand the students' trajectory toward the poor educational outcomes described in this problem statement.

\section{Prison Schools Reinforce Existing Educational Inequities}

As discussed in the previous section, students' academic indicators are poor upon incarceration. In addition, most students also fail to make educational progress during their incarceration (Anthony et el., 2010; Zamora, 2005). Students' academic progress during incarceration is influenced by multiple factors including persistent racial gaps in achievement, students' disability status, the structure of prison schools, and the transience of the student population. This section of the problem statement describes how the academic achievement gaps that are present in most urban schools are reinforced and amplified in prison schools.

Incarcerated youth are overwhelmingly students of color and the gaps in academic achievement that follow youth of color throughout their schooling experience also follow them into juvenile justice educational facilities. However, little research has specifically examined racial differences in academic achievement among juvenile offenders. In a five-year study of nearly 9,000 male and female students incarcerated at least once during high school, Tesoro et al. (2014) found that while overall standardized test scores were lower than average among the entire sample of incarcerated students, 
scores for juvenile offenders of color were worse than that of white offenders. Researchers also found that incarcerated youth of color had more school absences and lower grade point averages than incarcerated white youth in the year prior to incarceration (Tesoro et al.). The Tesoro study is one of the first to examine the intersection of the academic achievement gap with race and incarceration status. The authors indicate that academic interventions for incarcerated students, particularly students of color, may be instrumental in shifting the life trajectory of juvenile offenders (Tesoro et al.).

High rates of learning disabilities among students in juvenile justice educational settings also contribute to poor academic outcomes for incarcerated students. While there is wide variation in the percentage of students depending on the definition of disability used, most researchers agree that more than half of all incarcerated juveniles have some form of learning disability (Annamma, 2014; Foley, 2001; Leone \& Weinberg, 2010; Tesoro et al., 2014). The data do not include students diagnosed with emotional or behavioral disabilities. While incarcerated, getting appropriate special education services may be a challenge for special needs students. Individualized education plans (IEPs), which outline the types of services that students with disabilities are mandated to receive, are often lost in the transition from school to youth prisons (Annamma, 2014; Leone \& Weinberg, 2010). In addition, researchers have found that many juvenile justice schools do not have the staff needed to accommodate students 
with special needs (Leone \& Weinberg, 2010; Young, Phillips, \& Nasir, 2010). Unfortunately, students with disabilities are unlikely to get the necessary support to succeed in school - and these students constitute a growing number of youth offenders (Anthony et al., 2010; Baltodano et. al., 2005).

In addition to student characteristics such as race and disability, there are also factors within the prison that make learning difficult for students. There is an explicit focus on rules and order in juvenile justice schools. So much time may be spent on routines to ensure student and staff safety that learning often takes a backseat to control and order (Leone \& Weinberg, 2010; Young et al., 2010). Annamma (2014) refers to these type of rituals and routines as socializing practices and found that they significantly disrupt instruction in juvenile justice schools. While conducting classroom observations during a study of incarcerated young women with disabilities, the researcher noted that a 45 -minute class was interrupted 18 times to reinforce socializing practices such as reminding students to sit up straight and ordering them to keep their hands on their desk. In another class, she noted that 26 minutes of the class were spent on socializing practices. The remaining class time was devoted to basic skills instruction with no opportunity for peer interaction. The author concluded that socializing practices aimed at control constrain educational opportunities in youth prisons (Annamma). 
An ethnographic study by Young et al. (2010) included interviews with 40 incarcerated youth along with 17 class period observations. The findings emphasized that schools in prisons are designed around correctional practices and norms, not educational practices. Such prison norms meant that physical movement was highly regulated, even within school, and correctional officers maintained a disciplinary presence in the classroom. Furthermore, the researchers found that correctional staff directives often superseded the authority of teachers; this served to further undermine learning but was congruent with the goals of imprisonment (Young et al.). When correctional practices trump academic practices, it is difficult for prison schools to meet students' educational needs.

In addition to the factors discussed above, the transience of the student population and a lack of collaboration with the local public school system negatively impacts students' ability to make academic progress (Balfanz et al., 2003; Leone \& Weinberg, 2010; Young et al., 2010). In the ethnography described above conducted by Young and colleagues, students entered the school with a wide range of academic skills and experiences and attended for various lengths of time. Students interviewed for the study had sentences ranging from four months to two years. Many students arrived in prison without academic records and reported receiving work that was too easy or below their ability level. The result was time wasted on academic work that did not result in high school graduation credits or preparation for the GED (General 
Educational Development) exam. The researchers reported that the difficulty of transferring prior school records into the prison in a timely fashion was a barrier to providing students with the most appropriate education (Young).

A report by Leone and Weinberg (2010) on the educational needs of youth in the juvenile justice system also cited delayed transfer of educational records as a factor impacting both inappropriate placements for students and lengthy absences from instruction. Although litigation has resulted in agreements with specific timelines for the timely transfer of student records, the problem continues (Leone \& Weinberg). While there are many reasons for poor student progress that the prison cannot control, schools in the community can work together with prison schools to ensure that student records are transferred promptly or, in the absence of records, prison schools should conduct timely student assessments to ensure the proper placement of students. Meeting the instructional needs of incarcerated students is a complex task and one that most prison schools are not designed to address.

A preponderance of the evidence indicates that many adolescents enter prison schools at a disadvantage and fail to have their academic needs met while incarcerated. This often means that academic achievement gaps that are present in most urban schools are amplified in prison schools. More research is needed on ways to address the educational inequities within juvenile justice educational facilities. 


\section{Research Questions and Design}

While the quantitative data provide a compelling picture of the problem using traditional measures of academic achievement, the literature provides little qualitative data that illuminate the educational trajectories and experiences of incarcerated students. This research deepens our understanding of students' experiences in the school-to-prison pipeline. The primary questions guiding this research are: How do incarcerated students describe their educational experiences leading up to and during incarceration? How do incarcerated students make meaning of their educational experiences behind bars? The stories of young people, told in their own words, can demonstrate how to disrupt the flow of adolescents through the pipeline and create juvenile justice schools that help all students succeed academically.

The data collected for this study came from phenomenological interviews with students which followed a standardized, open-ended protocol developed based on a review of the literature and themes discovered during the pilot study described later in Chapter 3. Interview One consisted of a focused life history. During the first interview, I asked the students about their educational experiences up until the time when they became incarcerated with the goal of establishing the context of their school experiences. Interview Two consisted of the details of their current experience. During the second interview, I asked students about their educational experiences while incarcerated to better understand the details of school within the context of the prison. 
Interview Three consisted of reflection on the meaning of their past and present experiences. During this final interview, I encouraged students to reflect on the meaning of their educational experiences in juvenile hall and to share their own reflections of learning. Using this research design, I was able to draw out students' experiences as they walked through their memories of schools, teachers, and education.

\section{Purpose of the Study}

Existing research focuses on student deficiencies and poor academic outcomes using test scores and other quantitative measures. Minimal qualitative data exist in the field of juvenile justice education which would allow for a richer and more nuanced understanding of student outcomes and experiences. Also, while educators, researchers, and youth justice advocates have begun to call for systemwide reform, the voices of students are largely absent from the dialogue. The purpose of this study is to address gaps in the literature related to schooling in juvenile justice settings and to develop a deeper understanding of students' experiences in prison schools. In addition, this study adds the voices of students, who have historically been marginalized, to the existing body of research about the school-to-prison pipeline.

Further, this study brings forth the educational inequities that exist in both the juvenile justice and education systems that are amplified in prison schools. Young people of color are disproportionately impacted by the school-to-prison pipeline and are overrepresented in the juvenile justice system (Advancement Project, 2005). Recent 
data show that while youth of color comprise 38 percent of the total US youth population, they comprise nearly 70 percent of youth who are incarcerated (Burns Institute for Juvenile Justice Fairness and Equity [Burns Institute], 2013). Thus, the achievement differences observed among students of color are often concentrated in prison schools. The negative consequences of poor academic achievement and the negative consequences of youth incarceration are interrelated and both are disproportionately experienced by students of color.

Finally, this study contributes to a growing movement to address the way that young people are educated in the juvenile justice system. In order to change outcomes for young people in juvenile justice schools, it is necessary to rethink the way that schools in juvenile institutions are designed. Creating more appropriate educational environments for incarcerated youth must begin with a deep understanding of how such youth currently experience juvenile justice educational facilities. This study informs conversations around educational experiences with the stories of those most impacted the young people.

\section{Conceptual Framework}

Insight into the social purposes of schooling provides a conceptual framework for understanding students' experiences in prison schools. Schools are inherently social institutions, charged with the task of preparing and socializing young people for their adult roles in society. As social institutions, schools reflect the characteristics of the 
society in which they are located. In all societies, there is a social contract that underlies schooling. Noguera (2003), articulates what this contract means for young people:

In exchange for an education, students are expected to obey the rules and norms that are operative within school and to comply with the authority of the adults in charge. Like the social contract that serves as the basis of order in most democratic societies, students are expected to relinquish a certain degree of individual freedom in exchange for receiving the benefits of education. For the vast majority of students, this arrangement elicits a relatively high degree of compliance. (p. 343)

These social contracts are not explicit but are transmitted implicitly to students through the norms, customs, and habits of teachers and schools.

To understand how students are impacted by the social processes of education and its underlying social contracts, it is important to revisit the purpose of education. Noguera (2003) articulates three purposes of schools in American society - to control, to socialize, and to sort. The social purpose of education is graphically represented in Figure 1. 
Figure 1. Social Purposes of Education

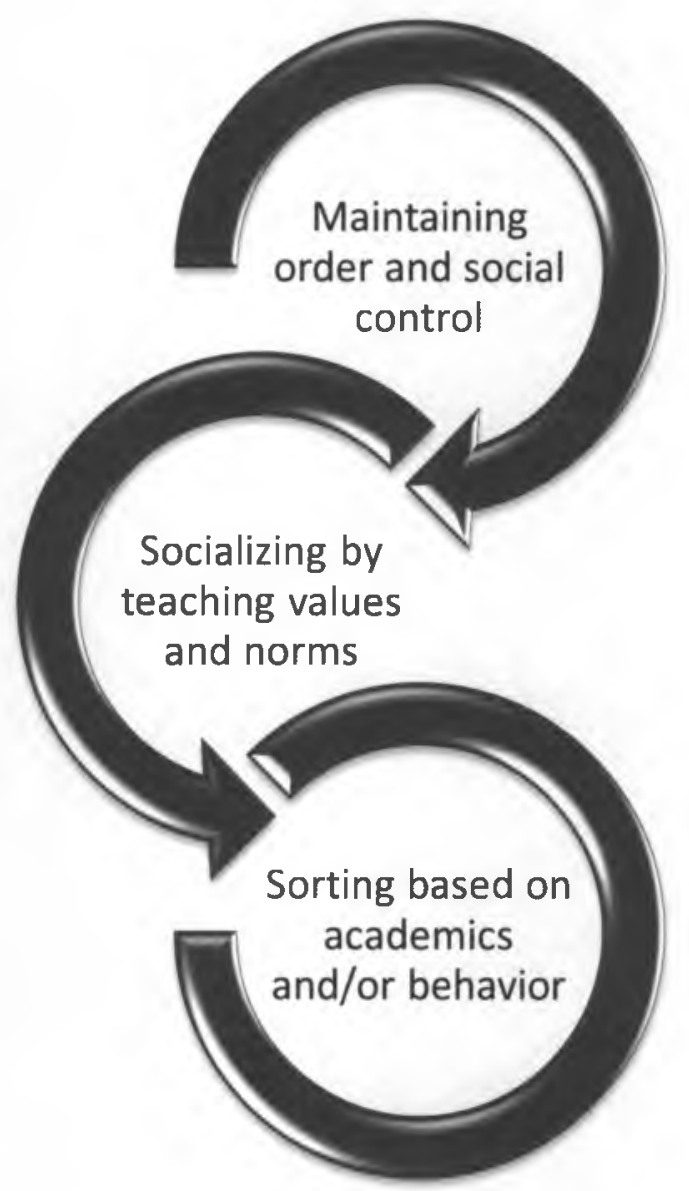

Figure 1. The interconnected social processes of schooling which form the basis of the social contract of education. Adapted from "Schools, Prisons, and Social Implications of Punishment: Rethinking Disciplinary Practices," by P.A. Noguera, 2003, Theory Into Practice, 42(4), 344.

First, schools function as institutions of social control and exercise considerable authority over students while they are in school. This control is so extensive that many basic civil rights of students are suspended while they are in school. For example, school officials need only reasonable suspicion to search students in public schools, but 
sworn law enforcement officials must have probable cause to search students (Beger, 2003). Second, schools socialize children by teaching the values and norms of American society. Social conventions, including compliance and obedience to authority, are taught both implicitly and explicitly. Through school, young people are instilled with a sense of what it means to be a member of society and they are rewarded for their conformity (Anyon, 1980; Noguera, 2003). Finally, schools sort young people based on various measures including their academic ability and behavior. In addition to the stated measures, students are often sorted by unstated measures such as race, immigration status, and income. In sorting students, schools play a role in determining students' professional and academic roles (Anyon, 1980; Noguera, 2003).

With an understanding of the social purposes of education, it is instructive to consider what happens when the social contract that undergirds education is broken. Youth attending failing schools with underqualified teachers, a lack of resources, and a weak academic program realize that they are being educationally short-changed. Young people who are subject to capricious discipline policies know that they are being unfairly excluded from school. Students recognize racism, sexism, and other forms of discrimination when they encounter them in the classroom and realize that teachers have different expectations for different students. Quite often, students who feel that the social contract of education has been broken will begin to act out. As Noguera (2003) states: 
Students who get into trouble frequently are typically not passive victims; many of them understand that the consequences for violating school rules can be severe, particularly as they grow older. However, as they internalize the labels that have been affixed to them, and as they begin to realize that the trajectory their education has placed them on is leading to nowhere, many simply lose the incentive to adhere to school norms... With the rewards of education largely unavailable to them, we must realistically ask ourselves why we would expect that students would comply with the rules and adhere to school expectations? When the social contract of schooling is broken or no longer operative for certain students should we be surprised that they become more likely to disrupt the educational process? (p. 343-345)

Students attending school in juvenile justice educational settings know that the social contract of schooling has long been broken. It may have been fractured the first time they were sent out of a classroom or when they were forced to repeat a grade. More likely, it was slowly eroded over time by the combination of failing schools, exclusionary discipline, and youth criminalization that has come to be known as the school-to-prison pipeline. According to Noguera (2003), “Once they [students] know that the rewards of education—namely, acquisition of knowledge and skills and ultimately, admission to college, and access to good paying jobs—are not available to them, students have little incentive to comply with school rules" (p. 343). With no 
incentive to comply, students disengage from education. Put simply, how long would you keep playing a game that you'd already lost?

An understanding of the social purposes of schooling is an important backdrop for this study. This framework is significant as it provides a lens for understanding students' educational trajectories leading up to and including prison schools. As student experiences are examined against the social purposes of schooling, this framework brings understanding to the behaviors that students engage in and the choices that students make. Actions that seem self-defeating or destructive may be reframed as protective or defensive. Through this framework, our understanding of students in the school-to-prison pipeline can deepen.

\section{Statement of Delimitations and Scope of Study}

This study examines the educational experiences of students attending school at one juvenile justice educational facility. It builds on the literature demonstrating poor academic outcomes for students attending such schools and expands on the literature by bringing in the voices of students. Since this area is under researched, the study uses an exploratory orientation. This is not an evaluation of prison schools or the instructional practices in such schools. The goal of this study is to describe these schooling experiences, in rich detail, from the perspective of the students. While the study sample mirrored that of the institution and can be considered representative for the purposes of 
this study, the generalizability of this study to other juvenile detention settings may be limited.

\section{Significance of the Study}

As discussed earlier, 100,000 children in the US attend school behind bars each day (Justice Policy Institute, 2009). In spite of the large numbers of young people attending school while incarcerated, little research has been conducted to provide educators with an understanding of the educational trajectories and experiences of these students. The current body of literature focuses on the poor academic outcomes that these students experience. While this data is instructive, it falls short in deepening our understanding of incarcerated youth - a large group of students whose academic needs are not being attended to.

In addition, while calls for juvenile justice reform are growing (Alexander, 2012; Bernstein, 2014), this dialogue has focused on diverting students from institutions without addressing the needs of those who are still there. While promoting alternatives to juvenile incarceration is important, it is equally important not to lose sight of the students who are already ensnared in the system. One goal of this study is to turn the gaze of reformers to those students who are currently attending school in the existing system of juvenile prisons. It seems counterintuitive but it is necessary to urgently reform the system while it is also being dismantled. 
In addition to the reasons outlined above, this study is significant because prison schools represent a significant but understudied area within the school-to-prison pipeline literature, which instead focuses on poor school experiences prior to incarceration. The pipeline literature that does address juvenile justice settings focuses on disproportionate minority contact in system and policies sentencing juveniles as adults (Holman \& Ziedenberg, 2006; Kakar, 2006; Sickmund, Sladky, \& Kang, 2004; Wordes \& Jones, 1998). The educational program is largely overlooked.

Ignoring the educational needs of the most vulnerable students has long-term implications for both individual students and for society. Poor educational outcomes for incarcerated youth lead to higher lifetime rates of both unemployment and adult incarceration along with lower earnings and poor health outcomes (Balfanz et al., 2003; Darling-Hammond, 2010; Holman \& Ziedenberg, 2006; Kirsch et al., 2007; McKinsey, 2009). By attending thoughtfully and conscientiously to the academic needs of young people, we can mitigate the economic, social, and psychological impacts of juvenile incarceration that ripple across society.

\section{Conclusion}

Understanding the educational experiences of incarcerated youth is a key first step in designing academic programs that meet the needs of young people behind bars. This qualitative exploratory case study utilized phenomenological interviews within a conceptual framework based on the social purposes of education to answer the 
following research questions: How do incarcerated students describe their educational experiences leading up to and during incarceration? How do incarcerated students make meaning of their educational experiences behind bars?

This dissertation is organized into five chapters. Chapter Two presents a review of literature relating to social reproduction in schooling and the school-to-prison pipeline. Chapter Three outlines the methods used to answer the research questions. Chapter Four presents the detailed findings of the student interviews and highlights key educational experiences of students leading up to and during their incarceration along with select student narratives that illustrate how young people make meaning of their educational experiences behind bars. Chapter Five concludes with implications for practice and recommendations for changing prison schools to improve the academic success of incarcerated students. 


\section{Chapter Two: Literature Review \\ It is easier to build strong children than to repair broken men. \\ $\sim$ Frederick Douglass}

\section{Introduction}

The problem statement presented in Chapter 1 illustrates that the academic needs of incarcerated youth are not being met by the juvenile justice educational system. Incarcerated youth have lower standardized test scores, lower grade point averages, higher rates of grade retention, and lower graduation rates than their nonincarcerated peers (Balfanz et al., 2003; Baltodano et al., 2005; Foley, 2001; Tesoro et al., 2014; Wang et al., 2005). Using nearly any traditional measure of academic success, incarcerated youth lag behind their non-incarcerated peers. In spite of this broad and compelling body of research, there is little data describing the educational experiences of students in the school-to-prison pipeline.

This study addresses gaps in the literature related to schooling in juvenile justice settings by describing student experiences and adding the voices of students to the existing body of research. The primary questions guiding this research are: How do incarcerated students describe their educational experiences leading up to and during incarceration? How do incarcerated students make meaning of their educational experiences behind bars? This literature review is designed to provide context for the study and to ground the findings. 


\section{Scope and Structure of the Review}

The literature review includes peer-reviewed research from education databases, such as Proquest Education Journals and JSTOR, along with academic and policy reports from sources such as the Coalition for Juvenile Justice and the W. Haywood Burns Institute for Juvenile Justice Fairness \& Equity. Some articles and books were recommended by professors or colleagues and are also included in this literature review. Except in the case of seminal pieces of work, the literature review was confined to articles, reports, and books published since 2000 .

The literature review provides an overview of research related to the educational experiences of incarcerated youth and is organized as illustrated in Figure 2. The review begins with an operational definition of the school-to-prison pipeline. Factors that contribute to the flow of students into the pipeline are then discussed with a focus on adverse childhood experiences, neglected urban schools, and exclusionary school discipline. Each of these factors negatively impact young people's ability succeed academically. Next, factors that protect students from the school-to-prison pipeline are discussed with a focus on positive student-teacher relationships and culturally relevant pedagogy. Each of these factors positively impact young people's ability to succeed academically. Finally, the literature review concludes with a discussion of prison schools as institutions of social control. This literature builds on the conceptual framework presented in Chapter 1 with an extended analysis of power, knowledge 
reproduction, and the hidden curriculum of schooling. Taken together, the literature review incorporates both the theoretical underpinnings and the experiential considerations that undergird this study. All are valuable when considering how young people experience schooling leading up to and during their incarceration.

Figure 2. Structural Framework for Literature Review

\begin{tabular}{|c|c|}
\hline \multicolumn{2}{|c|}{ Educational Experiences of Incarcerated Youth } \\
\hline \multicolumn{2}{|c|}{ School-to-Prison Pipeline } \\
\hline Contributing Factors & Protective Factors \\
\hline Adverse Childhood Experiences & Positive Student-Teacher Relationships \\
\hline Neglected Urban Schools & Culturally Relevant Pedagogy \\
\hline Exclusionary School Discipline & \\
\hline \multicolumn{2}{|c|}{ Prison Schools as Institutions of Social Control } \\
\hline Foucault, Power \& Control & The Hidden Curriculum Goes to Prison \\
\hline
\end{tabular}

Figure 2. The structural framework for the literature review is organized to reflect a range of concepts including social reproduction in schooling and the school-to-prison pipeline to reflect the breadth and depth of the educational experiences of incarcerated youth.

\section{The School-to-Prison Pipeline}

Increasing numbers of young people are attending school in prison. The population of America's youth prisons has grown over the past 30 years and this increase has been exponential for students of color. From 1985 to 1995, the number of youth in secure detention facilities increased by 72 percent nationwide (Holman \& 
Ziedenberg, 2006). During this same period, the proportion of white youth in detention centers decreased while youth of color came to represent the majority of youth detained. By 1997, the Office of Juvenile Justice and Delinquency Prevention (OJJDP) found that the minority population of detained youth exceeded their proportion in the general population in 49 out of 50 states (Holman \& Ziedenberg). This disparate trend continues today. Recent data show that while youth of color comprise 38 percent of the US youth population, they comprise nearly 70 percent of youth who are incarcerated (Burns Institute, 2013).

The phenomenon by which students, especially students are color, are funneled out of schools and into the juvenile justice system has become known as the school-toprison pipeline. There are many definitions of the school-to-prison pipeline. This study relies on the definition from Bahena, Cooc, Currie-Rubin, Kuttner, and Ng (2012) outlined in the introduction to a volume of essays about the pipeline. According to the authors:

The school-to-prison pipeline is an amalgamation of a number of different trends - from the overrepresentation of students of color in special education to the rise of zero tolerance school discipline policies; from an increased fear related to school safety to perverse incentives from test-based accountability systems to push out low-performing students. The pipeline functions on multiple levels, from one-on-one interactions between students and police 
officers, to policies that drain resources from schools, to societal discourses of racial inferiority and punishment. (p. 1)

This definition highlights the interconnectedness between the issues that drive students from schools into prisons. Though the pipeline metaphor is often used, it would be more accurate to describe this phenomenon as a web. Through a network of interconnected trends, young people are ensnared in this web. Their entrapment often leads to prison and, once entangled, it is nearly impossible to get free.

An elegant metaphor to illustrate the impact of this intersecting web comes from author Michelle Alexander. In The New Jim Crow, Alexander (2012) expands on the work of theorist Iris Marion Young to explain how a birdcage can be used to understand how various factors come together to ensnare people in the criminal justice system:

If one thinks about racism by examining only one wire of the cage, or one form of disadvantage, it is difficult to understand how and why the bird is trapped. Only a large number of wires arranged in a specific way, and connected to one another serve to enclose the bird and to ensure that it cannot escape. What is particularly important to keep in mind is that any given wire of the cage may or may not be specifically developed for the purpose of trapping the bird, yet it still operates (together with the other wires) to restrict its freedom. (p. 185) This metaphor is helpful when considering the numerous ways that young people are trapped by the school-to-prison pipeline. While a single factor would not typically 
result in a young person's incarceration, numerous factors work together to increase the odds of incarceration and reduce educational prospects for youth.

In the next section of this review, three of the factors that increase the flow of students into the pipeline are discussed. First, adverse childhood experiences and their impact upon learning are addressed. Second, the role of neglected urban schools is discussed. Finally, I focus on exclusionary school discipline policies and how they impact students of color.

\section{Contributing Factor: Adverse Childhood Experiences}

Childhood traumatic events or adverse childhood experiences (ACEs) are experiences that harm children's developing brains so profoundly that they result in a wide range of short- and long-term effects. The term ACEs was first coined by researchers during the CDC-Kaiser Adverse Childhood Experiences study, a seminal public health study that was the first to uncover a dose-response relationship between childhood trauma and the adult-onset of chronic disease, mental illness, and maladaptive behaviors (Felitti et al., 1998). This study examined ACEs among adult Kaiser Permanente members in the San Diego area - an insured and mostly middleclass sample.

Researchers sent a questionnaire to adults who had recently completed a standard medical evaluation and asked about the following adverse experiences during childhood: physical abuse, sexual abuse, emotional abuse, physical neglect, emotional 
neglect, violent treatment towards mother, household substance abuse, household mental illness, parental loss including separation or divorce, and having an incarcerated household member. Respondents received one point for each ACE indicated for a score of up to 10 points. Approximately 9,500 Kaiser Permanente members responded to the survey (Felitti et al., 1998).

More than half (52.1\%) of respondents reported at least one adverse childhood exposure while $6.2 \%$ reported four or more ACEs. Researchers found that the greater the number of ACEs, the more likely adult patients were to develop a number of disease conditions including heart disease, lung disease, liver disease, and cancer (Felitti et al., 1998). Since this groundbreaking study, more than 70 published research papers have demonstrated a link between ACEs and adult-onset physical and mental illness. The study of ACEs and their impact on adult health outcomes has been well-documented in the literature but the studies have been mostly limited to adults. A small but growing body of literature has emerged that examines ACEs among youth with juvenile justice involvement and the impact of ACEs on learning. This literature helps to illustrate how ACEs can contribute to the school-to-prison pipeline.

Examining the prevalence of and impact of ACEs among juvenile offenders is an emerging area of research though previous studies among juvenile justice-involved youth have already revealed high rates of trauma (Dierkhising et al., 2013). A study of young people who indicated recent ( $<30$ days) involvement with the juvenile justice 
system were surveyed about exposure to trauma. Trauma histories were collected from 658 adolescents who were being detained or were under supervision by the juvenile court. Age of onset of trauma exposure occurred before age 5 for $62 \%$ of youth and the vast majority of youth (90\%) experiences multiple traumas. The authors of this study called for trauma-informed juvenile justice systems that can respond to the needs of traumatized youth. While this study used a broader definition of trauma than the ACEs study, the research below examined the prevalence is ACEs in juvenile offenders.

A study of juvenile offenders in Washington State found that incarcerated youth had three times more ACEs than the population in the original CDC-Kaiser ACE study and had more school-related problems such as disruptive behaviors, low academic performance, and truancy (Grevstad, 2010). Similarly, a study by Baglivio et al. (2014) examined the prevalence of adverse childhood experiences in a population of 64,329 juvenile offenders in Florida. This study also found significantly higher rates of ACEs among juvenile offenders. Incarcerated youth were 13 times less likely to report zero ACEs and four times more likely to report four or more ACEs than their nonincarcerated peers (Baglivio et al., 2014). Baglivio and colleagues point to the need to screen for and address ACEs as early as possible in addition to creating traumainformed systems of care for traumatized youth. The rate of ACEs among incarcerated youth is high and the study below demonstrates how this influences juvenile criminal behavior. 
A recent study examined the impact of ACEs on different types of juvenile offending (Fox, Perez, Cass, Baglivio, \& Epps, 2015). Researchers in Florida collected data on juvenile offenders who committed one non-violent felony (called "one and done" or O\&D offenders) and compared them with juveniles with had committed three or more felonies (called "serious, violent, and chronic" or SVC offenders). Data on 10,714 SVC offenders and 11,861 O\&D offenders were collected. The groups differed in several key demographics. The SVC offenders were more likely to be male, to be youth of color, and were two years younger than their O\&D counterparts.

As predicted by the researchers, the SVC offenders experienced significantly more ACEs (Fox et al., 2015). Further, as ACE scores increased, the gap between SVC offenders and O\&D offenders widened. The study found that SVC offenders were twice as likely as O\&D offenders to have four or more ACEs. Further, SVC offenders were three times as likely as O\&D offenders to have six or more ACEs. Finally, each adverse childhood experience increased the risk of being an SVC offender by more than $35 \%$, even when controlling for other known risk factors for criminal behavior. These findings are the first to demonstrate a dose-response between ACEs and severity of juvenile offending. As the title of the study concludes, "Trauma changes everything" (Fox et al., 2015). The researchers suggest that ACE scores have the potential to be used as a screening tool before young people ever reach the juvenile justice system. 
This study and those cited above demonstrate that adverse childhood experiences are more common among youth in the juvenile justice system than their non-incarcerated peers. Further, the more ACEs that a student experiences, the more serious their criminal behavior becomes. Understanding this link is important as this discussion turns toward how ACEs impact learning and cognition.

The use of the $\mathrm{ACE}$ score as a measure of cumulative traumatic stress exposure during childhood is consistent with the latest understanding of the effects of trauma on cognition and learning (Baglivio \& Epps, 2015). Further, recent studies have begun examining the impact of ACEs on school-related outcomes among pediatric populations. This research has shown that childhood trauma has a more immediate impact on learning than previously realized. Studies with school-aged children have shown that early traumatic stress can negatively impact brain development and the cognitive processes which underlie learning (Bucker et al., 2012; Carrion \& Wong, 2012; Scott, Burke, Weems, Hellman, \& Carrion, 2013). Adverse childhood experiences can and do impact the ability to learn.

A systemic review of research on school-related outcomes of traumatic event exposure was conducted (Perfect, Turley, Carlson, Yohanna, \& Saint Gilles, 2016). Articles published in peer-reviewed journals from 1990 to 2015 were included if cognitive, academic, and teacher reported social-emotional-behavioral outcomes were included in the study and if the sample included school-aged youth (pre-kindergarten to 
grade 12). Based on the criteria, 83 articles were included in the sample. The researchers found that the cognitive, social, emotional, behavioral, and neurobiological issues that result from exposure to traumatic events can impair memory, verbal ability, attentional processes, and executive functioning (Perfect et al.). These impairments lead to poor academic outcomes including lower grades and lower standardized test scores. The authors go on to suggest that trauma has become so prevalent that all schools should consider the needs of traumatized learners. Research examining the link between ACEs and learning supports this conclusion.

A study among pediatric patients at a community clinic was conducted to better understand the impact of adverse childhood experiences among youth (Burke, Hellman, Scott, Weems, \& Carrion, 2011). A retrospective medical chart review was conducted among 701 youth aged 0 to 21 ; the mean patient age was 8.13 years and $58 \%$ of patients were African American. Among the sample, $67.2 \%$ of patients reported at least one ACE while $12 \%$ of patients had experience at least four or more. An ACE score of four or more was associated with increased risk for learning and behavior problems in school including low academic achievement. Among students with no ACEs, $3 \%$ had learning problems while the figure soars to $51.2 \%$ for students with four or more ACEs (Burke et al., 2011). This is especially notable given that a significant number of the participants were not yet school-aged. While the authors of the study call for pediatricians to be 
aware of the potential influence of ACEs, teachers and others who work with schoolaged children should be similarly informed.

Addressing the impacts of ACEs on students before, during, and after their incarceration is a complex task. A 2014 federal report contended that "a traumainformed perspective requires that systems 'realize' that trauma exposure is pervasive and impactful, 'recognize' the manifestation of traumatic stress symptoms and outcomes associated with trauma, and 'respond' to the information known about trauma exposure and traumatic stress symptoms" (SAMHSA, 2014). Recognizing and addressing the interplay between trauma, learning, and incarceration is essential for educators interested in understanding and disrupting the school-to-prison pipeline.

\section{Contributing Factor: Neglected Urban Schools}

While exposure to trauma impacts students' ability to learn, struggling urban schools also contribute to the flow of students into the school-to-prison pipeline. Students who attend failing schools are at greater risk for incarceration (NAACP Legal Defense Fund, 2005). Many schools, primarily in urban areas, simply do not receive the necessary resources to provide a safe and effective learning environment for students (NAACP Legal Defense Fund). Poor academic achievement is a predictor of adolescent incarceration (Balfanz et al., 2003; Foley, 2001) and students who do not earn a high school diploma are more likely to be incarcerated as adults (DarlingHammond, 2010; Foley, 2001). 
If schools are to provide all students with the same academic standards and educational opportunities, Darling-Hammond (2010) argues that schools must have adequate resources to provide a curriculum that reflects the standards that students will be evaluated against. They must also have teachers well-qualified to teach such a curriculum and the books, materials, supplies, and equipment necessary to support such teaching. Of course, resources are sometimes invested in interventions that do not improve student learning. However, low-performing schools can increase student achievement when policies are designed around investments that produce strong returns in terms of student learning (Darling-Hammond). In spite of the evidence that school expenditures do impact student achievement, many districts still lack adequate funds to educate students. This is especially true of urban schools that tend to serve high populations of students of color (Advancement Project, 2005; Balfanz et al., 2003; Darling-Hammond, 2010). These failing schools become the primary source of students flowing into youth prisons.

Researchers Christle, Jolivette, and Nelson (2005) conducted a series of studies to examine the impact of both student characteristics and school characteristics in contributing to the school-to-prison pipeline. High-performing and low-performing schools were compared across one state with respect to academic failure and dropout. The researchers used quantitative data collected from annual reports submitted to the state department of education along with qualitative data from school surveys, staff 
interviews, and on-site observations. The study suggested that although student characteristics are important, school factors may be more important in contributing to youth involvement in the juvenile justice system. Specifically, the researchers found that schools that provided positive structures along with high-quality academic programs may counteract student risk factors such as low socioeconomic status (Christle, Jolivette, \& Nelson). The study suggested that a systems approach is necessary to improve school performance and reduce the flow of students into the school-to-prison pipeline. Systems approaches include schoolwide alternative to suspension programs and academic support programs for young people at risk of dropping out of school.

As cited earlier, Balfanz and colleagues (2003) conducted a five-year study in a large mid-Atlantic city of 4,319 students who left school as a result of incarceration. Researchers found that most students were incarcerated during ninth grade and focused their analysis on these students. Balfanz et al. found that nearly all students in the study came from a subset of the school district's high-poverty, low-performing neighborhood high schools. In these schools, less than 10 percent of ninth grade students had gradelevel reading or math skills. In most cases, fewer than half of the incoming ninth graders succeeded in graduating. In spite of the high needs of the students, the researchers found that the schools received no funding beyond a standard per pupil 
allocation and increasingly relied on inexperienced and uncertificated teachers (Balfanz et al.).

The authors suggest that addressing the school-to-prison pipeline must begin with providing adequate resources to low-performing schools so that students stay in school and graduate with the skills and knowledge necessary for college and careers. Providing student-level interventions will not be sufficient to address the cascade of students through the school-to-prison pipeline. Systems approaches are essential. Many schools simply do not have the curriculum, teachers, materials, and facilities necessary to provide a high-quality education to all students. In the next section of the review, I will focus on exclusionary school discipline policies and how they impact students of color. Increases in student suspensions and expulsions, especially for minor infractions, have served to increase the flow of students through the school-to-prison pipeline.

\section{Contributing Factor: Exclusionary School Discipline}

Exclusionary school discipline, such as suspensions and expulsions, push students out of school and into the juvenile justice system. Since the 1990s, many school districts have adopted zero-tolerance approaches to school discipline. Punitive approaches to adolescent behavior have resulted in a dramatic increase in suspension and expulsion rates. In 1974, approximately 1.7 million students were suspended from school each year; by 2000, that number had climbed to 3.1 million (Advancement 
Project, 2005). The number of student expulsions is also on the rise. In 2000, approximately 97,000 students were expelled from school; by $2012,130,000$ students were expelled from school (NAACP Legal Defense Fund, 2005; United States Department of Education, 2014). In addition, increased police presence in schools and policies mandating the referral of students to law enforcement have blurred the lines between school and prison (Rios, 2011; Wald \& Losen, 2003). The consequences for students are illustrated in the real-life examples presented below.

Many incidents at school that would have been handled by the principal in the past now result in police intervention and arrest. A report by the Advancement Project (2005) provides numerous examples of the criminalization of youth for minor infractions at school. A high school student in North Carolina was arrested and criminally charged by a sheriff's deputy for cursing in front of a teacher. A fourthgrade student in Philadelphia was pulled out of class, arrested, and held for eight hours at the police station for bringing a pair of 8-inch scissors to school. A middle school girl was arrested and charged with battery for pouring chocolate milk on a classmate. A 7-year old student with special needs was arrested for hitting a classmate and scratching the school resource officer who arrested him. He was driven to the police station in the back of a patrol car, fingerprinted, and confined to a holding cell. These examples illustrate what can happen when zero-tolerance school discipline policies trump common sense in school discipline. 
Students of color are most often victimized by these harsh and exclusionary discipline policies. Overall, Black students are three times more likely to be suspended than white students (United States Department of Education, 2014). In addition, the research shows that African-American students are more likely than their white peers to be suspended, expelled, or arrested for the same kind of misbehavior at school (NAACP Legal Defense Fund, 2005). The disparities evident in school discipline rates are also present in the juvenile justice system. According to Wald and Losen (2003), Black youth with no prior criminal records were six times more likely to be incarcerated than white youth for the same offenses; Latino youth were three times more likely to be incarcerated than white youth. Thus, students of color who misbehave at school suffer harsher consequences than white students in the principal's office, at the police station, and in the courtroom.

Students experience a range of negative consequences as a result of these policies. A recent study by Balfanz, Byrnes, and Fox (2013) found that students who were suspended just once in ninth grade dropped out of high school twice as often as their peers who were not suspended. In addition, a report by the NAACP Legal Defense Fund (2005) found that a student who has been suspended is more likely to be retained in grade or to drop out of high school. Suspended students are also at greater risk for involvement in the juvenile justice system (NAACP Legal Defense Fund, 2005; Wald \& Losen, 2003). For adolescent females, the single greatest predictor of later 
arrest is having been suspended, expelled, or held back while they were in middle school (Wald \& Losen). Additional studies have found that incarcerated youth have higher rates of both suspensions and expulsions (Foley, 2001; Katsiyannis et al., 2008). The research points to a strong relationship between juvenile justice involvement and exclusionary discipline practices such as suspensions and expulsions.

When students return to school after their suspension or expulsion, they still suffer from the shame and stigma that comes from being publicly disciplined. Students are often targeted for close monitoring by school staff and by police (Advancement Project, 2005; Rios, 2011). Students whose school discipline also resulted in involvement in the juvenile justice system are additionally stigmatized. They may return to school shackled with an ankle-monitoring device as a condition of their probation or may be required to meet with their probation officer on the school campus in full view of their peers (Advancement Project, 2005). In addition, the conditions of their probation are often so stringent that one missed curfew or one failing grade may be enough to send a student back to juvenile detention (Advancement Project, 2005; Rios, 2011). Understanding how exclusionary school discipline policies impact youth in the juvenile justice system is important and this study helps to build understanding.

\section{Summary of Contributing Factors}

In this strand of the literature review, I discussed factors contributing to the school-to-prison pipeline with an emphasis on how adverse childhood experiences 
impede learning, how exclusionary discipline policies have contributed to the increasing numbers of students in youth prisons, and how neglected urban schools contribute to the pipeline. While improving instruction for incarcerated students is urgent and important work, it is also necessary to stop the unimpeded flow of young people from schools into prisons. An important first step is acknowledging the both/and nature of this work. While it is necessary to reduce juvenile incarceration rates, we must simultaneously attend to the educational needs of students currently in the juvenile justice system. In the following section, I will discuss how protective factors may serve to keep students from becoming ensnared in the pipeline.

\section{Protective Factor: Positive Student-Teacher Relationships}

Improving the relationships between students and teachers has positive and long-lasting consequences for students' academic development. Positive studentteacher relationships draw students into the learning process and spark their desire to learn. Further, research has demonstrated that when students feel a strong personal connection with their teacher, they are likely to have greater trust in the teacher, to show greater engagement in learning, to have more positive classroom behavior, and to achieve at higher levels academically (Rimm-Kaufman \& Sandilos, 2011). Relationships matter for student learning. Further, positive student-teacher relationships may help to keep students out of the school-to-prison pipeline by keeping them academically engaged. 
A longitudinal study of early student-teacher relationships examined the role of positive interactions with students' academic achievement outcomes. Curby, RimmKaufman, and Ponitz (2009) examined the extent to which the quality of student-teacher interactions and students' achievement levels in kindergarten were associated with students' achievement trajectories. Researchers collected information from parents, students, and classroom observations for 147 students enrolled in 36 kindergarten classrooms and followed the students through the end of first grade. The findings indicate that positive student-teacher relationships led to higher levels of academic achievement in the early elementary grades. Researchers contend that academic trajectories are established early in student's school careers.

Longitudinal studies that examine the impact of positive-student teacher relationships over time are useful for understanding how these relationships impact academic trajectories. Hamre and Pianta (2001) followed a sample of 179 students from kindergarten through eighth grade to examine the long-term impact of positive student-teacher relationships on a range of outcomes. Researchers examined data on students' cognitive development, the quality of student-teacher relationships, students' classroom behavior and work habits, students' grades and standardized test scores, and students' disciplinary records. The results suggested that early positive student-teacher relationships are unique predicators of academic and behavioral outcomes with mediated effects through eighth grade. Positive early relationships correlated with 
positive academic and behavioral outcomes. The researchers speculate that positive student-teacher relationships support students' academic and social competence in the classroom and, therefore, allow students to access a broader range of instructional and socialization resources (Hamre \& Pianta).

Klem and Connell (2004) studied survey data along with student records for over 4,200 elementary and secondary students to learn more about the link between teacher support, student engagement, and academic achievement. Researchers found that students who perceive teachers as caring were more likely to report engagement in school. In turn, high levels of engagement were associated with better attendance and higher test scores. Further, researchers found that middle school students appeared to benefit more from high levels of support than elementary school students. Middle school students were almost three times more likely to report engagement if they had highly supportive teachers. While Klem and Connell could not explain this finding, it does point the the importance of maintaining positive student-teacher relationships as young people move from middle to elementary school.

While positive student-teacher relationships have been shown to improve academic outcomes, they are also protective against behavioral problems and risktaking. Researchers examining data from the National Longitudinal Study of Adolescent Health have also found that positive student-teacher relationships are protective against behavioral problems (Crosnoe, Johnson, \& Elder, 2004). Using this 
national data set, researchers included 10,991 adolescents in a multivariate analysis. The analysis looked at socio-demographic factors, academic factors, and school factors and examined the role of student-teacher relationships against such factors. The findings indicated that positive student-teacher relationships were associated with fewer behavioral issues at school.

Additional research has also found that positive student-teacher relationships reduce referrals for behavioral issues. A study of African American students who were behaviorally at-risk for referral to special education examined the impact of positive student-teacher relationships (Decker, Dona, \& Christenson, 2007). This study differs from Cosnoe et al. in its focus on students already at-risk for behavioral issues rather than a general sample of students. Participants included 44 students and 25 teachers from five elementary schools. Researchers found that positive student-teacher relationships reduced special education referrals for behavioral issues. Further, as teacher reports of positive student-teacher relationships increased, positive behavioral outcomes also increased.

Rudasill and colleagues (2010) explored the mediating role of student-teacher relationship quality from kindergarten through middle school. In addition, the researchers studied how relationships impacted students' risk-taking behavior. Participants in the study were part of the National Institute of Child Health and Human Development Study of Early Child Care and Youth Development (NICHD SECCYD). 
Study participants were recruited at birth while data collected for this study were gathered at Phase II (4.5 years old) and Phase III $\left(4^{\text {th }}-6^{\text {th }}\right.$ grade $)$. The study sample included 1,156 participants. Researchers found that positive student-teacher relationships in early childhood were associated with less risky behavior in early adolescence. Though middle school students often report less positive teacher relationships (Hamre and Pianta, 2001; Rudasill et al., 2010), this study found that these relationships are still important for students as they enter the secondary grades (Rudasill et al., 2010).

While a direct link between positive student-teacher relationships and reduced involvement in the juvenile justice system has not been established, positive relationships have been shown to improve academic outcomes, reduce behavioral problems, and reduce risky behavior among students. Establishing positive relationships in the early elementary years and maintaining them throughout the middle grades is a promising practice to reduce the flow of young people into the school-toprison pipeline.

\section{Protective Factor: Culturally Relevant Pedagogy}

Culturally relevant pedagogy (CRP) is "a pedagogy that empowers students intellectually, socially, emotionally, and politically by using cultural referents to impart knowledge, skills, and attitudes" (Ladson-Billings, 1994, p. 17-18). CRP draws on students' existing knowledge and helps to resolve the tension that occurs when students 
must negotiate the academic demands of school while simultaneously maintaining their cultural integrity (Ladson-Billings, 1995). Although this pedagogical framework pioneered by Ladson-Billings in the mid-1990s was originally studied with AfricanAmerican students, there are broad applications for many disenfranchised populations. Indeed, Ladson-Billings (1995) contends that for educators interested in the success of students of color in any complex, urban learning environment, CRP provides important theoretical and conceptual groundwork. It is difficult to imagine a more complex educational environmental than the prison school.

Ladson-Billings (1995) argued that culturally relevant teaching must meet three criteria. The teacher must demonstrate "an ability to develop students academically, a willingness to nurture and support cultural competence, and the development of a sociopolitical or critical consciousness" (p. 483). In the next section, the criteria are discussed along with the potential of that criteria to address the unique issues of educating incarcerated students. Taken individually, each of these criteria can positively impact marginalized students. Taken together, they can serve as a powerful lever to impact the academic achievement, cultural competence, and critical consciousness of incarcerated students.

\section{An ability to develop students academically.}

Most students in juvenile justice educational settings have experienced exceptional levels of academic failure. In spite of this, prison schools will only succeed 
if they see all students as capable of academic success. Incarcerated students need to learn those things that are most relevant to their current reality and their future success. In short, the curriculum must be relevant and teachers must believe their incarcerated students are capable of mastery.

The teachers studied by Ladson-Billings (1994) expected and produced academic excellence for their students. This contrasts sharply with the reports of students in juvenile hall. In an ethnographic study of incarcerated girls by Annamma (2014), the girls reported that teachers often made them feel dumb or intellectually inferior. In fact, this theme came up 76 times in 34 student interviews. As discussed in the previous chapter, male and female students reported, in a study by Young et al. (2010), that teachers gave them easy work or busy work because of their perceived low intelligence. In some cases, this prevented students from enrolling in GED programs or acquiring the credits needed for graduation. In these studies, students did not perceive an expectation of academic excellence in their classrooms.

Students in juvenile hall can experience academic success with instruction based on rigorous learning objectives, critical thinking, high expectations, and personalized academic goals — the same type of instruction that supports learning in all students. Young et al. (2010) suggested that improving the academic experiences of students in juvenile hall must start with professional development for educators focused on the sociocultural needs of students. This type of professional development should 
include an evaluation of teachers' pedagogical philosophies and practices. Schools, especially those for incarcerated students, must assume that all students can be successful.

\section{A willingness to nurture and support cultural competence.}

All students enter the classroom with knowledge, skills, and experience that can be tapped to accelerate their achievement and learning. Teachers who nurture and support the cultural competence of their students can access this knowledge and use it as a bridge to facilitate new learning. However, cultural competence in teachers is difficult to define and even more difficult to measure. In addition, some expressions of culture can be inappropriate and negatively reinforcing. Young et al. (2010) found that students' criminal identities were reinforced through interactions between the teachers and the students. For example, one teacher joked about how students should guard their belongings when a student recently arrested and sentenced for burglary entered the classroom. This is not cultural competence. While some teachers may think this type of humor taps into students' existing knowledge, it is demeaning and reinforces the criminalization of young people.

Instead, teachers in juvenile justice educational settings must focus on helping the students understand and honor their own cultural beliefs and practices. In a study focused on conceptualizing and actualizing culturally relevant pedagogy, Young (2010) found that cultural competence in classroom practice emerged in three related themes: 
(1) know your students, (2) build relationships with your students, and (3) affirm students' cultural identities. This may be a challenge in juvenile justice educational settings where student mobility is high and where institutional structures discourage relationship building. Still, creating culturally relevant classrooms in prison is not impossible and researchers in the field of juvenile justice education have begun to call for culturally relevant curriculum as an essential component of correctional education (Jeffers, 2010; Leone et al., 2005).

\section{The development of a sociopolitical or critical consciousness.}

Culturally relevant pedagogy must support students in questioning structural inequality, racism, and societal injustice. It is imperative that the critical consciousness of students in the juvenile justice system is nurtured and developed so that students can challenge the status quo of the system. This critique is, perhaps, the most problematic aspect of actualizing culturally relevant pedagogy within a youth prison. Teachers are situated within and benefitting from the system that they encourage students to critique. Teachers may also be unprepared to discuss issues of social and racial inequality because of their discomfort with the issues or their lack of awareness of how these issues impact their students (Young, 2010).

However, students already critique the type of education they are likely to receive in juvenile justice settings. Students in an ethnographic study conducted by Young et al. (2010) reported that work in juvenile hall is easier than regular school 
work but it does not prepare them to return to schools in their community. Moreover, the students expressed concerns about their ability to transition back into local schools after the poor schooling received while incarcerated. Students already know they are being short-changed by prison schools and often by the schools they attended prior to incarceration. Actively developing critical consciousness may support incarcerated students in resisting the dominant narratives about who they are and what they can accomplish. While culturally relevant pedagogy was not developed with incarcerated students in mind, it is a promising practice for engaging young people and keeping them from the school-to-prison pipeline.

\section{Summary of Protective Factors}

In this strand of the literature review, I discussed factors that may protect students from the school-to-prison pipeline with an emphasis on how positive studentteacher relationships lead to improved academic outcomes and how culturally relevant pedagogy can keep students engaged in learning. Prison school need not be an inevitable stop in the school-to-prison pipeline. By applying research about what works to keep students in school, the flow of students through the pipeline can be slowed.

\section{Prison Schools as Institutions of Social Control}

This study was guided, in part, by conceptual frameworks based on social reproduction in schooling. Within that framework, I will discuss the dynamics of the hidden curriculum of schooling as well as the role of prison schools in exerting social 
control through the exercise of knowledge, power, and discipline. While all schools are characterized by the prevailing culture, politics, and economics of a particular society, these values are often hidden under the veneer of the official curriculum. In prison schools, this veneer is thin and the hidden curriculum is far less hidden. This analysis will discuss the convergence of public education and public incarceration or what happens when "the hidden curriculum goes to prison" (García \& Lissovoy, 2013). The work of Foucault (1977) will be presented to animate the concept of schools as disciplinary institutions. Finally, the role of social control in youth prisons is discussed. All of these concepts will be used to understand how school in prison is socially constructed and reinforced.

\section{The Hidden Curriculum Goes to Prison}

A seminal article by Giroux and Penna (1979) defines the hidden curriculum as the "unstated norms, values and beliefs that are transmitted to students through the underlying structure of meaning in both the formal content as well as the social relations of school and classroom life" (p. 22). The hidden curriculum is defined as those things in school which are unsaid but which come to be known and understood by those participating in schooling. The school functions not only as a socializing agent but also has the capacity to undermine the goals of the overt curriculum (Giroux \& Penna). The authors argue that what students learn from the formal curriculum is less important than 
what they learn from the ideological assumptions embedded in school. Thus, the formal curriculum is sometimes subjugated by the hidden curriculum.

Anyon (1980) demonstrated how the hidden curriculum of schooling can be actualized in classrooms. Her study examined the work and interactions of five socioeconomically diverse elementary schools. Anyon observed differences in the classroom experience of the various students and found that different knowledge, skills, and predispositions were being transmitted in each classroom. These skills were differentiated based on social class. Working class children were, according to Anyon, prepared for their role as wage laborers and were taught to be docile and obedient. Upper class children, however, were given "knowledge and practice in manipulating the socially legitimated tools of analysis of systems" (p. 89). Anyon concluded that by emphasizing different curricular and pedagogical practices, the students developed different cognitive and behavioral skills in each social setting. Thus, the social class of the students in each classroom were socially reproduced though the implementation of the hidden curriculum and, in part, through the implementation of different formal curricula as well. Well before the students entered the workforce, working class students learned how to labor while upper class students learned how to govern. Extending the work of Giroux and Penna (1979) and Anyon (1980) to the construction of classrooms in juvenile justice settings provides an interesting framework for considering the purpose of school in prison. While the cognitive skills promulgated 
by the formal curriculum take center stage in the discourse surrounding highperforming schools, obedience and submission take center stage in the dialogue about prison schools. In juvenile justice educational settings, punctuality, cleanliness, and docility are valued over intellectualism (Annamma, 2014; García \& Lissovoy, 2013; Young et al., 2010). Time in prison schools is regimented through schedules and routines that supersede educational goals. Obedience and conformity are the core academic program. It appears that curriculum in prison schools, both hidden and overt, is not designed to prepare students for opportunities beyond adult prison or low wage occupations. As García and Lissovoy (2013) assert, "the habits and dispositions that the contemporary hidden curriculum seeks to produce in students are ones that are suited to this prevailing condition of more or less permanent marginalization" (p. 56). As further suggested by the work of Annamma (2014), the hidden curriculum in prison schools is not only meant to demoralize and dehumanize students but also to dominate them. Indeed, teaching and learning processes in prison schools become exercises in domination.

The research demonstrates that, when the hidden curriculum goes to prison, it is less hidden. Norms and values that are unstated in traditional schools are made explicit in juvenile justice education. Both formal and informal knowledge are designed so that young people know their intellectual development is not valued but their conformity and obedience are. Examined through this lens, prisons schools are not failing at all. In 
fact, they are well-suited to their task and execute it with precision. Students quickly come to learn their place in prison schools. In truth, all schools have historically served as institutions of social control and prison schools can simply be viewed as an extreme example. In the next section, public institutions as agents of social control are discussed. The work of Noguera (1995) and Foucault (1977) are used to frame a discussion of social and disciplinary control in schools.

\section{Foucault, Power, and Social Control}

A classic article by Noguera (1995) considers of the history of American schools as institutions of social control. The author argues that education and juvenile justice have common roots and both systems were developed as a means to control and discipline the population. Indeed, the need to regiment and control the growing populace dominated the mission of early educational progressives (Noguera) as it later came to dominate the mission of juvenile justice advocates (Alexander, 2012). Schools, Noguera (1995) argues, have never been designed to educate all students in the same way. In fact, to ensure that students were trained appropriately for the kinds of work they would perform as adults, specialized high schools were developed early in the history of public education. As discussed in the previous section, one might argue that the modern prison school is just another type of specialized high school.

Noguera's analysis is guided by the work of Michel Foucault, a modern philosopher who developed theories that addressed the relationship between power and 
knowledge. Specifically, Foucault (1977) considered how public institutions exercise social control through the distribution of knowledge and the exertion of power and discipline. The exercise of discipline in schools is of foremost concern to Foucault because it is the primary means through which symbols of knowledge and power are perpetuated to youth (Noguera, 1995). Discipline in prison schools is exerted in ways both overt (i.e., the presence of correctional officers in classrooms) and covert (i.e., the lack of appropriate special education services for students who need them). As the distinction between school and prison is blurred, it is instructive to envision how Foucault might experience a modern high school.

Imagine Michel Foucault stepping into a modern urban high school. First, he would walk through the tall iron gates surrounding the school. He would see the school police (euphemistically known as school resource officers) and he may notice the keen eye kept on students as they move into the building. Foucault would hear the buzz of metal detectors and see students ordered to turn out their pockets. Once inside the school, he would note the fish eyes of security cameras in nearly every corner. Of course, he would be required to present his own identification and sign into a visitors' $\log$ before being issued a visitors' pass. Foucault may see the ubiquitous school identification badges hanging from lanyards around each students' neck and notice that each student has been assigned an identification number. He would observe the controlled movements of students from classroom to lunchroom and back to classroom. 
He might witness an argument between students and observe the swift disciplinary action taken by school security staff. Foucault might step back out the door to reassure himself that he was indeed visiting a high school and had not instead stumbled into a juvenile prison.

Perhaps Foucault would not be surprised by the modern high school. Schools, for Foucault, were seen as a form of disciplinary institutions with the purpose of observing, training, and surveilling students (Foucault, 1977). Thus, surveillance becomes a form of disciplinary power. Modern high schools are designed as panopiticons and allow for school administrators to exercise disciplinary power without leaving their office (Foucault). Panopticons, a type of architecture originally designed for prisons, allow for constant surveillance of students. Security cameras literally allow school staff to gaze into every corner of the school to maximize both observation and control. In addition, surveillance is also reinforced through classroom management systems, character education programs, and other schoolwide behavioral interventions. The tools of this system are micropenalties, small but ubiquitous sanctions through which students are constantly punished (Foucault). There are sanctions for time; tardiness and absences are penalized. There are sanctions for behavior; both overzealousness and lack of attention are penalized. Certain types of speech are penalized. Talking out of turn and vernacular forms of language are punishable offenses. There are even sanctions for the body; students receive penalties for 
slouching, shuffling, or wearing their pants too low. These penalties are meted out through a range of policies and procedures such as tardy slips, office referrals, phone calls home, detentions, suspensions, and expulsions.

Prison schools can be viewed as amplified versions of the modern highsurveillance high school. Researchers have demonstrated that social control often trumps the academic needs of students within juvenile justice educational facilities (Annamma, 2014; Young et al., 2010). One might argue that the true purpose of a school within a prison is a different kind of teaching and learning. Rather than teaching students the academic skills needed to succeed outside of prison, students are taught the social skills needed to succeed inside of prison. Indeed, young people educated behind prison walls often become better prisoners instead becoming better students. Noguera (1995) argues for a different kind of school environment — one that is humanizing with a strong sense of community and collective responsibility. Creating a different type of prison school would mean creating a different type of prison. While the ultimate goal for many reformers is the abolition of the modern juvenile justice system, we must urgently address the needs of the students within the existing system. This study seeks to understand how students learn in an environment that prioritizes control over learning with an eye toward reforming the system into something more humane, more just, and more appropriate for learning. 


\section{Summary of Prison Schools as Institutions of Social Control}

In this strand of the literature review, I presented frameworks based on social reproduction and the dynamics of the hidden curriculum as well as the role of prisons schools in exerting social control through the exercise of knowledge, power and discipline. In prison schools, the hidden curriculum is made explicit. This overt exercise of power and authority can be used to understand social reproduction in prison schools.

\section{Conclusion}

The literature review provided an overview of research related to the educational experiences of incarcerated youth. The review began with an operational definition of the school-to-prison pipeline as a web of interrelated factors that push students into the juvenile justice system. Factors that contribute to the flow of students into the pipeline were then discussed with a focus on adverse childhood experiences, neglected urban schools, and exclusionary school discipline. Each of these factors negatively impact young people's ability succeed academically. Next, factors that protect students from the school-to-prison pipeline were discussed with a focus on positive student-teacher relationships and culturally relevant pedagogy. Each of these factors positively impact young people's ability to succeed academically. Finally, the literature review concluded with a discussion of prison schools as institutions of social control. This literature built upon the conceptual framework with an extended analysis of power and 
the hidden curriculum of schooling. Taken together, the literature review incorporated both the theoretical underpinnings and the experiential considerations that ground this study. 


\section{Chapter Three: Methodology}

Thinking about the ways one conducts research with youth and communities in that it positions researchers as evolving and situated, always being mindful of how critically important it is to resect the humanity of the people who invite us into their worlds and help us answer questions about educational, social, and cultural justice.

\section{Introduction}

Django Paris \& Maisha T. Winn

An exploratory case study design with phenomenological interviews was used in this study to explore the following questions: How do incarcerated students describe their educational experiences leading up to and during incarceration? How do incarcerated students make meaning of their educational experiences behind bars? Understanding the way in which youth experience schooling leading up to and during incarceration is an important step in designing more effective juvenile justice educational programs. This chapter provides an overview of the methods used in this research study. The role of the researcher is first described. A description of the site and the participant selection process follows. The chapter concludes with a description of the data collection and analysis.

\section{The Role and Perspective of the Researcher}

As a researcher in the field of qualitative inquiry, I consider myself to be the primary instrument of the research study (Creswell, 2008; Saldaña, 2011). As such, it important that I remain aware of my own history and identity as I move through the research. As a social justice educator concerned with the inequities of the juvenile justice education system, I am professionally committed to dismantling the juvenile 
justice system. As a woman of color, I have personally witnessed the long-lasting harm suffered by individuals and communities as a result of the system. My experiences teaching and volunteering in juvenile halls has shown me that confinement is nearly always traumatizing and harmful to adolescents. I believe that the current juvenile justice system is broken beyond repair and should be abolished. However, I also know that we must urgently address the needs of the students within the existing system. All of these perspectives influenced my study and impacted how I approached the research.

During the collection and analysis of my data, I remained mindful of my personal and professional values. Throughout the dissertation process, I enlisted the support of critical colleagues in examining my own assumptions and attitudes about the research. My critical colleagues have all earned or are currently earning a doctorate and are familiar with the dissertation process. Their insights, questions, and comments helped me to address potential biases during the review and analysis of the data. I also debriefed the interview findings with two trusted professionals in the field of juvenile justice to gain an additional perspective on the research. In addition, my dissertation advisor played a crucial role in helping me remain mindful of potential biases through regular advising and critical conversations. Finally, I used data memos to process my experiences during data collection.

My perspective as a researcher is also influenced by my past qualitative research including a pilot study conducted as a class project. For the pilot project, I interviewed 
adults who were incarcerated as adolescents about their schooling experiences in juvenile hall. Through that project, I attempted to answer research questions about the participants' educational experiences, their relationships with teachers, and their identity as learners. The project allowed me to gain experience in interviewing participants and analyzing qualitative data. In addition, the protocols used during the adult project informed the protocols which were used for the adolescent project.

\section{Study Design}

This study used an exploratory case study design. Case studies center on a single group or unit of analysis for study which in and of itself is valued as a unit that provides for in-depth examination (Saldaña, 2011). In this study, the institution serves as the case or unit of analysis. There are different ways to select a case and the case in this study have been chosen for its ability to reveal both the breadth and depth of student experiences in prison schools. Because the institution houses both male and female students of varying dispositions across a range of security levels, this selection of this case allowed for research across a broad swath of juvenile prison school experiences.

This case study research employed an exploratory orientation. According to Butin (2010), an exploratory design is best used with an issue that has not been carefully examined in the literature or when an issue is not well understood. Although there is a plethora of data demonstrating poor academic performance for incarcerated 
youth (Baltodano et al., 2005; Foley, 2001; Katsiyannis et al., 2008; Tesoro et al., 2014; Wang et al., 2005; Zamora, 2005), scant data are available that describe incarcerated students' experiences in juvenile justice educational settings (Caldwell \& Curtis, 2013; Foley, 2001). Therefore, an exploratory orientation was taken in this study to allow ideas and themes to unfold from the students. The goal of this study is to describe rather than to explain.

In addition, this study used phenomenology — "the study of the nature and meaning of things" (Saldaña, 2011, p. 7). A phenomenological approach to interviewing is often taken when the researcher seeks a deep understanding of how another person experiences something (Saldaña, 2011; Seidman, 2013). There is a burgeoning body of research to support the use of interviews in the study of incarcerated students (Annamma, 2014; Inderbitzin, 2005; Winn, 2011; Young et al., 2010). Interviews bring the voices of students to the forefront of juvenile justice research and are considered superior to quantitative techniques in capturing the stories of incarcerated youth (Young et al., 2010). Through a focus on events, concepts, and the lived experiences of incarcerated youth, this study brings the voices of students to the growing body of school-to-prison pipeline literature.

\section{Description of the Site}

All research was conducted at a juvenile justice educational facility run by a county office of education in northern California where I have an existing relationship. 
I was previously employed for five years by that county office of education and taught in the facility during intersession. The county office of education runs two facilities for students at the same location. The juvenile hall (referred to here as the "Hall") is a 24hour secure detention facility capable of housing 350 young people. At the time of this research study, the Hall housed approximately 100 male and female students per day. The county also runs an adjoining minimum security residential program. The minimum security facility (referred to here at the "Camp") can house up to 50 adolescent males ages 15 through 19. At the time of this research, the Camp housed approximately 35 students per day. Across both facilities, the majority of youth are students of color and the average student age is 17. A more detailed description of each facility is included below.

The school year in both the Hall and the Camp is 220 days long. Students attend class for five 55-minute periods each day. All high school students take classes together regardless of age, grade level, proficiency level, number of credits earned, or special education needs. All students take mathematics, English, social studies, science, and physical education each day. No electives in art, foreign languages, or other content areas are offered in either facility. Elective credits are awarded through packets that the students complete independently. One packet, approximately 50 worksheet pages, is worth 5 credits toward graduation. No homework is given in either facility. 


\section{The Hall.}

The Hall is a 24-hour secure detention facility that was built in the past ten years. It is what most people think of when they think of a juvenile hall. The Hall consists of ten units though only six of them are currently being used. The units are segregated by age, gender, and level of offense. The research for this project took place in two maximum-security units for boys aged 14-18 and in one mixed-level unit for girls aged 12-18. Each of the Units has the same layout. There are 36 rooms for students that are approximately six feet by eight feet. Each room has a bed, a locker, and a toilet-sink combination. All students have their own room. In addition to the rooms for the students, each Unit contains two classrooms, two interview rooms, a shared bathroom with showers, and a command center for continual surveillance. Correctional officers staff the command center which includes camera views of the entire Unit including the classrooms and corridors leading to the Unit. The center of the Unit has tables bolted to the floor that are used for meals, games, and unit meetings. Each Unit also has a recreation yard, a forty by forty-foot cement yard enclosed by twenty-foot cinder block walls. The Hall contains a gym that students are allowed to visit three days per week, and a library that students are allowed to visit once per month. Boys and girls wear the same clothing: khaki pants and dark green shirts and sweatshirts with black sneakers. Shirts must be tucked in at all times. 
Students in the Hall are awaiting trial, have been adjudicated in juvenile court and are serving their full sentence, or have been sentenced in adult court and are serving a partial sentence before being transferred to adult prison to complete their sentence. All of the boys in Units 2 and 4 are awaiting trial for felony charges or have already been convicted of one or multiple felonies. The girls in Unit 6 are being held for a variety of charges though more than half have been sexually exploited and are being held for charges related to their exploitation.

\section{The Camp.}

The Camp is a minimum-security residential program for adolescent males between 15 and 19 years old. The Camp consists of several faded brown buildings spread across a small campus. There is a dormitory which can house up to 50 students, two classrooms in the school building, a recreation building, and a cafeteria. A small garden sits in the middle of the campus. There are picnic tables situated underneath live oak trees where students sit, talk, and eat snacks between classes. The camp has a basketball court and a soccer field along with a breathtaking view of the Pacific Ocean. The buildings are over 50 years old and there are tall cyclone fences around the Camp topped with razor wire. However, the gates are open for most of the day and students could try to run. Some do run but most choose to stay and complete their sentence.

Unlike the Hall, the Camp has a level system and students can earn privileges for good behavior. Each level has a different color and you can see which level the 
student has earned based on the color of his shirt and sweatshirt. Students at the lowest two levels cannot leave the Camp. Students at the highest two levels are allowed to go home for visits each weekend and during holidays. These students are also able to leave the Camp for field trips. Entering the Camp is much different than entering the Hall. While it is necessary to stop by the front office to get a visitors' pass, there are no gates or security officers preventing anyone from walking into the Camp. Correctional officers walk around the Camp keeping an eye on the students but the atmosphere is far less institutional than the Hall.

All of the boys in the Camp have been adjudicated and have all been convicted of misdemeanors, status offenses, or probation violations. In some cases, students served time at the Hall before being transferred to the Camp for good behavior. Most of the students in the Camp are serving a sentence less than one-year long. Sometimes, the students at the Camp are sent to the Hall as a punishment for fighting or other rule violations.

\section{Participant Selection}

In order to facilitate participant recruitment, I first established relationships with teachers. I attended staff meetings at both the Hall and the Camp to introduce the project to the staff. At the Hall, two teachers out of 12 allowed me to visit their classroom to observe and recruit students. At the Camp, one teacher out of two allowed me to visit her classroom to observe and recruit students. In total, three teachers 
participated in the study and 10 classrooms observations were conducted in their classrooms. All recruitment was done through these observations. After completing a classroom observation, the teacher would introduce me to the students and I would explain my project. All students participating in the project volunteered during one of these classroom observations.

In total, 28 youth consented to participate in this study. Of the 28 youth, five were female and 23 were male. Of the students who consented to participate, 15 were African-American, eight were Latin@, three were mixed-race, and two were white. All of the students were between 14 and 18 years old; the average age was 17. Although voluntary sampling was used with the students, the age, gender, and racial composition of the sample mirrored that of the institution. A summary of students' interviewed is included below.

Table 1. Summary of Participants

\begin{tabular}{|l|l|l|l|l|l|l|}
\hline & Pseudonym & Age & Gender & Race & $\begin{array}{l}\text { Security } \\
\text { Level }\end{array}$ & $\begin{array}{l}\text { Length of } \\
\text { Current Stay }\end{array}$ \\
\hline S1 & Ahmed & 17 & Male & Mixed Race & Maximum & 537 \\
\hline S2 & Brandon & 17 & Male & Black & Maximum & 225 \\
\hline S3 & Travis & 18 & Male & Black & Maximum & 655 \\
\hline S4 & Lisa & 15 & Female & Latina & Mixed & 120 \\
\hline S5 & Shamieka & 16 & Female & Black & Mixed & 13 \\
\hline S6 & Jesus & 18 & Male & Latino & Minimum & 125 \\
\hline S7 & Andrew & 17 & Male & Mixed Race & Minimum & 150 \\
\hline S8 & Carlos & 17 & Male & Latino & Maximum & 232 \\
\hline S9 & Sergio & 17 & Male & Latino & Maximum & 185 \\
\hline S10 & Juan & 18 & Male & Latino & Minimum & 365 \\
\hline
\end{tabular}




\begin{tabular}{|l|l|l|l|l|l|l|}
\hline S11 & Angelo & 17 & Male & Black & Minimum & 120 \\
\hline S12 & Raymond & 17 & Male & Black & Minimum & 100 \\
\hline S13 & Roberto & 18 & Male & Latino & Minimum & 225 \\
\hline S14 & Andre & 16 & Male & Black & Minimum & 60 \\
\hline S15 & Jorge & 17 & Male & Latino & Minimum & 178 \\
\hline S16 & Raphael & 18 & Male & Latino & Minimum & 242 \\
\hline S17 & JaMarcus & 17 & Male & Black & Minimum & 295 \\
\hline S18 & Dominique & 18 & Female & White & Mixed & 28 \\
\hline S19 & Vanessa & 17 & Female & White & Mixed & 25 \\
\hline S20 & Erykah & 14 & Female & Black & Mixed & 3 \\
\hline S21 & Peter & 17 & Male & Black & Maximum & 122 \\
\hline S22 & Daniel & 17 & Male & Mixed Race & Maximum & 3 \\
\hline S23 & DeShawn & 16 & Male & Black & Maximum & 79 \\
\hline S24 & James & 16 & Male & Black & Maximum & 48 \\
\hline S25 & Michael & 15 & Male & Black & Maximum & 12 \\
\hline S26 & Donte & 15 & Male & Black & Maximum & 15 \\
\hline S27 & Timothy & 15 & Male & Black & Maximum & 12 \\
\hline S28 & Tyrone & 17 & Male & Black & Maximum & 138 \\
\hline
\end{tabular}

Table 1. The participants in the study, who have all been assigned pseudonyms, mirror the age, gender, and racial composition of the institution.

The average length of stay for the students in the sample was 147 days at the time of interview; the longest length of stay was 655 days at the time of interview.

Since the students attend school in the institution year-round, the average participant in the study had spent at least 5 months attending school behind bars. Since I only captured the length of the students' current stay and since many of the students had spent time in the facility previously, the majority of them had more than 5 months' experience to draw from when discussing their time attending school while incarcerated. 
On average, each student was interviewed two times for a total of 60 minutes. Students who were 18 years old signed an IRB-approved informed consent to participate in interviews. Students aged 14-17 signed an IRB-approved minor asset to participate in interviews. Parental consent was obtained from students' parent, guardian, or court-appointed ward through the students' probation officer.

\section{Ethics and Protection of Human Subjects}

This study presented several ethical considerations. First, there is always the risk of loss of privacy for students participating in any study. Although this risk has been mitigated through the use of pseudonyms, the risk cannot be eliminated completely. Student interviews collected through the study have been protected through password encryption to protect the privacy of students. Second, although this study focused exclusively on students' experiences with school while incarcerated, other issues related to incarceration did arise during the course of the interview. As a mandated reporter, I am subject to the California Child Abuse and Neglect Reporting Act (CANRA). Under this law, I must make a report to county welfare officials if I reasonably suspect or if a minor reports that he or she has been the victim of any of the following: physical abuse; child sexual abuse; willful cruelty or unjustified punishment; unlawful corporal punishment or injury; general or severe neglect. To address this issue, disclosed my mandated reporter status to students prior to conducting interviews. During the interviews, there were no disclosures that required a report under CANRA. 
A third consideration is the potential discomfort that students and/or teachers may face if they read the results of the research study and found themselves to be portrayed negatively. I addressed this issue by removing or obscuring identifying details. All teacher names have been changed and the names of schools, cities, and counties have been redacted.

Finally, I feel that there are ethical issues that are unique when conducting research with youth and communities who have been historically marginalized by systems of inequity. As a researcher for justice, I follow in the footsteps of Paris and Winn (2014) who are "committed to working to end a long history of colonizing approaches to research, policy, and practice in communities of color and other marginalized communities." (p. xvi). For me, this means that I approached this project with humility and appreciation for the interview participants. In presenting my findings, it means humanizing the research. Humanizing approaches involve building relationships of dignity and care for both researchers and participants (Paris \& Winn). My commitment to my participants is to share their stories in a way that puts their humanity, not their criminality, at the forefront. It is an expression of justice and is how I support equity within my research practices. For this reason, I chose not to disclose the reason for any students' incarceration. 


\section{Data Collection}

During the study, student interviews, teacher interviews, and classroom observation data were collected. The majority of the data collected for this study came from phenomenological interviews with students which followed a standardized, openended protocol developed based on a review of the literature and based on themes discovered during the pilot study described above. All student interviews were divided into three discrete interview periods. Using multiple interviews allowed me to develop a greater rapport with the students. Also, allowing time to pass between interviews gave students time to reflect on their experiences. Finally, since the focus on my study is telling students' stories, phenomenological interviews allowed for more complex stories to unfold. As a result of scheduling limitations, sometimes interviews were conducted in the same sitting with a break in between. Each student was interviewed at least once and up to four times. On average, each student was interviewed two times for a total of 60 minutes. All interviews were conducted in the Hall or in the Camp and all interviews were digitally recorded. This allowed me to take minimal notes and give my attention to the participant.

Interview One consisted of a focused life history. The goal was to put the participant's experience in context by asking him or her to share as much as possible about him or herself in light of the topic up to the present time (Seidman, 2013). During the first interview, I asked the students about their educational experiences up 
until the time when they became incarcerated with the goal of establishing the context of their experiences. After asking the participant some introductory questions, I asked if they could recall their very first day of school and the educational history moved forward from there.

Interview Two consisted of the details of their current experience. The goal was to concentrate on the concrete details of the participants' present lived experience in the topic area of the study (Seidman, 2013). During the second interview, I asked students about their educational experiences while incarcerated to better understand the details of their experience within the context of the prison. I started by asking the student to walk me through an entire school day from the first period to the last. Several questions about school in the facility followed.

Interview Three consisted of reflection on the meaning of their past and present experiences. The goal was to have participants reflect on the meaning of their experience by reflecting back on the first two interviews (Seidman, 2013). During the third interview, I encouraged students to reflect of the meaning of their educational experiences up to and including juvenile hall and to share their own reflections on learning. I started by asking the student the purpose of school in juvenile hall and followed this with more reflective questions.

Additional data for this study came from teacher interviews and classroom observations. In this study, these data are being treated as secondary sources and have 
been used only to provide access to and context for the student interviews. I interviewed three teachers for the study and, though they did not share any information about individual students, their reflections on the institutions provided useful context. The teacher interviews followed an open-ended protocol based on the student interviews. I also conducted ten classroom observations. Again, the goal of the observations was not to observe specific students but to help establish my presence in the school and learn more about educational context. Field notes were taken during the observations that were later turned into narratives and data memos.

\section{Data Analysis}

All student interviews were digitally recorded by me and professionally transcribed including informal and broken speech; this type of detail is inference-laden and helped me as I searched for deeper meaning in the transcripts (Miles, Huberman, \& Saldaña, 2014). Field notes taken during observations and teacher interviews were typed and organized by classroom and class period observed. Data memos, which were written during data collection and analysis, were also typed and added to the data corpus.

The first cycle of data analysis began with an initial reading of the transcripts and field notes in order to begin coding. Coding is the process of "working through iterative cycles of induction and deduction to power the analysis" (Miles et al., 2014, p. 93). During this cycle, I began with in vivo coding. In vivo coding uses words or short 
phrases directly from the interview transcripts to create codes. This form of coding is especially useful for studies such as this one that seek to preserve and honor the participant's voice (Miles et al.).

The second cycle of data analysis focused on descriptive coding and categorizing. The descriptive codes assigned labels to the words and phrases identified in the first round of coding (Miles et al., 2014). These codes were eventually used to create an inventory of topics for categorizing the data and laid the foundation for analysis across interviews. After the cycles of analysis and coding were complete, I grouped the codes thematically. Since the research question centered on students' experiences up to and including incarceration, the themes were organized along a trajectory that captured the temporal aspects of the student experiences. Each theme contained several strands which characterized the theme. These themes and strands are discussed in detail in Chapter 4.

\section{Validity}

Among qualitative researchers, validity is often a contested term. Some feel that it is a quantitative construct that has no place in qualitative inquiry while others use it because it suggests a more rigorous stance toward qualitative work (Miles et al., 2014). Creswell and Plano Clark (2011) assert that employing strategies that address potential issues in data collection, data analysis, and interpretation serve to address validity and that these strategies should be employed in all research. Finally, Saldaña (2011) 
suggests that the constructs of credibility and trustworthiness are more appropriate for qualitative inquiry and believes that the goal is to persuade the reader of our rigor. Setting controversy aside, it important to persuade the reader of the soundness of my methods and that is what I focus on below.

To increase the validity of the study, the student and teacher interview protocols were reviewed by all members of my dissertation committee and their feedback was incorporated into the protocols. The student interview questions used were piloted with a group of adults who were incarcerated as adolescents prior to using them in the study. During data collection, the same interview protocols were used for all student and all teacher interviews. Also, interviews were conducted until repetition in themes began to occur. During data analysis, interview transcripts were taken through two cycles of coding. Student interview data was triangulated with teacher interview data and classroom observations. These steps were taken to ensure that the findings truly represent the phenomenon that I set out to explore.

\section{Reliability}

The underlying issue with reliability is whether the process of the study has been consistent over time and across methods. Here, issues of quality and integrity are further addressed (Miles et al., 2014). To increase the reliability of this study, clear research questions were developed and the study design are congruent with them. The role of the researcher has been clearly articulated and several attempts made to address 
biases. The same student protocols were used for all 28 student interviews and the same teacher protocols were used for the three teacher interviews. All data were collected by a single researcher and was collected under similar conditions. Across both the student and teacher interviews, the findings reveal similar themes across multiple participants. The reliability of the study is related to its transferability. Although the sample was not random, the sample is representative of students in the juvenile justice system in an urban setting. Therefore, the results could have transferability to a similar context. The repetition of the same key ideas across multiple interviews suggest a high level of reliability within the findings.

\section{Conclusion}

In this chapter, I described the methodological approaches that I employed in conducting this study. The data were drawn primarily from student interviews with classroom observations, teacher interviews, and data memos as supporting sources. Incarcerated students are uniquely qualified to provide a description of prison schools. This study seeks to address gaps in the literature related to schooling in juvenile justice settings by providing a detailed account of students' experiences. 


\section{Chapter Four: Findings}

Teachers don't really know what we was goin' through to get here and stuff like that. Kids probably didn't have nowhere on the outs to go. They get three meals a day here, a place to sleep, stuff like that. Clean clothes every day. Even if they [teachers] had just a

little sense of what it was like, what the kids was goin' through when they was out, maybe they'd act different and treat 'em different, but they just treat 'em as another person that committed a crime.

-Brandon, age 17

\section{Introduction}

This study examined the educational trajectories and experiences of incarcerated students. As previous chapters have noted, quantitative measures of student achievement have shown that the educational experiences of incarcerated youth fail to prepare them for future academic success. This study supplements the existing quantitative literature by examining the experiences and outcomes of incarcerated students through a qualitative lens. Further, this study brings the voices of students into the literature about the school-to-prison pipeline and juvenile justice reform.

This study used phenomenological interviews to answer the following questions: How do incarcerated students describe their educational experiences leading up to and during incarceration? How do incarcerated students make meaning of their educational experiences behind bars? Twenty-eight currently incarcerated students were interviewed in three phases. Interview One consisted of a focused educational history and students shared their educational experiences up until the time when they became incarcerated. During Interview Two, students discussed their educational experiences 
while incarcerated and framed the details of their experience within the context of the prison. In Interview Three, students reflected on the meaning of their educational experiences in juvenile hall and their entire schooling experience.

Findings are organized along an experience trajectory that emerged from an analysis of students' experiences across schooling and fall into three broad themes. The first theme is positive early school experiences. Within this theme, strands related to positive teacher relationships, positive learning environments, and family and community influence were uncovered during the interviews. The second theme is school disengagement in middle and high school. Within this theme, strands related to school detachment, school discipline, public shaming and exclusion in school, and being caught between school and the streets are discussed. The final theme is academic reengagement in prison school. Within this theme, positive teacher relationships appear again along with strands related to the weak academic program, reengagement in learning, and the uncomplicated learning environment. Figure 3 is used to graphically illustrate each theme and its accompanying strands.

To allow the voices of students to be at the forefront of this study, each theme and its accompanying strands are organized around student narratives. In each section, the theme is first defined and then introduced with a student story designed to illustrate all strands of the theme. Next, each strand is defined and quotes from other students are used to further illustrate and develop each strand. Finally, the findings are integrated 
across the various strands and each section closes with final words from the young people. The chapter closes with a summary of the findings while the following chapter focuses on analysis.

\section{Figure 3. Summary of Findings}
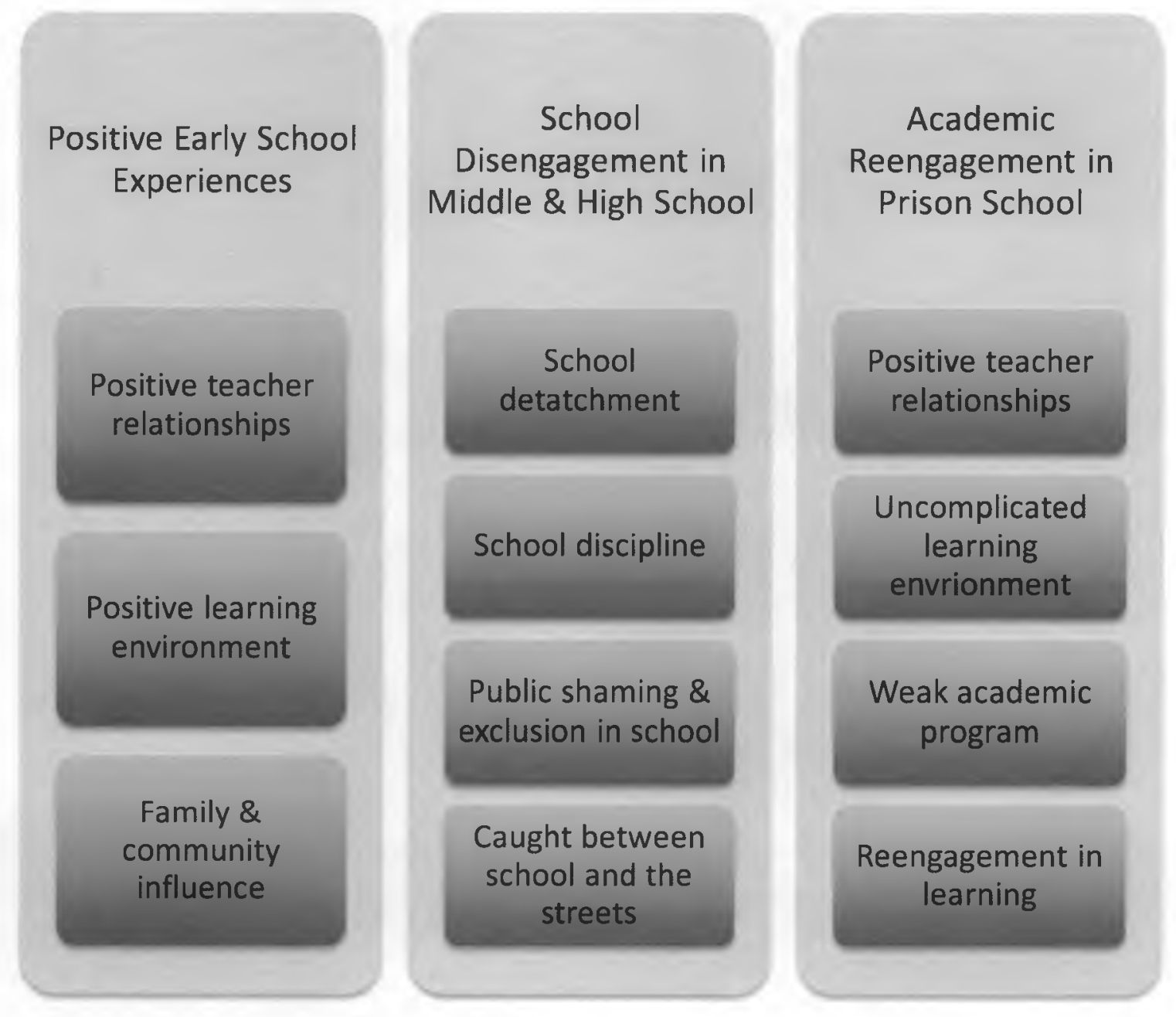

Figure 3. Findings are organized into three broad themes with supporting strands. The first theme is positive early school experiences. The second theme is school disengagement in middle and high school. The third theme is academic reengagement in prison school. 


\section{Positive Early School Experiences}

When we were little, school was hella cool. We played, colored, and learned our numbers. We played soccer at recess. And if you messed up, the teachers didn't put you out. They were understanding cuz you were just a little kid.

Yeah, it was cool back then.

$\sim$ Sergio, age 17

The first theme that emerged from the study centered on students' positive early school experiences. Nearly all study participants experienced school as a affirming place in their elementary years. In spite of later difficulties, the early years of schooling began like most students' early years - with happy memories of preschool and kindergarten. When I asked the students to tell me about their first day of school, all of them smiled and dropped their chin before telling me stories of tearful separations from their mother, the kindness of their first teacher, and about making new friends. All of the students had positive stories to share about elementary school and nearly all of these centered on positive relationships with teachers and administrators. Other strands from students' early experiences included joy and excitement in learning along with the role of family and community. Many of the participants told me that "school was fun" when they were in elementary school and this was evident in the stories that they told. All three of these strands related to the theme of early positive experiences in school are illustrated through the story of Dominique - the narrative that introduces this theme. 


\section{Dominique: The Rose That Grew from Concrete}

There's a quote [on the wall] outside. It says something about the rose that grew from concrete. I would explain myself using that because I have been through a lot.

Dominque is a tall, willowy girl with green eyes and long strawberry blond hair pulled into a tight ponytail. She is nervous when I meet her and tells me that she is really worried about her case; she may be tried as an adult. Also, she is a senior who is close to graduating so she is worried about missing so much school. While we talk, Dominique fidgets with her hands and smiles often. She seems like the kind of girl who wants to please. Dominique shares her early school experiences with me and her story echoes the themes found among many students.

It's hard to explain who I am. I have goals. I've been through a lot. There's a quote [on the wall] outside. It says something about the rose that grew from concrete. I would explain myself using that because I have been through a lot. I still manage to-I try to stay positive and try to always look at the better side of things. I try to always just find the positive in all the negative. Even being in here for what I'm here for, it does get hard sometimes, but I really try to, you know, I try to stay positive about everything. I would describe myself as a positive person. Yeah. One thing that I've always wanted to do with myselfI've always wanted to become a juvenile probation officer, so it's a funny story that I'm in here. I want to work in law enforcement. I took criminal justice classes for it and everything, but I'm just praying and I'm hoping that I can get a 
second chance. This is my only-this is my first offense. I do want a second chance to prove to the courts and everybody that that's not who I am.

I remember my first day of school. My school was down the street from my house, and so my dad walked me. I remember being so scared. I was like, who is this lady? Who are all these kids? I remember I had to stand-I was the first one in line. I had to stand on a number and that was the number of your classroom. I remember my dad walking away and I was crying so bad, like, no. My dad was crying. I'm really close to my dad, and so my dad was crying telling me not to cry. My teacher's name was Miss Curtain. I remember we got in the classroom and it was super bright in there. I made a joke and I was like, Miss Curtain, can you please shut the curtains? That's the only thing I remember about the first day of school. Yeah.

I always did like school because it got me away from my environment at home. I've always been close with my teachers. One of my teachers, her name was Miss Herrera, and I looked at her like my mom, cuz my mom wasn't around. I was really close with her and I looked forward to going to school every day. Every day that we had a substitute, I would get so mad. Where is she? Yeah. 
And I've always liked English. I've always liked improving the way I use my words and just the words that I do use when I talk. I still try to learn big words. I always hated math. I'm not good at math.

I remember when I was in fifth grade, we had a huge teddy bear. I think it was from Build A Bear Workshop or something. My teacher—every week, each student got a chance to take him home. You got to take a book home and you had to write about what you and your bear did, what you did with the bear all week. I remember I took it home and my dog chewed it up. I remember being so sad. What am I gonna tell my teacher? That's the only bear we have. I taped him. I tried to tape him back up and I took him back to school the day it was supposed to go back. I gave it to my teacher and I remember crying, like, I'm so sorry. I felt so bad. I will never forget that bear.

I remember going to sign up for middle school. I was going to sign up for school with my step mom. I felt like it was like high school. I was like, I'm a big kid now. Then when I got there, I remember being so intimidated by the eighth graders. And my step mom was telling me to stay focused cuz there's more to get into. 
I remember my favorite middle school teacher Miss Bauer. I really liked her, mostly because she looked like my mom. She reminded me a lot of my mom. She acted like her. I just really connected with her and she really helped me get through middle school, just the stages of it.

My mom went to jail when I was four, and then I went to live with my dad. Up until I was-actually, up until now, she just started back into my life. She's always been in and out of my life, so she would be around for a couple months and then I wouldn't hear from her for months. I think maybe being in here, she's just now realizing that I need her.

But back to middle school. I remember I had double math. Pre-algebra and algebra too. Both of 'em were in the morning, so I was like, oh my gosh. This is not what I wanna go to. I loved English even more because my English teacher—his whole class—it looked like a disco party. He was different in his classroom. He made me want to go to his class and pay attention.

I think that was the hardest year for me, mainly because everybody else fit in and I wanted to do what everybody else is doing. I went from being this kid who I did not care about fitting in - I didn't care if I had friends or not. When I hit 
high school, that all changed. I think that's where my whole life started going downhill, because I was just trying to - I guess high school is - that's when you're trying to find yourself. That's what I was doing, but I was doing it all the wrong ways. Yeah, I think my freshman year-that was really hard for me. I was putting my parents through a lot, because I wasn't going to class. I just didn't care about school. My teachers would tell me like, you're not gonna graduate if you keep doing the things you're doing. You're not gonna have no chance of graduating. I had a zero point five GPA. It was just bad.

My sophomore year came and I was doing the same thing. Nothing changed, and my step mom was just getting tired of it, because she was getting phone calls every day that I wasn't in class. They pulled me out and they put me in independent studies. That was the best thing they could've ever done, because being on independent studies, I would just be home all the time and I had nothing to do, so I just did the homework. Plus, I had the same teacher 'til I was in my junior year. Well, at the beginning of my senior year, but I left. I was really close to my teacher and she really guided me through everything. I've been a 4.0 student ever since my sophomore year. 
That's when my education became important to me and I realized if I don't graduate, what am I gonna do with my life? I need my high school diploma. My advice to anyone in this situation would be just while you're in here, try to stay positive. My sister wrote me a letter and in the letter it said your current situation is not your final destination. I loved that and I've been telling everybody that. I would say just be positive and really use the time that you're in here to really step back and look at yourself and look at where your life is headed and decide whether that's what you want or whether you want to make a change. Being in here, this is really an opportunity to really analyze yourself and see is this what you really want for your life, back and forth in jail, or do you want to be home with your family making something of yourself? That would be my advice is just to stay positive and do what you can to help yourself.

As Dominque's story illustrates, her early experiences in school were positive and her dominant memories were of elementary school as a welcome reprieve from a chaotic home life. Dominique remembers positive relationships with teachers, especially with those who reminded her of her missing mother. She also talks about the role of father and step mother in taking her to school and in encouraging her. In the next section, the theme of positive early school experiences is explored across three related strands: positive teacher relationships; positive learning environment; and the influence of family and community. 


\section{Positive Teacher Relationships}

Positive relationships with teachers were a highlight of elementary school for the students interviewed. Many of them spoke fondly of their favorite teachers and could describe the teachers in vivid detail. In this section, I discuss how positive teacher relationships were one of the key educational experiences of students in elementary school. Positive teacher relationships anchored students to school and made them feel secure in their schools and classrooms. Developing relationships with teachers who were willing to help them was a theme that returned when the students discussed school in juvenile hall.

A 15-year old student named Timothy who described himself as athletic and well-mannered told me about his favorite teacher in elementary school who was always willing to answer his questions. Timothy said:

Mr. George was my favorite teacher. Cuz he always was-cuz he-every time I asked him a question he'd help me. I don't know. I ain't never had no teacher that really—you feel me? I don't know. It's hard to explain. He really cared about if somebody was learning or was not learning. You know what I mean? Some teachers really don't care, but that teacher really did care. He showed that he cared. Every time I asked him he came over and helped me. 
Timothy also described himself as someone who used to play around too much and tells me that many teachers didn't like him because of that. With Mr. George, however, Timothy found someone who could look past his jokes and see him as a learner.

A mature 18-year old student named Jesus told me, "I'm a good kid, but I just made poor decisions." Jesus told me that one day, he would like to come back and work in the prison to help students who are in the same situation that he is currently in. He went on to tell me about his favorite teacher who tried to help him make better choices. He said:

My favorite teacher was probably my fourth grade and my fifth grade teacher, it was the same teacher, Ms. Steele. Cause she would always help us, not just with school. She would try to get us ready for middle school, and try to make us do good decisions and stuff to get ready for middle school and stuff.

Jesus told me that if he could talk to Ms. Steele, he would want her to know that he still remembers her words and her encouragement. Jesus shared that he has not had many teachers since Ms. Steele with whom he felt a personal connection.

A student named Peter who attended a large comprehensive high school told me about an administrator who showed his concern by being kind and reliable:

The assistant principal was this guy named Mr. Winston. He was a black dude. He was a basketball coach, and he was the type that helped all the kids that was strugglin'. He will help them, he will talk to them, and he will motivate them to 
do better. Like, do little classes at the end of school and stuff, and help them with homework, help them with anything they needed. He will always check on you, no matter what. If he say he's gonna check on you, he's gonna check on you. He's gonna come to your classrooms, just sit there and see how you're doin, and all that. I liked him because he always motivated me to do better. $\mathrm{He}$ was, like, "You see me, I'm assistant principal." He was like, "If I can do this, you can do it too." Bein' that good person, puttin' that good bug in my ear, you feel me? I liked that.

My conversations with Peter made it clear that few people in his home life checked on him or "put that good bug" in his ear. For a time, Mr. Winston was a lifeline for Peter. He has even come to visit Peter since he has been locked up.

Several of the students mentioned that their favorite teachers were the ones who would listen to them when they had problems or help deescalate difficult situations at school. A 17-year old student named Angelo who likes to ride dirt bikes tells me that he struggled in middle school. I am familiar with the middle school that he mentions and ask about the principal. Angelo lit up and told me:

He retired now. But he was hella cool. One time, I almost got into a fight. I was on the computer and my teacher told me to come here. When I went to her somebody tried to hop on my computer, and knew I was on it. I almost got into a fight with 'em. Mr. Green speaking to me came right up there and he stopped it, 
and took me out of class. 'Cuz he know I had anger problems. Then he came out the classroom, said after class come to talk to me. I talked to him. He was telling me like it's not even that serious to be tryin' to get into a fight over the computer. That was cool.

Angelo is one of many students who used the term "anger problems" or "anger issues" to describe their emotional state. When I asked him why he has anger problems, he told me that he has always gotten angry very quickly. To control his anger, he said that he sometimes laughs at inappropriate times - a trait that has earned him the ire of many teachers throughout the years.

Another student, a charismatic 17-year old named Raymond described how teachers used to look out for him when he was in elementary school. He told me: My favorite teacher was Ms. Laura. She always took the time out, like when I got in trouble, she never sent me to the office. She always talk to me so I could do better. Then after fourth grade, I had this music teacher. Well, he was my fifth grade teacher. He played drums, too. That was like my role model. We used to play drums together. He took me to his church to play drums at his church when I was 11. No, like 10. Then we had that bond ever since. Raymond tells me that he is still in touch with the music teacher who often helped him out of difficult situations that resulted in a trip to the principal's office. He tells me that starting in the fourth grade, he was in the principal's office often. 
A common theme among the students when discussing positive relationships with teachers was the individual attention that they would receive. Daniel, a 17-year old student, told me that science is his favorite subject because he could always learn something new in science class and sometimes he got to blow things up. Daniel told me about his elementary science teacher:

Ms. Kelly was my favorite teacher. She was a cool teacher. She had -at the time, she had a snake in her class. She had a snake, and she used to let us feed it. She was just cool, 'cuz some of my teachers were mean. She was really cool, like if I had problems, she would pull me to the side and ask what was wrong and stuff.

Students also appreciated the teachers who pushed them to work harder or who provided them with unique opportunities for learning. Brandon is the oldest boy in a family of twelve children. He tells me, "My elementary school was cool. It's a good school. I went there all the way up until fifth grade. All my brothers and sisters went there. I got five brothers and six sisters. My nieces and nephew go there now." Brandon goes on to tell me about his favorite teacher in elementary school:

Ms. Thompson was my favorite teacher. Cuz she'll push you to do your work. That was one of the teachers you couldn't go in her class lollygaggin', stuff like that, cuz if you didn't get it done, you was for sure stayin' after class to get it done. 
Brandon also appreciated the way that Ms. Thompson would incorporate Black History into the classes. Brandon says, "We did a reenactment of the 16th Street Baptist Church that was bombed in Alabama. And we learned about the Civil Rights Movement and stuff." He also said that Ms. Thompson kept some snacks in her room and she'd slip them discreetly to students who might need them.

A 17-year old student named JaMarcus lost his father to street violence. He shared this with me in a nonchalant manner, "I'm a athlete. I like school a little bit. I'm close to graduatin'. My favorite subject is math. At home I got two brothers and two sisters. Pretty much that's it —oh yeah, my father's dead. He was murdered." This student remembered how his teacher encouraged political activism which gave him an outlet to channel his feelings:

Yeah, my favorite class and teacher was English. My favorite teacher it washer name was Anna. She was always doin' stuff for us. She was always gettin' us to- - cuz it's like the school is towards downtown, so she was always gettin' us out of school to go to the protests and stuff. When they was doin' the protests, the Trayvon Martin protests, and the Michael Brown protests, and stuff like that, we was always goin' over there. She was settin' up meetings with the mayor and stuff like that, too. We got to talk to the mayor and stuff. I was cool for me, like, to take my anger to the streets. 
JaMarcus is just one of many students whom I met with a father, brother, or immediate family member who had been killed violently. Though this is common among young people with involvement in the juvenile justice system, the frequency and nonchalance of these proclamations was always jarring to me.

The positive relationships with teachers that the students described when they were young was not surprising. In elementary school, some of them were just beginning to experience the trauma, gang-involvement, and drug use that would characterize much of their time in middle and high school. For many teachers, it is easier to comfort a grieving six-year old who acts out than to comfort that same student when they are 16. To understand students' experiences in prison school, we must understand their first steps into the educational system. In addition to positive relationships with teachers, those early steps included an excitement about school and learning which is discussed in the following section.

\section{Positive Learning Environment}

Many of the student participants indicated how much they enjoyed school when they were young. It was common to hear that "school was fun" or "school was cool" when they recounted stories from elementary school. Students talked about attending their first day of school with their parents and feeling unsure about what to do at school. Many students laughed when they talked about crying on the first day and not feeling sure if their parents would return to pick them up. After getting over their initial 
trepidation at school, they came to enjoy it. Many students talked about doing fun projects, playing games during recess, and going on field trips.

One student, a gregarious 17-year old student named Raphael told me how much he enjoyed art class. He said:

Art was my favorite subject. I used to like to draw a lot. I got- they used to give me awards sometimes for that, for bein' a good art—like to draw and stuff. I remember at one time, I drew something for my class. I think it was in the first grade. Ms. Jacob. I drew - -it was me and my_I drew me and my friends playin' basketball and stuff. Then I remember one time I came back two or three years later to visit her and see her, and then she still had that picture. She had it behind her desk on the wall right there. I was like, "You still have that?" She's like, "Yeah, you were a good artist."

Raphael talked about how much easier the school environment was when he was a younger child. He said, "When you're a little kid, the teachers talk nice to you. Like a mom. But when you get older, not anymore." In future interviews, Raphael expanded on the issues of how complicated school became as he got older.

Another student, 15-year old Michael had two memorial tattoos on his forearms - one for his father and one for his cousin. He lost both of them during middle school. Michael, who speaks with a lisp, told me, "I love school. Even now, I still love school." In elementary school, he said: 
School was cool. It was fun all the time. School was always fun until I got older and older and older. I had to do more work at school. Stuff started getting like all right, but, yeah. In fourth grade we always would play this game. These little math questions. They'd give us gold fish every time we'd get an answer right and stuff like that.

Michael told me that although he was always the "class clown" the teachers still liked him because he did his work. His teachers in juvenile hall told me that he is now a serious young man and rarely laughs.

A 17-year old student named Ahmed had a spectacular memory and shared many stories about his early years in school. An English language learner, Ahmed remembers his first day in school in the United States as a third grader. He has an aptitude for languages and learned English quickly. He recounted a trip to science camp as a fifth grader:

We went to a science camp, science field trip, somethin' like that. It was pretty fun. Um, it was in the hills somewhere. Like, they had little, um-little cabins and stuff like that. And then it was, like, me and a couple of my friends that went, so we were in the cabin together. And then we had, like, a older person who would watch us $24 / 7$. So, it—yeah, it was fun, though. They had like, a big ol' cafeteria, swimming pools, you know, rec room, like, game rooms, and all that. And, like-and then we went hiking and stuff and took pictures of, like, all 
these little insects and animals we seen. And they taught us about all the different plants and what poison ivy or whatever looks like — and not to touch this, not to touch that. So it was pretty cool.

Ahmed told me that his elementary school was a "really good school. Everything was all new and nice." He is one of several students who equated a nice school environment with a good learning environment.

Peter, who shared the story above about the assistant principal and basketball coach who used to check on everyone, told me about the difference between his middle and high school environments. Although they were both in the same school district, they were very different schools:

My middle school was cool. Because they had just rebuilt it, and they had a lot of new equipment, like SMART Boards and all that, brand new books, and a lot of school supplies. But then high school, it was sort of a downgrade because that's, like, a bad quality school. I just left that in the back of my head and just get tryin' to start and graduate from there. Because it was dirty. A lot of ripped books, a lot of pages was ripped out of some of the books. The equipment we used was very old. They had the old, old projectors. Mind you, I was just in middle school and they had all the new stuff. It was a downgrade. To me, it was. Although Peter saw this new learning environment as a "downgrade" from his previous school, he was determined the make this best of it. The idea of ignoring the bad things 
was common among many of the students who were mostly determined to make the best of a bad situation. In spite of everything that the students were experiencing at home or in their community, they came to school with an openness and an excitement about learning. In the next section, some of the ways that students experienced family and community - mostly positive but some negative - are shared to provide context for students' orientation toward school.

\section{Family \& Community Influence}

In recounting their early school experiences, many young people talked about the influence of their parents, family, and broader community. Nearly all of the students indicated that their parents encouraged them to try hard in school - even when their parents had little education themselves. Many of the students indicated that their parents had dropped out of high school but very much wanted to see them graduate. In some cases, their parents had a secondary education from another country but were working as a laborer since immigrating to the United States. Overall, students recalled feeling encouraged by their parents, siblings, and community to work hard in school.

Andre, a 16-year old student who is popular among his classmates and teachers, tells me that he always wanted to do good in school. When I ask him where the motivation to do well came from, he told me:

It was from my teachers and my family. Cuz I lived with my mom all my life so my dad he always been somewhere - wherever he's been at. I visit him 
sometimes, but I didn't really live with him. He didn't really see me every day. I don't think any of my brothers or sisters graduated high school. I think they all dropped out in the 11th or 12th grade. They was always telling me do better, and you're gonna be the one to change it up. You're gonna be the one to make a difference and finally do right. Then so I got to school. I tried my hardest. Then my teachers always said I see you got potential. I see something in you. I know you could grow up and be great. I took that and I just did what I could do to make everybody proud of me. To show them what I could do.

Andre told me that the ambition he had to do well in elementary school has not faded. He still wants to graduate - even if it means having a diploma from a juvenile detention center. When we talked about graduation, he got up to mimic walking across the stage, receiving a diploma, and raising the diploma above his head like a trophy. We share a laugh together before the prison staff told Andre that he must sit down or our interview would be ended. Though all interviews took place in a private room, the rooms had windows and cameras for the staff to observe us during the interview. This incident was a reminder that we were always being watched.

Seventeen-year-old Peter told me that he is very intelligent and said that school is important to him. He said, "When it comes to school, I look at it as a big deal, and that it's really gonna help me in my life. When I am in school, I'm very focused." He also told me that his family encouraged him to do well in school. 
My mom always told me if I just do good in school. I can make mama happy by doin' good in school, period. Period. "Just do good in school. That means don't bring back no Fs. Do good in school, I'm gonna always be happy." That's what I did, but there was sometimes I just made her angry. She'll get frustrated and she'll be crying because of the things that I'm doin'. I will hate it, but it's my family too. I don't wanna just leave 'em. I don't just leave people. That's just not what I do. Especially people I love and who I grew up with. She kinda understood that, but she was like, "What's gonna happen when you gotta leave these people? What's gonna happen when they try to leave you?" Peter's comments underscore not only his mother's desire for him to do well in school but also the pull of the streets that many students mentioned. For some young people in the study, mothers were cited as a grounding or stabilizing influence.

Sometimes, the students discussed celebrating school milestones, such as graduations, with their family members. Peter went on tell me:

Middle school graduation was one of my best days. It was big. I liked it. I liked it because my dad was there. My dad never really comes to big things like that. It was cool to see my dad pop up. I didn't even know he was coming, but when I walked the stage, I seen him standin' by my mom. It was real good feeling. 
Peter told me that he has not seen his father since that day. He wants very much to graduate from high school in the hopes that his father will come to the graduation ceremony.

A few of the students talked about the reputation of their families that preceded them in school. Typically, these students grew up in the same neighborhood with their extended family members and they all attended the same school. Raphael told me:

A lot of teachers, cuz my older cousins, there were older than me, but they [the teachers] knew my mom and stuff because she used to take my cousins to school. They used to be, like, "Those are your cousins. Huh, Raphael?" I'm like, "Yeah." They're like, "Oh, I remember that cousin. He was wild. He was a wild kid." Just I guess some of the teachers judge me cuz my cousins and stuff. Yeah, that's what happened.

Sometimes the students had reputations at school that were influenced by their family. More often, however, students themselves were responsible for the school relationships that began to deteriorate. In their early years, however, most of the students received positive support from their families and were encouraged to do well in school. Even parents who were not academically successful wanted better outcomes for their own children. 


\section{Conclusion}

In their early educational experiences, primarily elementary school, most students reported positive experiences with school. Students discussed caring relationships with teachers who approached them with compassion and understanding. For nearly all students, school was a safe place and they felt a sense of community among the other students. In addition, many students talked about the support they received from their family during that time. Most were encouraged to work hard in school. There was a joy in learning that many of the students radiated as they described science projects, field trips, and fun games in the classroom. Dominique's story, which opened this section, illustrated how many of the students were happy in elementary school and felt a strong connection to school.

The transition between elementary and middle school was a turning point for many of the students. They became increasingly disengaged from school as they entered adolescence. As Michael told me:

After fifth grade, I was not doing good. I was going down the hallways wanting to be class clown. I started changing. It was like first we was so young. The only thing we liked to do was go to school, see our friends, play basketball. As we got older it was just a lot of other stuff on our minds.

In the next section, I discuss the transition to secondary school and how the transition was the beginning of school disengagement for many young people. In addition to 
discussing the impact of school discipline and exclusion, the students shared many of the things that began to pull them away from the streets.

\section{School Disengagement in Middle \& High School}

I guess as I got older, I went to high school, I just started sayin', "Forget school" and started hangin' out more. I was leavin' at lunchtime and don't come back. That's about it. School just didn't matter much no more.

$\sim$ Brandon, age 17

The teacher would send me out to detention. All my friends were there, so I just jammed there. Like sometimes I wouldn't even go to class.

I just go straight to detention.

$\sim$ Roberto, age 18

Student disengagement from school in middle and high school is the second theme that emerged from this study. Disengagement took many forms from cutting class to coming to class high to acting out in class. In all cases, there was no single incident that resulted in disengagement from school. Rather, the disengagement was the result of a slow erosion over time. While they were becoming increasingly disengaged from school, many students were also subject to harsher discipline. Actions that would have merited a detention in elementary school were soon punishable by suspension and expulsion. As punishments became more severe, the students were increasingly subjected to public shaming and exclusion. Finally, students ended up caught between school and the streets. For the students in this study, the pull of the streets proved to be stronger than the pull of school. All four of these mutually-reinforcing strands related 
to the theme of school disengagement in middle and high school are illustrated through Juan's story. His narrative of school disengagement introduces this theme.

\section{Juan: Another Dropout}

When I got here, they thought I wasn't gonna graduate. I was gonna be one of the other statistics that drop out when they got here. I felt like I wanted more for myself. I don't wanna be another dropout.

Juan was eager to talk about his experiences attending school while incarcerated and is one of the first students to volunteer for an interview. Reflective and mature, he has serious soft brown eyes, olive skin, and close cropped black hair. Before the interview, his teachers told me that he is a hard-working student and is close to graduating. When I first met Juan, he was quick to assure me that he is a nice person. In fact, one of the first things that he told me is:

I'm a good guy. Most people think I'm not cuz they don't know me. But the people who really know me think I'm funny and caring. I'm a caring person. Other people that don't know me, they think I'm just one of them kids that's gonna end up in prison, all that stuff. In trouble. I just don't let that bother me. I know who I really am.

As our time together progressed, it became clear that many people in a variety of settings have told Juan that he is not a nice person and that he isn't going to amount to much. Juan seems determined to prove them wrong. 
As a child, Juan had a difficult time at home. His father was abusive and his home did not feel safe. At school, Juan began acting out and teachers began to withdraw from him. He remembered what it meant to be a "bad kid" in school and to be blamed for things that he didn't do. Juan often got the feeling that teachers were just waiting for him to mess up. He remembers a favorite teacher, Ms. Loran, who used to talk with him when he began to act out. Juan told me:

Yeah. My favorite teacher was Ms. Lora. I don't know. I just liked her. All my teachers, they all been women. I don't know. I think I get along with women better than men. I don't know. I just like them better. Then she always talked to me one on one. I used to be goin' through things when I was in elementary with my parents. That's why I started acting up, bein' rebellious. I started fires. She would just bring me a pencil and a paper so I could draw. She already knew when I sometimes got mad, I wanna draw. That would just calm me down. It was my favorite thing to do when I was mad, is just do art. Until now, I still do art. I just draw what I look at. If I look at a sun or look at the mountain, I draw that. If I look at the sky, I draw the clouds. Stuff like that. If not, I'd just mess around and start doing whatever. It would somehow become a picture.

When describing elementary school, Juan recalled how much he enjoyed being at school. Much like Dominique, whose story introduced the first theme, elementary 
school was a haven for Juan in an otherwise chaotic life. During middle school, however, things began to change:

What I liked in middle school is bein' able to go to different classes. Instead of stayin' in one class for the whole day, goin' to different classes. Meeting new people. Every time a new kid come into our school, we'd go introduce ourself. We'd watch them, see what they up to and what crowd they go to.

But I didn't like the segregation stuff. We had the Mexicans, the Blacks, and then we had the Pacific Islanders. We had the Asians over there. I didn't like that. I feel like everybody should just get along. We shouldn't care about all race or color. Sometimes there would be fights. It would be over gang stuff-over colors or what street you're from. That's the thing I didn't like. Most people think that other people are racist. Some people think they're better than others. I think they get with their own groups just to protect themselves. That's what I believe.

In middle school I was one of the bad ones. I would get expelled and stuff. I just didn't like school. In middle school and high school, I stopped goin' to school. I started doin' drugs and stuff. I was smokin' marijuana. Then I got to drinking. From that, ditching school, getting into fights, and from there it got bigger and bigger and bigger. I stopped goin' to school. 
It my neighborhood, there was a lot of gangs. Just gang stuff. I don't know. Where I'm from, there's nothin' but gangs. Nothing but hoods. It was really nothin' else you could do besides stay in school and get punked all the time. I didn't like that. I didn't like to get bullied. Once I got in a gang, I felt like I had more power. It's like they wouldn't be able to do nothin' to me no more.

Juan was suspended often throughout middle school and has few positive memories of that time in his education. He recalled the day of his eighth grade graduation with regret. Juan went to school with his new graduation clothes on and was excited to walk the stage. He remembered that his attendance and grades were poor but he was still being promoted. His family would be there to watch it happen. During the school day, however, Juan got into a fight with a rival gang member. He doesn't remember why but he remembered the consequences. He told me:

I didn't walk the stage. My last day there, I got in a fight, so they just told me to go home. And I watched everybody walk down [to the school] cuz I lived down the street. Down the street, you got the high school. That's where they do the middle school graduation. I lived right next to the high school. I watched everybody. Everybody's all dressed up. I was just wearin' my regular clothes by then and sitting on the porch. All ready for graduation but at home. At the time, 
I just didn't care. Now I'm like, "Man, I shoulda just never fought." That cost me my graduation.

Later in the interview, Juan talked about his desire to graduate and finally "walk the stage." He told me that it is an important milestone to him and one that he is looking forward to.

Once Juan entered high school, he was a known gang member and his time in high school was brief. He fought often and attended three different high schools and, finally, his district continuation school. However, it was his arrest that resulted in his expulsion from the continuation high school and his eventual incarceration.

The day I got expelled, I was at the house. That's when my friend hit me up. I guess one of my friends, he's older than me, he got shot by some other people, some other rival gang. We went out there lookin' for the people. Then we didn't find nobody, so we just started driving by the hood, showing up at houses and stuff. We was just tryin' to retaliate, but we couldn't find nobody. Then the next day, it was on the news. I guess they were lookin' for somebody who was shot at their house.

From there, it went downhill. Somebody got killed. We would go through the same. One of our people got killed. Then I got locked up cuz I was out trespassing at our high school that I got expelled from. I got arrested for 
trespassing from security. They tried to choke me. I choked him back. I got arrested for that. A week later, they came to my house. I was on the run for a week. They came to my house, knockin' on my door. My brother was there, like one month. He was barely born. I had my little baby brother on me.

Then they just came to my house. They came lookin' for me. My mom wasn't home. She went to the store to buy me somethin' to eat. It was five minutes after she left. That's when the cops showed up. They told me, "Are you Juan?" I'm like, "Yeah." "All right. Where's your mom at?" I was like, "She went to the store." We had to wait 20 minutes for my mom to come back. When she came back, she was surprised. "What's all the police doin' here?" I was like, "Mom—-" I told her everything. I broke everything down. "Yeah, I did this and that. That's what I did here. They came here to take me away." She started cryin'.

That's when I saw-I just got mad. I felt like, "They're makin' me look like a killer." They handcuffed me and all that, threw me on the ground. Fucked me up really bad in front of my mom and my little brother. That made me mad. When they took me out, everybody was outside. All the neighbors lookin' at me, like I did something wrong. The cops just put me outside, put me on the ground, read 
me my rights and everything. They took me to juvenile hall, and I got booked in. Ever since that day, I've been in and out juvenile hall.

Juan's eyes are shiny with unshed tears when he describes his mother crying while he was arrested. He told me that everyone in his neighborhood thought he had killed someone and the rumor persists. He is earnest when he tells me, "I did some bad shit but I'm no killer. I ain't no killer." When he is eventually released, he tells me that he cannot go back to that neighborhood. Juan tells me that his plan upon release is to join the Army. He said:

I talked to my PO. She was like, "If you graduate - " I'm tryin' to join the Army right after this. "If you graduate, we can shave some time off for you to join the Army." I was like, "Okay." I started just doin' my work. At first I didn't understand it cuz I wasn't learnin'. Then I started doin' my work, started learnin', started readin' books. That's when everything became easy for me. Right now I need four more credits, and I'ma graduate. I went from 17 to 126 . I only need 130.

I feel like when I get out, I'ma have people try to hate on me cuz they don't know that I changed. They'll want me to do the same thing I used to do. I don't wanna do the same thing I used to do. That's what landed me here. I feel like it's gonna be a struggle when I get out. 
Through Juan's story, it is evident how many of themes related to school disengagement play out across the young people's experiences. He shared how his behavior in school and his gang involvement led to increased disciplinary consequences at school. His multiple suspensions and expulsions culminated in a very public arrest. Even now, Juan is concerned about the consequences of his former life. In the next section, the theme of school disengagement in middle and high school is explored across four related strands: school detachment; school discipline; public shaming and exclusion in school; and being caught between school and the streets.

\section{School Detachment}

For nearly all of the participants in the study, the process of school detachment began late in elementary school or early in middle school. The process was gradual - a slow accumulation of factors that led students to disconnect from school. Students began to cut classes or if they left campus for lunch, they did not return for class in the afternoon. It is possible that school also became more challenging during this time. For students who were behind academically, struggling with learning English, or dealing with a learning disability, cutting class was a way to escape an increasingly uncomfortable academic situation. Many of the students began smoking marijuana during that time and their drug use negatively impacted their school attendance and motivation to do well. 
Vanessa, a seventeen-year old student, introduced herself by telling me that she has a "serious drug problem." She said she started smoking marijuana at age 11, started drinking at age 13 , and was using heroin by the time she turned 14 . She is currently on methadone, an opioid used to help ease heroin withdrawal symptoms. Both of her parents and her older sister are all addicts. Vanessa tells me that she has been clean for four months but she spends the entire interview twitching and scratching her arms. This can be a side effect of the methadone treatment. When I ask about middle school, Vanessa told me with a groan:

Oh, geez. Middle school was a little hard because I started getting locked up in eighth grade. Sixth and seventh, that's when I started doing drugs, started hanging out with people I shouldn't be hanging out with, disobeying my family. Not per se running away, but sneaking out and staying at a friend's house and not come back 'til the next day type of thing. That's how my parents-doing all these bad things, but in school, my grades a little bad. Then I started catching up. I started doing after school programs and I was still doing drugs a little bit. I did after school programs and then doing better on my tests and having a tutor during school so I can get help with math. Cuz math is my worst subject. Vanessa told me that science is her best subject and since she loves animals, she wants to try and become a vet tech. She told me, "Oh, yeah. I love animals, though. I just 
really wanna help animals. I don't know if I could do people. Animals are easier cuz they don't talk." We both laughed when she said this.

Lisa is a petite girl with long hair and braces who looks much younger than her fifteen years. She told me that all of her family are gang members and her father is currently in jail. Although Lisa struggled with school in fourth and fifth grade, she told me that she started cutting class early in middle school:

After a while, I started actually just doing bad things, bad influence and stuff. Then sixth, seventh grade I just start cutting and ditching. I didn't care about school. That was seventh grade. Eighth grade I just dropped out completely. I only went for one semester, one quarter. The ninth grade I dropped out too. I wasn't really looking forward to college or finishing my school. I was just more about the streets and stuff.

Like many of the students, Lisa began experimenting with drugs early. She told me that was just a fourth grader the first time she smoked marijuana and was drinking by sixth grade. I asked her if her teachers noticed. She said her teachers didn't notice because she was always quiet in class and as long as she stayed quiet, no one bothered her.

For many students, middle school was also when they first began committing crimes and getting deeper into gangs. Raphael, who grew up in a violent neighborhood surrounded by gangs, told me: 
School was cool until eighth grade. It was fun until eighth grade. That's when I stopped, I guess. We all — that's when we just stopped. We were just smoking. Then just doin' anything, like stealing—try to steal bikes and stuff. Doin' whatever. Cuttin' class most of the time. Goin' to school hella late.

When I ask Raphael what he remembers most about eighth grade, he told me, "It was all crazy stuff happenin'. Like a lot of the drugs and stuff. Lot of gang violence. Like back then, it was cool for me, I guess, cuz I used to like stuff like that in middle school." While Raphael was not a gang member, he told me that he hung around gangsters so everyone at school thought he was a gangster too.

Daniel is a 17-year old gang member with tattoos on his face who has been to juvenile hall 12 times. He told me that he loved to read when he was a child. In fifth grade, however, he was jumped into the gang that his siblings were already in. Daniel told me that the start of gangbanging was the end of reading. He said that after he got jumped in:

Well, I didn't read no books no more cuz that's when I started smokin'. Cuz in sixth grade that's when I started smokin' and drinkin' and stuff like 'dat and really gangbangin'. 'Den, yeah, I didn't no read no books. I got kicked out in sixth grade. Well, I got expelled in first grade too. I got expelled in first grade. I got expelled in sixth grade and-yeah, in sixth grade and eighth grade. 
At the time of our interview, Daniel had just been arrested for a serious crime and was likely to be charged as an adult. When I asked him what he would tell a young person in his situation, he said, "If you come in for what I'm in for, it's prob'ly too late. I'll tell somebody not in here to don't gangbang. 'Dat shit retarded." While many young people were able to hold their emotions in check during the interview, Daniel began to cry after he tells me this. When I asked him if he'd like to stop the interview, he shook his head and we continued.

While I was not surprised to learn about the students' drug use, it was surprising to learn how many of them used drugs while at school. For many, there was something thrilling about using drugs on campus and getting away with it. Ahmed told me, with something akin to pride in his voice, that using drugs did not impact his attendance:

It [smoking weed] didn't make me stop goin' to school or nothin'. I was still goin' to school. Then startin' up high school and everything, durin' lunchtime I would go with my friends cuz we had — goin' to high school was different, too, cuz we would go off campus. In junior high school, we weren't allowed to do that. We started goin' off campus and stuff for lunch. Then me and my friends would go and smoke and come back on campus and then go to fifth and sixth period. Though he attended fifth and sixth period, he did not earn passing grades. He told me that when he was arrested, he had been attending high school for almost two years but he only had credits for PE. 
Seventeen-year-old Jorge told me that he started drinking with his family at a young age. His mother abandoned him when he was baby and his father is an alcoholic. By the time Jorge was in middle school, he would often drink or smoke week with his friends on campus. He told me:

One time we got drunk before class. I didn't get in trouble though. My friend did because he was too drunk and he threw up by the teacher and the teacher smelled the alcohol. It was eighth grade. We used to get drunk all the time in class and the teachers didn't used to tell. Cuz I always acted goofy. The teachers really can't tell. She knew when I was high because I used to always come stinking. Then she never used to get me in trouble. I always had a feeling that when I was high I used to do my work faster and like, don't talk as much. Then I graduated.

He told me that there was a woman who worked in the front office of his elementary school who looked out for him. He said that he was able to walk the stage during graduation because of her kind intervention.

While many of the students missed school because they chose to cut classes or were excluded for disciplinary reasons, sixteen-year-old Andre told a more complicated story about middle school. He said:

When I started middle school, my mom trusted me more. After school, I'd go to the house. Throw my backpack down and cut. Leave and start go kick it with 
people. That's one of the reasons I fell off. I didn't really do my homework. I came back, I went to school. I played around. I was in the hallways talking to females or whatever. It was just too much for me, I guess. So in seventh grade, my mom sent me to live with my dad. Then my dad took me out of school because he was - he owned a restaurant or whatever. So I was working there and not going to school anymore. Then my mom found out and took me back. So I went to eighth grade for the last month or two. When I got there, I had no grades. I had a 0.0 . I guess that's probably why I didn't graduate in eighth grade. Then I moved on to ninth grade anyways.

In Andre's case, his own school disengagement and the dysfunction in his family combined to accelerate his progression out of school. He moved on to high school but was missing many skills that he would have learned in middle school. He addressed the deficiencies by avoiding classes altogether:

High school was kinda bad, I guess. I fell off again. High school, it was the same thing with middle school. High school was a big difference from middle school, elementary school. It was way bigger. You could run around the whole school. I think because-I don't know. Me getting older, my hormones, I guess, start really-I felt like a man. Can't nobody tell me what to do. And with the people I met, I met more people like me that was like-they really thought they was the man. We got together. We were just too cool for school, I guess. We didn't go to 
school. We'd be like, "What you trying to do today?" We'd whatever. We'd leave school. Hop the gate. We gone. Let's go kick it. I did that for a minute. We'd just be chilling.

Andre was arrested for the first time midway through his freshman year of high school. When he got out of juvenile hall, he was back to doing the same old things. Andre mentioned several times that his high school was so big that it was easy to get lost in. High schools that were big enough to "get lost in" were mentioned often by the students in the study. Many of them attended comprehensive high schools with 2,000 to 3,000 students. Shamieka, a 16-year old girl with a sweet smile told me about the large high school where she attended ninth grade:

First I went to [name of high school redacted], that's a big, big school. If you don't know that, it's one of the biggest schools. It has four different sections. They call 'em houses, like house one, house two, house three, house four. That's what they call it—it's so big. If you went to that school, you'd be like, oh my god. That school's so big, so it's just so easy for you to just go off campus. Nobody see you. First I was goin' to school in that school. I don't know. That school was too hard. I cannot do it. There was just so many people there. I don't know.

Shemieka eventually attended every high school in her district including the district's continuation school and independent studies program. She says that the independent 
studies program was the worst. "They would give me work, and I would have to do it, but it was like, I never did the work. I wouldn't do work." When I ask her why she wouldn't do the work she said, "I don't know."

Many students in the study spent some time in continuation school either because they were short on credits or because the school referred them for disciplinary reasons. In some cases, their behavior did not improve with the referral. Ahmed told me:

Half the people there [at the continuation high school] don't even listen or don't care about what they're doin' or get done with what they're doin'. They listen to their music and stuff. Then durin' film, they always turn the lights off in class so it'd be hella dark. Then I got cool with these two girls that were in my class, and then one of my friends ended up gettin' switched to that class. It was four of us always in the corner, just chillin' and just makin' jokes and stuff and watchin' the movie. Then, I still smoked weed. My friend had a vape pen, so we used to be in class just smokin' the vape pen.

Many students told me that they preferred the continuation school because the day was shorter. It is ironic that a school focused on credit recovery had a shorter school day than a regular high school but this is often the case for continuation schools. This is also true in prison schools. 
Many of the male students described themselves as athletes. For those that played sports in middle and high school, athletics helped them to stay engaged with school. Jesus told me that while he was involved in wrestling, his school attendance was good and he kept his grades up. In his second year of high school, however, things changed:

Yeah, in my sophomore year, that's when I stopped wrestling. At the end of the school year, so my junior year-what happened in my junior year? I started just—at first I was still doing good, but slowly, I was—I was thinking about getting high slowly, but I'm still coming to class, still high. Then, after a while, I would just—no, I'm not going to go this period, I'm going to go another period. Then it ended up not being from first period all the way to my car-my auto tech class. Cause I thought my car class was two periods, so I would just skip one - from first period to six period, and I would just do those two- those last two periods, and then it ended up being the whole day I didn't go. Yeah. And when I wasn't in school, I was just usually just getting high, smoking, going around not even the school, not even by school, just go chill. Yeah.

Eventually, Jesus was sent to a continuation school but he says he did not like the environment. He tells me, "I wasn't feeling it either. I went two days and I just stopped going." When pressed, he tells me that he did not feel welcome at the new school. 
For nearly all of the students in the study, school disengagement was a gradual process that began in sixth grade and progressed through middle school. Students began to skip classes or came to class high. Large comprehensive high schools made it easy for students to get lost on campus and some used this time to smoke weed or drink. Even at continuation schools, ostensibly designed for credit recovery, students remained academically disengaged. For students who were cutting class or acting out while on campus, school discipline soon followed. In the next section, the impact of school discipline on students' educational trajectories is explored.

\section{School Discipline}

For many students, school discipline contributed to their escalating disengagement from school. During middle school, they experienced more severe consequences for fighting and stealing that included suspension, expulsion, and sometimes, their first arrest. Once students became well-known in the principal's office, they were often under more suspicion when something at school went missing or someone got caught with drugs. This suspicion led to increasingly strained relationships with teachers.

Seventeen-year old Ahmed was often in trouble for fighting. Small for his age, he said that he often needed defend himself and it is one of the reasons why he began hanging around with gang members. With them by his side, he told me, the bullying stopped. However, he was soon called on to fight rival gang members. After one fight 
in the school cafeteria that ended up on YouTube, he talked about how his suspension impacted his school attendance:

Then I got suspended [for the fight]. And I just didn’t come back for more than a week. And my friends were like, "Why you didn't come to school?" I was, like, “They suspended me for three days." I'm, like, "I was just, like, "Fuck it.' I'm gonna come back whenever I feel like it."

This sentiment was echoed by several students who talked about extending their suspensions by failing to return to school or never going back after being expelled.

A studious seventeen-year-old student with glasses named Sergio told that he is the kind of person who doesn't step up right away. He prefers to hang back and watch situations unfold. He said, "I'm pretty cool. I'm like funny, I joke a lot. I try to turn bad situations into good situations." Sergio told me about his early years getting into trouble at school:

Middle school was more where I got introduced to a lot of things like fighting, stealing, even if it ain't like stealing cars or anything but it was like stealing from other people's backpacks you feel me or something, a lot of things and getting in trouble. Getting in trouble, like detention, and all that type of stuff, that's all what happened in middle school, everything. It just led to like more worse situations the further into middle school, into freshman year. 
To remove him from a bad situation, his mother transferred him to a high-performing school in a new neighborhood where he says things went from bad to worse. He was soon expelled from the new school for fighting. While waiting for his expulsion hearing, he was out of school for two months.

Raymond, a seventeen-year-old student with chocolate skin and mischievous eyes also told me about being disciplined at school. He attended school with many of his cousins and they were often in trouble together:

Well, in seventh grade, I started smokin' weed, so I start goin' to school high. I be just talkin' hella shit to the teachers, and bein' disruptive or walkin' up the class. Something. Not doin' my work. Causin' hella problems in the classroom with my cousins. Yeah, but three or four days out of the week I'm always suspended or something. It's barely two days that I stay in school the whole day. When I asked him if his frequent absences from the classroom made it hard for him to learn, he answered with bravado and told me, "I'm like, I don't even wanna be in here no more. I don't wanna be in here no more. I just didn't wanna do it." Soon after, he ran away from home and ended up in a series of group homes.

In some cases, students began committing illegal acts at school. Students who were young gang members were often pressed into selling weed. The younger they were, the more likely they would be called upon to sell drugs because younger students would get lighter sentences. A student named Jorge told me: 
I went to [middle school name redacted]. The first day I got into it with some kids because of the gangs. Then I had my friend, one of my friends that's right here [in juvenile hall]. I've been knowing him since we were younger. We used to kick it all the time. He'd tell me about how was middle school. He put me up on game. Then I used to sell some weed in school. Then this kid got caught. The kid snitched on me. Told them that I was the one selling drugs. I got in trouble for that. I got suspended. After that I started getting suspended for weed and stuff. By eighth grade, I was still selling weed in school but I did it more out of school. I started doing good. I mean I got suspended once or twice because I got in a fight. But I know a lot of teachers in middle school used to like me.

Jorge told me that even in middle school, he had teachers who looked out for him and wanted to see him succeed. In addition to selling weed and fighting, he was always talking in class. He tells me that it was probably better to go to school high because he wouldn't talk as much. Jorge is among a handful of students who mention the calming effects of marijuana and indicated they preferred to attend class while high.

For some students, discipline in school resulted in their first contact with the police. Raphael, the student mentioned earlier who talked about violence and gangs in his neighborhood, recounts the first time that he was arrested.

Then there's one kid. He came to the school. I think he was in middle school or something. He came over there with a metal bb gun and stuff. Then he was like, 
"Raphael, come here." His name was, I think —I forgot what happened to him, but his name was Lamar. He was like, "Raphel, come here." It was during recess. Then he-I guess he sneaked in the school or something. He showed me the bb gun, and he was like, "Look." Then there was a kid. I guess some other kid. Then he was all like - he like--he just saw it and gasped, and then he ran. Then he went and told the teacher. Then the teacher grabbed — came running. Then the kid, Lamar, he ran. Then I ended up gettin' suspended for being in on the stuff. It was like "Raphael was with him. He was showin' him the gun and stuff." I was like, "Wow." They [the school] were like, you were with a gun and stuff. We can call the police right now for having a gun. I was like, "It was a bb gun." Then it was like, "Oh, well." And they called the cops.

Raphael told me that he was booked and released for this incident so he thought it wasn't a big deal. However, the next time he was arrested, the arrest for the gun counted against him and he received a harsher sentence.

Raphael was not the only student in the study who experienced his first arrest while at school. In fact, the line between school discipline and juvenile incarceration was increasingly blurred for students in the study. This led to arrests on campus - both by school police and police from other jurisdictions. School discipline also led to extended absences from school while students were suspended or awaiting the outcomes of expulsion proceedings. For many students, discipline became the primary 
means through which they were excluded from campus but was not the only way that exclusion occurred. In the following section, I share incidents from students that included public shaming and exclusion that pushed them further from school.

\section{Public Shaming \& Exclusion in School}

Nearly all students in the study found themselves excluded from school in ways that were public and were often humiliating. The students who were regularly disciplined through suspensions and expulsions were also excluded in other ways. Students were not allowed to participate in field trips and were restricted from recess as a punishment. In some cases, young people were also barred from participating in school ceremonies such as graduation. This exclusion was embarrassing and sometimes students acted out as a result of it. In many cases, the sting of being excluded was evident when students shared stories although they were many years removed from the incident.

While nearly all students had positive experiences in elementary school, JaMarcus was a notable exception. He was the student whose father was murdered when he was just seven years old. During elementary school, JaMarcus told me about a colored card system was used to control students' behavior.

I didn't like elementary cuz it was — we always had some cards, green, yellow, and red card. A green card if you did it good, a yellow card if you got a warnin', and a red card that's if you did bad. They take away your recess. I got a couple 
of red cards. I used to didn't have no recess. And everyone knew it was cuz I was bad. My fourth grade teacher was a dude, and he was like the meanest—he was too strict for elementary kids. He was way too strict. He used to take away people recess, too. I used to always have to sit on the bench every recess. It was addin' up to where I could - I knew for the whole next two weeks or somethin' I wasn't gonna have no recess.

While JaMarcus told me that he did not like the card system because he received red cards and lost recess, he also said that students' cards were on display in the classroom. As soon as the principal or another teacher walked into the room, they would look at the cards to see who had misbehaved that day. In addition to being shamed through the use of red cards, JaMarcus was further disciplined in the school office when he acted out: [Elementary school name redacted] was cool. It was just that me and my little brother we got different dads. His grandma on his dad's side worked up there. I used to get in trouble a lot at school. My mom told her if I ever get in trouble, basically she can hit me. She gave her permission to whip me. I used to get in trouble in class and then I used to get beat up in the office.

This indignity happened often enough that the teacher would sometimes skip issuing him a red card and simply send him straight to the office.

Seventeen-year-old Jorge, the gang member mentioned above who began selling drugs in middle school, remembered that people were not happy to see him in the 
office. Though Jorge had mostly positive memories of elementary school, he also remembered spending a lot of time in the office. He told me that the office secretary used to chide him when he walked in. Jorge was required to sit on a chair across from her desk:

When I was in elementary, I used to always be in the office. One time I got in trouble and I was in the office for a whole month, no recess, no nothing. I used to hate that. When I was in the office everybody'd be like—They'd say, "It's Jorge." I don't know. They were not too happy to see me.

In avoid time in the office, Jorge would sometimes leave school and run back home. He would jump over the fence and wait in the backyard for this father to come home. This is just one example of how exclusionary school discipline practices pushed young people out of school.

One unexpected finding was how often students were excluded from school events. During one of my early interviews, a student mentioned that he was not allowed to walk the stage during middle school graduation because he had gotten in trouble too many times during the year. After this comment, I began asking students about their eighth grade graduation. Though all of the students were promoted to ninth grade in spite of failing grades and poor attendance, more than half of them were barred from participating in graduation ceremonies. 
Fifteen-year-old Donte told me that he considers himself funny, confident, and smart. He remembered his graduation from elementary school. He said, "I was happy. Everybody, families and friends and stuff, were there. It was just off the stage, and they call our name and give us a certificate and stuff." Donte did not have the same experience in middle school. He told me:

[Middle school name redacted] was cool, I went there during my eighth grade year and I did very good at that school, but I didn't get a chance to graduate because I got suspended during the last — during like the last few weeks of school. They had a rule that if you get suspended or in any trouble then you couldn't walk the stage. Then I got suspended and I didn't walk the stage. Though Donte told me that he doesn't care about graduation, he also said that he very much wants to graduate from high school so he can have his chance to "walk the stage."

In addition to being excluded from graduation ceremonies, students also recalled being excluded from other school events. Seventeen-year-old Tyrone always attended school with his siblings and cousins. During our second interview, he told me that his cousin was just booked into the facility that morning. His cousin told him that Tyrone's brother had been shot the night before and he didn't know about his condition. I ask Tyrone if he would like to reschedule the interview but he wanted to continue. He told me that he can't make any phone calls until a supervisor comes to approve them and the 
interview is a good distraction. Tyrone told me about his cousin who just got booked in:

Me and my cousin was always - I don't know. When I get around my cousin, or when he get around me, we're just bad together. I don't know. We used to get in fights and everything around people and stuff. We used to just do stuff on purpose. We didn't go to school - I mean, we didn't go to classes sometimes. Now, we just started goin' to classes and stuff. Yeah. We couldn't participate and stuff 'cause we didn't go to the class and stuff. We couldn't go to field trips and stuff.

Tyrone remembered that while he and his cousin got into plenty of trouble, they were also blamed for things they did not do. He told me, "The principal. I did not like the principal 'cause he used to always try to get me and my--when something happened at the school, even though we didn't do it, he would try to say we did it." This exclusion eventually pushed Tyrone further away from school. He told me, "Nobody wants to go where they're not wanted." Excluding students from school events and ceremonies was one way of excluding them from the broader school community.

One of the students in the study, the gregarious Raphael, tells me about a frank conversation he had with the principal during which he was asked to leave the school:

Then a lot of stuff-it was a lot of tension goin' on in the school with the little gangs and stuff. Then plus I was doin' bad in school. I was gettin' straight F's 
over there at [high school name redacted], so I was like-they were the-Mr. Garcia was the vice principal or something. He was like, "Oh, man. You're not doin' nothin' good over here. You're not even getting' no credits done or nothin'. You're a junior or somethin'. Man, we're gonna switch you up to another school, a continuation school. Man, you're not doin' nothin' good over here. You bringin' danger and stuff." I'm like, "All right." And I left.

Raphael told me that he was hurt by this remark. He did not see himself as a danger to the school community but agreed to leave. Raphael told me that he preferred the continuation school because the students were older, less prone to fights, and more focused on earning credits. His story of the continuation school is interesting and contradicts what other students had to say about that learning environment.

Several students talked about the ways that their criminal behavior was publicized at school. Students were arrested at school, forced to attend school while wearing GPS monitoring devices, and had to meet with their probation officers at school. One student attending a continuation high school told me that his probation officer had so many students on his caseload at the school that he had an office at the school. While some young people told me that they did not care about being criminalized at school, 15-year old Donte objected to this treatment: 
On December 1st, the first day of December the police arrested me because they said I had a warrant for my arrest. Then ever since then I've been here. They coulda picked me up anywhere but they came to my school.

Donte tells me that when he gets released, "I can never show my face at that school again." His arrest at school was a significant turning point in his educational trajectory. While public shaming and exclusion takes many forms, the message was clear to the students impacted: You are not welcome here. It is not surprising that many students would choose to leave school in the face of such pressure. When the pressure of being pushed from school was combined with the pull of the streets, most students turned to the streets. In the next section, students describe the pull of the streets which included gangs, drugs, violence, and a way of life that was familiar to many of the students. When they were torn between schools that were rejected them and the streets that were embracing them, it is not surprising that many chose the the streets.

\section{Caught Between School and the Streets}

The young people who participated in the study discussed how the streets impacted their ability to attend school and focus on learning. The streets is a broad term that encompasses many student experiences including gang involvement, community violence, family violence, the realities of poverty, and the various impacts of both selling and using drugs. The experiences shared here are not directly related to the 
students' experience in school but the experiences situate the young people's school experiences in the context of very complicated lives.

Peter is the seventeen-year-old student who discussed the vice principal who often checked up on him and other students who were struggling at school. He told me that when he was attending school, he felt that he was torn between his life in school and his life on the streets:

It was like I was livin' two lives. I was playin' basketball too, but I was also carryin' weapons, havin' large quantities of money, gettin' high. I did that because I didn't want to leave my friends who I grew up with. People ask me, “Why?" Because I love 'em so much, you feel me? I just don't wanna let 'em go. There's gonna be a time when I'm gonna have to, though. I know that. Just not right now. I didn't want to. Then it'll be another life when I'm with my friends that I play basketball with. Do homework together, play ball together, basically be around people who was tryin' to get to the same place I'm tryin' to get to. Tryin' to be successful in life. I think that we should think of the bigger picture and not what we have right now. I liked that. I really liked that. I don't know, it was just that time. The money was bringin' me back to them, the love for them was bringin' me back to the people that I shouldn't be with. I don't know, I just kept goin' back. 
Ultimately, Peter ended up choosing his friends and the streets. While he felt a sense of loneliness at home, with his friends he had companionship. If he could have chosen both school and the streets, he told me that he would have. Peter, more than many of the students in the study, has a clear understanding of the ramifications of being caught between school and the streets. In spite of this, he continues to struggle.

Fifteen-year-old Lisa also struggles between school and the streets. Her situation is complicated by her family dynamics. Lisa comes from a gang-involved family. Throughout her childhood, her own gang involvement seemed inevitable based on her family history and going to school was complicated by this involvement:

All my family, they mixed up. I don't wanna just--that's just all I know. I don't feel like gang bangin's my future. You get me? It's stupid, fighting over a color. That's what I tell everybody. I know this dude. He got jumped in. A week later, got in a fight, and he got shot and killed. I was just like, "Well, I told him to not be in a gang. That mean it's not-they don't play." Then that's why I stopped going to school over there. I didn't like goin' to school in [city name redacted] cuz I felt like at the school, they will do something to me. They tried jumpin' me before. They tried actually doin' so many things. I got stabbed in my leg before. And what gets me upset's that my cousin just died in that gang.

When I asked Lisa what she would do instead of being in a gang, she shrugged. Then she told me, "You wanna know what I do best? Sell drugs and get money." With no 
viable alternatives for young people caught between school and the streets, the streets will always be the easier choice. Lisa went on to tell me:

My mom, she actually grounded me by being inside the house, cuz she knew that my favorite thing is being outside. That's how I started being bored. After that, cuz I'll hang with dope dealers and stuff. I end up like-cuz I see how they got money quick, and I wanted to help my mom cuz I seen her stress out a lot. I thought it was cool and I wouldn't get in trouble, so I ended up doing it too, not just to give my mom. Afterwards, my mom would ask me, "Where are you getting all this money from?"' She started finding out, cuz in sixth grade or seventh, so I can't get a job. She was like, "Where are you getting all this money from?" I was like, "Oh well, I got a job." I lied to her. She's like, "Well, that's a lie," cuz you know how if you're underage you still gotta get your mom's permission. She already knows that so she was like, "Yeah, I don't believe that. She was just too tired to argue though so she would just go to bed.

Lisa shrugs and looks away as she shares this observation. I wonder about the relationship between Lisa and her mother but do not press her to discuss it.

Similar to Peter who shares his dilemma above, Jorge also struggles with his desire to do well in school while staying connected to his friends. While he liked doing his schoolwork, it was difficult to continue in school while also hanging out with his 
friends. Even when his peer group shifted away from gang members, many of his friends still committed crimes. Jorge told me:

Then later all my friends were potheads. They weren't like gangsters anymore. They were all potheads. I got out of - I stopped hanging around with gangs and started kicking it with my pothead friends. When we'd talk I used to be like, "I'm not going to be thug. I just smoke weed." I didn't use to like gangs. I was like I'll just meet with my friends. We just smoked and we'd talk. Me and my friends used to talk about school all the time. When I used to hang around with my thug friends they used to be like, "We're going to hit this thing. We're going to rob somebody." That wasn't really me. I liked getting high but I also liked doing my work. That was ninth grade.

Jorge went on to tell me that this behavior caught up with him in the tenth grade:

Tenth grade? The beginning of the school year I was on GPS. I was cool. That's cool. For three or four months I was doing good in school. For two months I was doing good. Then for like a month and a half I started doing bad. I would skip school. Then I got GPS. That's when I caught my first case, kicking it with my thug friends, Then we broke into a house and they snitched on me. They didn't get in trouble. They all blamed it on me. I'm the only one that got in trouble. Then I was on GPS for about eight months. I did hella good. I used to smoke weed still. Then I was going to get out of probation already and I was going to 
get off GPS. Then they violated me cuz I was high. I came out dirty on a pee test. They locked me up for two days, for the weekend. I don't know. I felt like I'm never coming out. I'd never been in jail or none of that. I felt I'm never coming out. Then that day that they're supposed to pick me up they're supposed to pick me up about 5:00. I don't know. I didn't come out until like 8:00. I was like, "I'm staying here. The judges hate me." I felt nervous. Then I got out. Then I did good for like five months.

For Jorge, being caught between the school and streets was a complex choice. Much like Peter whose story is shared above, I have the feeling that Jorge would have chosen both if he could have. Jorge could see the long-term benefits of education but was lured by the short-term fun of hanging out with his friends and smoking weed.

For Ahmed, the streets provided acceptance and companionship that he did not get at home. He told me that his mother worked long hours and he was often home alone. Ahmed found love and acceptance in the home of his close friend. He told me: My mom was always busy working. But I'd go to my patna's house, and his mom accepted me. She even called me son and everything, but the way he grew up, his whole family are gang members. All his brothers, his brother's wife, his mom, his real dad-they were all in a gang, growin' up. If I come home like that, wearin' all red, pants saggin', red belt hangin', tattoos and stuff, my mom would be, like, "What are you doin'? What's wrong with you?" She'd probably call the 
police on me. But his mom just-she accepted it. She understood, I guess, because she came from the same background. She supported it for him. For his birthday, she got him this clean red belt and these shoes - they call 'em debos, but the ones she got—she got him specialized ones. The whole shoe is like a red bandana. It was clean.

In spite of the love and companionship that Ahmed felt at the home of his fellow gang members, he also knows that gang membership is a dead end for him and his friends: It's like that. You get put onto a hood. You get jumped in, and then if you try to get out, you're gonna get jumped out, you're gonna get killed. I know some people that tried that and it did happen. It's messed up, all the stress and all the things their family gotta go through after that. You know? When we were young, when we were around the same age, we were playing football for our schools. Then we started gangbangin', and before we even turned 21, we get shot. You know?

Ahmed told me that when he leaves juvenile hall, he is worried about his personal safety. Even though he was not in a gang, he spent many years as a gang-affiliate. Upon release, he is planning to leave the state and continue going to school.

Vanessa, the student above who opened our interview by telling me that she has a really bad drug problem, told me more about how her addiction has made it difficult 
for her to focus on school. She comes from a family of addicts and her own struggles with addiction began at a young age:

I've done so much drugs since I was 11 to 18 . Nah, 17. I turned 18 here. 17. God. Yes. I had no teenage years. I tried to grow up too fast, basically. I grew up too fast for myself and I wasn't focused on school, so I was just on drugs. I really want to stay sober, because I wanna be able to live. Cuz when I was 14, cuz all the drugs I was doing - I just asked to look at my mug shots a week ago, and you can see all of 'em when I got locked up and I was on heroin. I looked like dead. I looked dead. I don't want to look like that and I don't want towhen I was 14 , I said, oh, I'm not even gonna make it to 18 . Now I made it to 18. Now I want to make to 80. I want to at least make it to where I could get old. For Vanessa, the drugs gave her an opportunity to escape. In talking with her, escape appears to be a theme from her life. She went on to say, "I kept running away. I run away from my problems most of the time. I don't know how to talk about things, cuz a lot has happened in my past." Vanessa told me that she wants to stay clean but she does not know if she will be able to. I ask her if there are any supports available through school to help her and tells me that there are not.

At the age of fourteen, Erykah is the youngest student that I interviewed for the study. She has sparkling brown eyes and a sassy walk. Her first stay in the facility was 
at the age of 12 but she managed to stay out for nearly two years. Now she is back for the second time in less than a week and she is not happy about it:

I was disappointed in myself when I came back here. I'm going like, "Damn, I'm back. Four days, already? I haven't even been out for a week, not a month, not two months. I'm back already." I thought I was gonna be here for Christmas. When they told me that I wasn't goin' home yesterday I started cryin'. I started throwin' up everywhere. I just—my nerves was bad because I need to be home for Christmas. I need my family. I can't be in here for too long because I have anxiety.

In spite of her strong dislike of being incarcerated, she made choices in the time leading up to her incarceration that she knew would lead to another arrest. When I ask her why, she just shrugs. Erykah tells me that she does not know why and I believe her. For many of the students, being caught between the school and the streets left them with few options.

\section{Conclusion}

As students in the study grew older and moved on to middle school, the joy of learning faded for nearly all. School became a hostile place where they were subjected to derision, suspicion, and discipline. In some cases, the students were guilty but in others, they were simply guilty by association. During middle and high school, students reported deteriorating relationships with teachers. Many experienced formal exclusion 
as a result of disciplinary polices but were also subject to informal exclusion as a result of behavior issues. Many of the participants were not allowed to go on field trips and most were barred from participating in eighth grade graduation activities. Finally, students expressed a feeling of being caught between school and the streets. As their complex lives increasingly revolved around the drug economy, gang life, and other activities, school simply faded away. Some students attended high school but others never enrolled. School became a footnote in a complicated life. Jorge told me that he does not really see the point of going to school. He said:

High school won't prepare you to be on the streets. I don't really see the point. I mean it's going to prepare you to go to a school out there but it's not going to prepare you for the streets.

What does prison school prepare students for? In the next section, I discuss students' experiences while attending school behind bars. For many young people in the study, attending school while in juvenile hall was the beginning of reengaging in school for the first time in many years. The factors impacting the reengagement, and how students make sense of it all, are discussed below.

\section{Academic Reengagement in Prison School}

I don't even consider it to be school. Everybody playing around. It 's just more of a-I don't know. This ain't [laughter], it's really not school. You go to a real school you know how a school is. You feel me? It's not school. 
When I'm struggling with a question or something, they actually help. They won't really give me an answer, but they will show me how do I solve a problem, or to get the answer. That's enough help that I need.

The third and final theme that emerged from the study centered on students' academic reengagement while attending school in juvenile hall. Many of the participants in the study found that they were able to focus on school for the first time in many years. Without the distraction of being caught between school and the streets, students were able to concentrate on their education. Most of students cited positive teacher relationships and an uncomplicated learning environment as key factors in their engagement in school. They all appreciated the opportunity to earn credits quickly. In spite of this, many young people also criticized the weak academic program and said many of the classes covered material they already learned in middle school. All four of these strands related to the theme of academic reengagement in prison school are illustrated through the story of Ahmed. His story about rediscovering education while incarcerated introduces this theme.

\section{Ahmed: A Wake Up Call}

I've been here for two years and I've changed here as well, and I've learned a lot from this. It's like a wake-up call. You know?

Ahmed is a 17 -year old student who is not quite what he seems. The scar across his forehead - a souvenir from the day his skull was cracked by a baseball bat and stitched back together with staples - makes him look violent but he is very soft-spoken. 
His brown skin and long black ponytail make him look like many of the Mexican students that I meet in the facility. However, Ahmed is a refugee from Afghanistan though he tells me everyone thinks he is Latino. The tattoos across his neck, arms, and hands make him look like a gangster and maybe he is. He won't say. He does tell me that he has lived in three different countries and is fluent in five languages: Farsi, Russian, Portuguese, Spanish, and English. Ahmed is a world of contradictions. Ahmed is gregarious and is excited to be talking to someone new. He gives me a detailed account of his life and seems to enjoy the process. Over several interviews, his story unfolds. He was born in Russia, where his parents met, and later the family moved to Brazil. When Ahmed was eight years old, his father was killed during a robbery. Ahmed, his older brother, and his mother moved to Atlanta where he first learned English. He moved to California just before middle school. During middle school, Ahmed's grade began to fall. He started cutting class with his friends and smoking weed during lunchtime. This behavior continued as he entered high school and he was eventually sent to a continuation school. After a short time at the continuation school, Ahmed was arrested. At the time of our interview, he had been incarcerated for almost two years. He remembers the difficult early days of attending school in juvenile hall:

When I first got here, I had too much on my head. The police investigated me. They told me what I'm lookin' at. They told me to give them the information 
about the people and they would let me go and stuff. I already know how all that goes, so I was, like, "No." Like, "I don't know what you're talkin' about." They're, like, "All right. You're gonna get charged with this." I'm, like, "All right." They really ended up charging me with it. Then they told me I'm lookin' at a minimum of 12 years. I'm, like, "All right." I was kinda hardheaded, and I just grew up too fast. My mom always tells me that, too. "You grew up too fast."

I had a lot on my mind, so goin' to class, I was just wakin' up here, and the breakfast they had-I wasn't eating for two weeks cuz I'm not used to this food. I was just sittin' there quiet. I wasn't talkin' to nobody. I always keep a small circle. I don't trust a lot of people. Bein' in that unit and here, period, and bein' with people that are locked up with me-I was just, like, "I don't know none of these people. I don't even wanna get to know none of these people. I'm here to do my time, and I just wanna go back home." It was like that.

In class, all I was thinkin' about with how I let my mom down, how when I got my bookin' call and I called her, how she was cryin', and how my little sister was cryin', and how my brother was disappointed with me and mad at me. That's the only thing that was really goin' through my head cuz that's all the family I got. 
A month in here felt like a long time. I finally started getting phone calls. My mom put money on the collect phone, so I started talkin' to them. She-every time I hear her voice—she'll hear my voice, she'll start cryin'. "I can't believe you're over there. I can't believe you're away from us. I don't know if you're safe," this and that. "I don't want nothin' to happen to you." I just built myself up in here. I was, like, "Mom, don't worry." I was, like, "Be positive." I was, like, "I'm gonna be out soon. It's all right." I was, like, "I need you to be strong for me," this and that. I was, like, "How do you expect me to be strong if you can't be strong for me?"

I started gettin' visits. We found out how the visits work and everything. My mom came to visit me, and it just didn't feel right. You know? It didn't feel right at all. Goin' in that room and sittin' down and knowin' that I'm locked up, and seein' my mom and little sister comin' through the door all sad with a couple of snacks and stuff in their hand, I'd just look at them and I'd just look down and start shakin' my head. I'm, like, "Damn"—excuse my language_-"I fucked up." You know? Then I went back to my cell. Visiting was over. I went back to my cell, and I just sat there. I had this knot in my chest cuz I feel so bad. I try so hard to push it out, but I couldn't cry. 
Finally, I start paying attention in school here. And they [the teachers] see how my mentality changed cuz when I first came in, I was just goin' to classes like, "Okay." I asked how do the credits work here, and they told me and everything. I was, like, "All right. Cool." I was just doin' class work, but then I seen that because I was failin' the classes when I was going to school in outs, I wasn't gettin' credits for that. I'm, like, "Ooh, damn." If I would've been doin' that, I would've been graduated by now. I could've been takin' college classes.

Then I seen kids graduating and then some of my friends I got real close with here. Their graduation day came, and I seen him wearin' the gown and their parents comin'. I'm, like, Damn." I'm, like, "You know what?" It started motivating me. I'm, like, "I wanna graduate. I wanna graduate."

My mom kept tellin' me — after she stopped stressin' as much cuz she knew I'm okay, and once we got used to me bein' here and stuff, on both sides, my mom's side and me, it wasn't as hard on us no more. Then she started talkin' to me, like, "How's school here? How's your school goin'? Are you still in school? Are you tryin' to graduate? What's goin' on? How do the credits work?" 
I explained everything to her. She was, like, "Wow. That's good." She was, like, "They give y'all that opportunity." She's, like, "You should graduate." She's, like, "Do all your work." She was, like, "You know only got time right now." She's, like, "So you might as well do all the work and finish school, get your diploma." I'm, like, "You know what? You're right." Then my mom was just tellin' me. I had a visit. This was over a year ago. She's, like, "I'm gonna be so happy if you graduate, so happy if you get a diploma." She was, like, "You're gonna be my first son to get a diploma." She's, like, "I'm gonna be so happy," this and that. So that really motivated me and I kind of made up my mind.

All the teachers are really cool to me. I like all the teachers. Sometimes I have my days when I wake up so I be not in the mood and I'll be quiet, but I'll still do my work. I got all A's and B's here. Since I been here, I been getting good grades. I don't have nothin' to really distract me, so I do all my work, the little projects and stuff. Yeah. Actually, in here I've learned more stuff in class than I have on the outs. I don't know if that's weird to say, but it's the truth.

The teachers here, they explain it to you multiple times, and if you don't understand somethin', they'll restart the whole thing and go over it with you again to help you get it. Then, honestly, another reason why I've gotten it is 
probably cuz I've been here for so long. Every year they redo the year because there's always new people comin' in and out. I've been here for so long, so some of the stuff I learned my first year, they'll do the same the second year because it's all new people from the last year, but I'm the only one that's still here. That's good for me but maybe not good for college. Maybe I should be doing different work by now.

Then we have programs here and they tell us, "You're not gonna really get nowhere. You're either get to the penitentiary or six feet under." I'm, like, "That's crazy," cuz I didn't believe it at first, but it really is true. All these gang members are locked up. The affiliates are locked up, doin' time, some serious time. Since I've been here, a lot of homeys I knew from the outside, I've kicked it with and went to parties with and kick-backs, got shot since I been here.

I pray every day, too, and I thank God. "Thank you for putting me in this place because I know I can't get shot, and you're keeping me away from the streets because you wanna teach me a lesson and you wanna keep me away from my family because you want me to feel the pain and see how bad it feels." I talk to God and I pray and I thank him for everything he did for me and everything he's still doin' for me and helpin' me get through this time as well. 
It makes me happy to know that I'ma get it [my diploma] on time. Not late or nothin'. You know? That's a good thing. Then I feel my mom's gonna be really happy cuz I'm gonna be her first child to get a high school diploma. You know what I mean? I'm pretty sure it's gonna be big for her, cuz she already got her diploma. She done with college and stuff. She went to college and everything. Seeing her son do it and the right things, the positive things, I think-I'm pretty sure it will make her happy. Then when I graduate, too, they let my family come. They'll come and all that. That will be cool.

As Ahmed's story illustrates, attending school behind bars was a time of reconnecting to his education. He discussed the positive relationships that he has built with teachers during his sentence and talked about how the learning environment makes it easier for him to focus on school. In contrast with these highlights, Ahmed also referenced the easy academic program and the fact that the teachers repeat the same material each year. In spite of this, Ahmed is excited to earn his diploma and graduate in front of his family. In the next section the theme of academic reengagement in prison school is explored across four related strands: positive teacher relationships; uncomplicated learning environment; weak academic program; and reengagement in learning. 


\section{Positive Teacher Relationships}

Many students in the study discussed the positive relationships that they have developed with teachers at the prison school. The discussions around teachers reminded me of the things they discussed when sharing their early educational experiences. While doing classroom observations in the juvenile hall school, I found the teachers to be warm, engaging, and willing to help the students when they needed additional assistance. The students echoed this in their remarks about the teachers.

Seventeen-year-old Angelo told me that the teachers in the juvenile hall school give him the help that he needs in school.

I can depend on my teachers in here. They get me where I need to go. When I'm struggling with a question or something, they actually help. They won't really give me an answer, but they will show me how do I solve a problem, or to get the answer. That's enough help that I need.

Angelo told me that if he needed more help, he is sure that he could find a teacher who would help him. He said, "I spend more time with these teachers in here than I spent on teachers on the outs. So I know them and they know me." The idea of being known by the teachers is a refrain that is repeated by many students and is one of the things that students like most about attending school behind bars.

When I met Travis, he had just turned 18 and had completed all of the courses needed to graduate. He told me that he had almost no credits when he first got to 
juvenile hall but earned enough for a diploma during the almost two years that he has been incarcerated.

They, I ain't gonna lie, they get the job done. Cuz I don't need her [a teacher's] class, and I passed her class. She like, I mean, she gave me other work to do, get my credits up. 'Den I just be listenin' to her and she be talkin' to the kids about the work and stuff cuz I did last year. I just got it done, and I'm just like-I just be lookin' at em like if I can do it you niggas can do it too. Ain't no different than me. Just be doin' my work and stuff like it's cool over 'dere too. I'm like it's cool can't get no better 'dan 'dis.

Travis told me that his graduation ceremony had already been scheduled but he was still trying to get permission for his family members to come. The graduation ceremonies happen in the facility so students' families must pass a background check in order to attend. Travis tells me, "I'm ready to graduate. I'm gonna make my mom happy by doin' that."

Raphael enjoys attending school in the facility and told me the mandatory attendance in juvenile hall schools means that the students build better relationships with the teachers.

Here, the teachers look way more comfortable. They know you more, too, cuz you basically live here. You know 'em for seven to eight, nine months. They know you for that long. They gonna get to know you really well. Then it's not 
like you can miss a day of school. You can't just cat off on school. You can't go lay in your bed. You gotta go to school here, so they gonna see you everyday. I feel like people — we build more relationships with the teachers here than on the outs.

Raphael made an important point about teacher relationships - it is easier to build them when students have perfect attendance. However, he also mentioned that the teachers are more comfortable and I noticed this as well. All of the teachers had adapted to the correctional environment and seemed not to notice the doors, keys, and cameras.

Seventeen-year-old Tyrone told me that he likes the teachers in juvenile hall and he feels that they really enjoy their work with students. He said:

Sometimes we be gettin' substitutes and stuff, and I don't think they really care about what they been teachin' us and stuff. Our regular teachers, they really try and teach us stuff. I guess they love workin' here 'cause I ask most of them why don't they just teach on the outs? They're just like, 'cause they want to come in here and teach to see what-'cause they want to know if juvenile hall kids are smart, or they just make dumb decisions. They be talkin' to us, or sometimes we won't even do work. We just talk about stuff, like bring up a topic, and we'll just talk about it. 
Tyrone appreciated both the instruction from the teachers as well as the space that the teachers provide for dialogue. He told me that he never had teachers that would just talk to students about their lives and their problems.

Jesus is one of the students that I interview with an imminent release date and a plan to attend community college. He told me that one of the teachers at the school has helped him to get prepared for life on the outs. He said:

Yeah, for sure, cause the teacher next door, Mr. Cervantes, he's the one that enrolled me in college and got me my financial aid and all of that. He sent me for my placement test too, and my probation officer too, I could tell he wants me to do good in the real world. He took me to the colleges, different colleges to go look at 'em. He took me to my—for my placement test. He went to go take me yesterday too. He took some other kids too that are not even-not even on his caseload, he wanted to take 'em too to get them interested. Yeah.

Jesus told me that one day he wants to come back to the juvenile hall and work as a juvenile institutional officer, the correctional officers who work in the facility. He feels that with his background and experience, he can help students turn their lives around the way that he has changed his.

Brandon is one of many students who mentions the extra work that teachers will give if the young people are just a few credits short of graduation. He told me: 
If you close to graduating, they [the teachers] give you extra work, like book packets, books, and stuff to work on in order for you to get them extra credits that you need, English, economics, U.S. history, stuff like that. Then they'll work with you the whole time that you're here for you to get on that track to graduate. That's cool.

Brandon told me that he is glad they have schools in juvenile hall. He said it is better than sitting up and staring at the walls. Based on his charges, he will likely be transferred to an adult prison after adjudication and he told me that he wants to take advantage of the opportunity he is now receiving. Brandon wonders aloud if he will be able to attend college in his next institution.

The number of students who reported positive teacher relationships while attending school in juvenile hall surprised me. I expected that many would have only negative things to say about the experience and I was heartened to learn of the positive connections that many students reported. Given the small classes and mandated daily attendance, this finding is understandable. In the next section, students describe the uncomplicated learning environment that is present in their prison school. While many of them were dealing with complex issues and problems on the outs, while incarcerated many of these problems were no longer present. This allowed many students to focus on school for the first time since they were in elementary school. 


\section{Uncomplicated Learning Environment}

Several of the students mentioned the uncomplicated learning environment that they found when attending school while incarcerated. In prison school, there are no athletics, no dances, and no clubs. Since the units are segregated by gender, there are no distractions related to sex and dating. The students only attend classes each day for five periods, including daily PE, and see only $2-3$ teachers daily. There are very few tests and no homework in prison school. The learning environment is less complicated and many young people found it easier to concentrate in this simpler setting.

Brandon, the seventeen-year-old student who is anticipating time in adult prison told me that attending school in juvenile hall is less complex than school outside of the institution. He said:

It's way different from — from goin' to school on the outside. I wouldn't say it ain't as-I would say it ain't as complicated as school on the outs, but it ain't as good goin' to school on the outs, like bein' able to-I don't know. It's just much different. It wouldn't say you can compare the two.

For Brandon, the schools are so different that he feels that it is not even possible to make a comparison between them. Other students echoed this sentiment. Unspoken in Brandon's remarks is the idea that school on the outs may be of better quality. This concern is discussed in greater detail in the following section. 
Jesus, the student who wrestled in high school and would like to come back to the juvenile hall to work, told me that attending school behind bars is very different from school in the outs.

Well I think it's a lot different. There's only a couple kids; there's only 20 kids, no girls, and the teachers are the same-yeah, the teachers are about the same, but they help us a lot more than other schools. Yeah. We don't have to go far to go to our class, we just go right here.

Jesus' comments encapsulate many remarks made by students throughout the interview who summarized some of the reasons that school behind bars is less complicated. I ask Jesus if school would be more complicated if there were girls. He laughs and says, "Girls make everything more complicated."

Andre, a sixteen-year old student who has been incarcerated for two months made some interesting remarks about attending school in juvenile hall. He told me that he likes the classes because they are shorter than regular school and he is happy to have no homework. He said, "If we did have homework I wouldn't even do it. I already feel like I'm in jail. How you gonna give me homework when I'm in jail? That's crazy." Andre went on to say:

This school, it's like a vacation to me. You don't got nothing to worry about. They wake us up every day. We're not waking ourselves up. On the outs we gotta wake ourselves up. We got a bunch of responsibilities. Gotta wake up on 
time so we can take ourselves to school to get ready, get good grades, do all our homework, and go to every single class. Here, they make sure you go to every class. You're gonna go to every class. There ain't no skipping class up here. Ain't no cutting school or faking sick so you could be absent. I haven't even heard a kid say I can't go to school cuz I feel sick. I think they know better. School is easy up here, though. It's just a smooth day. It's the same thing every day. The days go by fast. School's over at 1:00 every day.

Andre said that the teachers must really like teaching in this environment to put up with the students. "Some of the kids, they don't really care about none of this. They've been disrespectful. They feel like they in jail. They don't care about nobody here. The teachers, they deal with that. I ain't seen nobody quit so far." He is correct that the school has many long-time teachers and the turnover rate is lower than for many nearby comprehensive high schools.

Sergio, the studious young person with glasses described above, also told me that he enjoys attending school in juvenile hall. Early in our interview, he shared with me that he has always liked school and still likes it. Sergio said:

School here is good. Actually I do like it. I really didn't like-I really didn'tlike school in the outs is not my thing 'cause too much negative influences and stuff, you know like keeps me away from school. In a structured facility, a structured environment, I can do well in school. Once I'm out and about, 
school's like the last thing on my mind. Yeah, so school's like-I like school, don't get me wrong, but it's just there's other things that get my attention than schools sometimes.

Sergio's comments remind me of many students who talked about being distracted by drugs, gangs, and the lure of the streets. One benefit of attending school while incarcerated is that he is able to concentrate. I wonder if the fact that he is sober for the first time in many years has also impacted his reengagement in school.

JaMarcus the student who mentioned the red card system and the beatings he would get from his grandmother in the school office, told me that it is easy to focus on school when there is nothing else to focus on.

School here, I've just been-I been busy up here. I think I been more focused up here than I ever been at any school. I realize I need to stop playing cuz I was gonna-I was almost gonna have to do a extra semester or somethin'. I was gonna have to graduate after everybody else. Now I been doin'-I been basically doin' work every day, so now I'm 'bout to graduate early. I went from 'bout to graduate late to graduating early. Because I ain't got nothin' but time up in here. I ain't got nothin' but time. I ain't got nothin' else really better to do. Yeah, I mean, I was always-I was too easily distracted and stuff. 
I ask JaMarcus if he will be able to remain focused on school after his release. He tells me "probably not." His current plan is to complete as many credits as possible while he is behind bars because he will not be going back to school once he is released.

The number of students who noticed and appreciated the uncomplicated learning environment was an interesting finding. While some students lamented the loss of athletics, clubs, and dating, many of them also found it easier to concentrate in an environment where going to school every morning is the only option. While the uncomplicated learning environment was noted by the students as something positive, the weak academic program was discussed as a negative by nearly all students in the study. This deficiency is discussed below.

\section{Weak Academic Program}

While many students had positive things to say about the relationships they have with teachers and their appreciation for the uncomplicated learning environment, many of them also critiqued the education that they receive in prison schools. Nearly all of the students told me the school in juvenile hall is easier than school on the outs. While some students appreciated the easier work in the classroom, many students indicated that they were bored or uncertain about whether the diploma they were earning would prepare them for college.

Michael is a fifteen-year old student who tells me that he is never returning to juvenile hall. It is his first stay in the institution and he offers the most information 
about life outside of school including details about the food, rooms, and interaction with correctional staff. Michael also offers a clear picture of the school day:

This school? It's like a daycare for big kids. It's not good. Because this school. You really don't do nothin'. It's like you could learn somethin' in here, but you really can't. Cuz they don't teach. They don't really teach you. They basically just give you assignments. Outside the school they teach you and you in there for longer. We in a class about 30 minutes. Really they don't really teach you nothin'. Just homework and word puzzles or get on computers on Word and start typing. Stuff like that. Read. I think that if you're in here long enough you could learn something because people graduate from here.

When Michael says that juvenile hall is like "daycare for big kids," I realize that he has hit upon a clever analogy for the juvenile hall. Much like daycare, there is time for school work, for play, for naps, and for snacks.

Peter, a small fifteen-year old, offered another interesting turn of phrase to describe school in juvenile hall:

School here is baby food to me. It's too easy. They teach us stuff that's already common sense, you feel me? But I think it's because we in jail. Most kids here don't go to school. Most kids who is in here is in here because they don't wanna go to school, so they feel like they gotta teach it the easiest way ever. You know how you can be like, "Okay, $9 \times 5$ is 45 ." So she's gonna put $9+9+9+9+9$. 
Okay, I think we kinda get the deal; 9 x 5 is nine five times. You know what I mean? They break it down all the way. Too much. Like if we were in kindergarten.

When I ask him if some students might need things broken down like that, he tells me, "Yeah, I do. I do. There is, but I can't complain because I'm gonna get it done either way I go. I gotta do either way it goes." He goes on to tell me that he wishes they had grades in juvenile hall instead of just putting all of the students together in one class. Another student, Shamieka, also said that school in juvenile hall is easier. She thinks this is because they have students from different grade levels together in the same classroom. She told me:

School here is just kinda easier, like, cuz they know it's like ninth grade is tenth grade level, and eleventh grade is twelveth grade, so they have to make it likeended up really easy for the ninth graders and tenth graders. It's way easier than 11 th grade is.

Shamieka would also prefer classes based on each student's current grade. I imagine this would be difficult but not impossible. It also makes me wonder how students with special needs are being served in the institution. While there are many students with learning disabilities, I did not observe any differentiated instruction during my ten classroom observations. 
Timothy is another student who does not consider school in juvenile hall to be real school. While he is critical of the school, he still appreciated the opportunity to earn credits:

School in here just—for me I feel like they just try to get you in the classroom. You don't need to be doing that much work. You could watch TV instead ofyou can do little stuff. Like school on the outs you're doing constant work in each class. You've got six periods, each class you're doing work basically. Here you're watching TV instead. I don't consider this really school but I am getting credits.

Timothy went on to tell me:

People in the classroom. People don't take school serious. Kinda how I was, but you know you see how-I'll notice how people was looking at me when I was in the classroom on the outs and now I see-you feel me, like all that type of student. I don't know. Being here it's an eye opener. You don't wanna come back to this.

While Timothy did not have anything positive to say about the formal education he received, it did appear that he is learning something. When he looked at the students who are not taking school seriously, he saw himself. It seemed that he did not like what he saw. 
Daniel, the student who has been to juvenile hall 12 times, told me that he is doing the same work that he did during previous stays in the institution. This comment was echoed by other students. Daniel said:

I don't know. Like the 'tings 'dat 'dey teach here it's just like, I don't know, I done been learnt it 'fore in like sixth grade. Cuz when we do work in here I done been-I been comin' here since I was like 14. I done been-I been doin' this same work for years. Same-ass worksheets. I mean, this ain't really school. I don't know. 'Dey have it cuz a lotta kids come from different ages and shit, so 'dey gotta do somethin'. They do what they can but_-it's just here cuz legally they hafta have it. Know what I'm talkin' 'bout?

It is true that juvenile halls are legally mandated to provide students with an education. While it is possible that many students see school in juvenile hall as a legal requirement, Daniel is one of the only students who explicitly refers to it as such.

Many of the students tell me that they are learning the same content that they already covered in middle school. Erykah had already told me that she is an honors student at her high school on the outs. She told me that attending school in juvenile hall is boring. She went on to say:

It's not challenging. It doesn't challenge me at all. I know everything that she's teaching 'cause I already learned judicial, legislative, executive branch in eighth grade. That's past what I'm on. The math she's teaching we learned sixth grade, 
seventh grade. It's like it's not challenging me. If it's not workin' for you, you need to challenge yourself. Make your own problems. I made my own math problems the other day. It wasn't even a correct—-there's not a correct answer to the math problems you want, but if you know that what they're doing and you're finished their work, turn it in and do your own work. Make sure you're challenging yourself to your ability because they're not gonna challenge you the way you need to be. They're on a low class teachin' level and they didn't really go to school to be up here. You can't expect up here from a place down here. I just challenge—challenge yourself.

Erykah told me that she recently got a referral for complaining about the school work. She told the teacher that she had already learned the content and asked for some gradelevel work. She told me:

I got room time like 30 minutes last night, my first time ever having room time. I didn't even know I had room time until like-it was at night time and it was because my teacher felt that I was being disrespectful. I talked to her today, she explained it to me and I explained to her. That's fine.

Room time means that the student is required to stay in his or her room during evening open recreation time. It is the most commonly used punishment and is dreaded by nearly all of the students. It is unlikely that Erykah will protest about her coursework in the future because she is assiduously avoiding room time in the future. 
Andre also told me that the level of the coursework reminded him of middle school. He searched for a word to describe the school in juvenile hall and in the absence of something suitable, he invented his own word: jaily. Andre told me:

At juvenile hall, I kinda feel like, I don't know. It's a classroom in the unit. It just feel like kinda — what's the word? I don't know. Just jaily. It's guards watching you all the time. The teachings kinda watered down-for one of the classes, we'd watch a movie almost every day for one of the periods. Then the other period, we'd just read a book. That's our credit. I don't really remember doing any tests or anything like that at juvenile hall. When I was first in juvenile hall, they was teaching us one step algebra equations, like three times $\mathrm{n}$ equals nine. That wasn't helping me at all. I learned that in middle school. They could probably make it a little harder to prepare us for the real world.

In addition to sharing his thoughts about the nature of school in juvenile hall and the weak academic program, Andre also wondered if the program prepares students for education outside of institutions.

In addition to Andre, Angelo is another student who expressed concern about whether school in juvenile hall prepares the students for future academic success. While he contended that the credits helped to move him along academically, he expressed doubts about the content. Andre said: 
Does this school prepare you for real school? It do, but it don't because-how could I say this? I can't even explain it, but it do-the part that it do, it's-it give-you're credited, so you do go to school, but then it's- they're not teaching you more than — they're not teaching you enough, but they're giving you a grade up though.

Angelo's concerns are shared by Raphael who also expresses doubts about the rigor of the academic program. Raphael said:

I feel like it kinda does, but I feel like I'm not sure if it's - if it was me on the outs, I thought the work was harder over there. It's either that I concentrate more here, cuz work seems easy here. At the same time, it's probably—-they tell me that, "Oh, it seems easy, cuz on the outs, you weren't concentrating at all. You were just busy doin' other stuff." I think it's probably true, though, cuz on the outs, I didn't even look at the question for a minute. I was just like, "Oh, I'm checkin' off this. I'm not worried about that." I guess just cuz--I don't know. Raphel is not sure if the work is easier or if it just seems easier because he is more focused. It is likely that both of these assertions are true. In the end, Raphael does not really know.

Because this study focused on the experiences of the students and did not include an assessment of the academic program, it is difficult to know the actual grade level of the school work. Further, because the institution does not track student 
outcomes, it is also difficult to know if the program prepares the students for high school or college coursework in the community. However, it is clear in talking with the students that they feel the work is below grade level and they have doubts about their preparation for future academic work. In spite of their critiques of the academic program, many of the students reported feeling reengaged with school and learning while they are in juvenile hall. In the next section, students describe how school in juvenile hall helped them to reconnect with learning.

\section{Reengagement in Learning}

For some students, attending school in juvenile hall gave them an opportunity to find joy in learning again. In the same way that positive teacher relationships was a strand that was present in both early elementary and prison school, engagement in school is also a strand that repeated. Students mentioned it both early and late in their academic trajectory. Much like the early stories of positive learning environments in elementary school, these stories also centered on enjoyment in learning.

Brandon is the student mentioned above with twelve siblings who recalled learning about the Civil Rights Movement with his favorite teacher. He told me that the teachers in juvenile hall make learning fun and work hard to make sure the students understand the material. Brandon said:

With him [social studies teacher], he'll break it down to you. He'll break it down to the class and then if you still need extra help, he'll break it down to you one- 
on-one. Then for all the lessons that he teach, he can show you a documentary or a movie to go with it. That way it'll put it in a perspective that you know. Instead of you just readin' a book and then you not really gettin' it, you can see the video and it'll break it down to you.

In addition to the social studies teacher who will break down the content for him, Brandon shared that his science teacher does the same thing. He mentioned a recent science lesson where the students made models of atoms. Brandon told me:

Basically, the same with science class. We don't really do a whole buncha bookwork in there. She [the science teacher] do fun stuff to make you really get it. Like, we were just doin'-I forgot what it's called. A couple of days ago, we was just doin' somethin' about atoms and we got to build some little molecules out of a pipe cleaner and hair beads.

Brandon is one of many students who talked about science class and the activities that happen during the class. It was a favorite among many of the students.

Sergio has attended juvenile halls in other counties and told me that this one is more hands-on. During his 6-month stay in the juvenile hall where the study is being conducted, he told me that he has learned a lot based on the teaching style. Sergio said: I've been to a couple other juvenile halls and they're just like—it would be like book work so I wouldn't even do it. I'd just be like, "Fuck it." I'm just chillin'. This juvenile hall is like more like--they interact with you. They tell you how 
you're doing. If you need help, they help you and stuff. They don't just put the book in front of you and expect you to do stuff. They walk you through the steps, so that's what I like in school. It's like cool because they interact a lot with us. It's cool. They help you try to get extra credit too if you need it, you need like graduate extra credit, wherever you need it. Yeah, it's cool. It's nice. They help you a lot here.

Sergio also told me that some of the newer students are not ready to take advantage of the opportunity and it sometimes stresses the teachers. He said:

I think the teachers like it, but sometimes they get stressed out because some kids just be - don't care about school. They just do whatever they want, really how they want. I feel like-well I know Ms. Barreto, 'cause she tells us straight up, she be like, "At least two of ya'll or three of ya'll are listening to me. At least I'm getting through to two or three of ya'll. As long as I'm getting through to a couple of ya'll, it don't matter. I feel fulfilled." I'm like, all right, that's cool. She feels cool with at least a couple of us listening and then if others don't wanna learn, she can't make 'em learn. She just goes on with the process and doesn't let nobody interrupt.

Sergio told me that he expects to have enough credits for graduation before he is released and he is excited to earn his diploma. He feels that if he gets a diploma before 
he graduates, his time in juvenile hall will not have been wasted. "At least I'll have something to show for it," Sergio told me.

Raphael told me that he has learned many things since attending school in juvenile hall that he probably should have learned sooner. One reason why he is more successful in school now is that he is more interested in school and is more willing to ask for help when he needs it. Raphael shared that:

On the outside, I'll just be like, I don't know how to do this. Here, I actuallyI'll be stuck on one problem. I'll be like, “Well, what do I here?” I'll actually ask for help, which is something—over here, I guess they got me interested in education. Yeah. They got me interested in stuff. On the outside, with-I didn't necessarily know what adjectives and-I knew what a noun and verb was. It was a whole bunch of pronouns and all that. I didn't really know what that meant, til I got really here, til I started paying attention to that stuff. Yeah. It helped me out a lot in school. Yeah. It was cool. Yeah.

Raphael told me that, for the first time in his life, he is considering college. After the formal interviews are complete, we talked about the media studies program at a local community college. Raphael told me that he loves to be on camera.

Peter told me that he never thought about school as a path for him because he assumed he would always be able to earn money illegally. He shared that since that 
path doesn't seem to be working out for him, he has decided that it is time to take school more seriously. He said:

You need school to be successful. If you wanna live the good life, you need to go to school, period. Most people talkin' about how wanna buy their mama a house, how they wanna get their mama a car. If you go to school, you could do that, but if you keep doin' the bad things you're doin', you just gonna keep endin' up right where you at.

Peter has decided that school could be a turning point in his life. Much like Raphael, Peter hopes to attending community college after he finishes high school.

The many students who referred to prison school as a turning point in their education was an thought-provoking finding. It is likely that all of the factors mentioned above contributed to the reengagement in learning that occurred for some young people. It is not unexpected for students to be more engaged in their learning if they have positive relationships with teachers and a learning environment with few distractions. Schools in juvenile hall have a unique opportunity to work with young people at a time when their attention can be focused on school in a new way. Finding ways for prison schools to capitalize on that opportunity will be discussed in Chapter Five. 


\section{Conclusion}

For students attending school behind bars, many became academically reengaged for the first time in many years. Those who had not attended school regularly were now required to attend school daily. While school experiences just before incarceration were overwhelmingly negative, students reported positive teacher relationships when attending school while incarcerated. The small class sizes, selfcontained environment, and compulsory attendance allowed students to focus on their studies. Many students were able to build relationships with teachers in prison schools and many felt that the teachers genuinely cared about their academic progress. In fact, the support from teachers in the prison school emerged as a primary theme from the interviews. In spite of this, students also offered biting criticism of the type of education they are being provided with in juvenile justice educational settings. Nearly all students reported that the work was too easy and did not prepare them for future educational opportunities. Even those earning diplomas shared doubts about the usefulness of their "juvie diplomas" and wondered if they were prepared for higher education.

In spite of the ups and downs of attending school while incarcerated, it was a positive educational experience for some students. Ahmed, whose narrative opened the theme related to academic reengagement, told me: 
Man, I honestly— to be honest with you, like being here, I think gave me a chance to get my diploma, cuz to be honest with you, if I was out still doin' the same things, then I would never got a wake up call like that. I don't think I would get a diploma. I would probably get a GED but not a diploma. I want a diploma. I feel good.

Ahmed's story is an example of a student who still believes in the promise of education to help him achieve his goals in life. In the concluding section of the findings, I will discuss how students make meaning of their educational experiences while they are behind bars. This final section opens with the story of James, a young man who has given up on education. He has decided that his future has only two potential paths and neither of them require a degree.

\section{Students Make Meaning}

Is this school preparing me for the future? Mmm. I cain't really say nothin' on that one cuz it's a difference between here and bein' out cuz in here you're just used to somebody tellin' you what to do and stuff like that. I wouldn't really say it's preparin' you or gettin' you ready or, as they say, rehabilitatin' you to go back out.

$\sim$ Brandon, age 17

In reflecting upon their experiences, students expressed numerous ways of making meaning of their educational experiences. Returning to the conceptual framework from Chapter One is instructive in considering how young people make meaning. The conceptual framework for the study is built upon an understanding of the social purposes of schooling. Schools are social institutions, charged with preparing 
and socializing young people for their adult roles in society. In all societies, there is a social contract that underlies this agreement. In exchange for an education, students are expected to comply with the norms and rules that are operative within the school. When reflecting upon their experiences, most students continued to believe in the social contract of education and were continuing to strive for the benefits promised by this contract. These students were working hard to earn credits toward graduation and some unspecified future goal that was made possible by the diploma they were working toward. This hopefulness toward their current education and the future possibilities is evident in the previous theme about reengagement in learning through prison schools. Student meaning-making when the contract is intact is illustrated through Ahmed's story which opens the previous section.

For other students, however, the social contract of education had been irrevocably broken. They would attend school because their attendance was compulsory. Their cooperation, however, could not be coerced. Student meaningmaking when the contract is broken is illustrated through the story of James. James believes that the educational contract is broken for him and his life has taken shape accordingly.

\section{James: I Know I Ain't Livin' Right}

I mean I ain't gonna lie. The life I'm living, I know there 's only two ways it gonna end up: dead or in jail. It's my choice in life. 
It's always easy to do wrong but hard to do right. That's what I don't get. I don't get that at all.

James is an African-American teenager in his 16th year of life with sad eyes.

Before I start talking to him, I know that he has seen more pain in life than a 16-year old should. He is small for his age with a slight build, close-cropped hair, and acne sprinkled across his chocolate skin. He shares a name with his grandfather with whom he is very close and talks about toward the end of the interview. James is currently a ward of the court and describes his home environment as "unstable." When he is released from juvenile hall, he will be sent to his fifth group home.

James remembers his first day of school in a Head Start early childhood education program. When I asked him if he remembers kindergarten and he said with a laugh, "Yeah, that I was the only grade I graduated from." James went to the same elementary school as his father and uncle - both of whom are currently serving life sentences in prison. He liked school, especially math, and rainy days in class were his favorite. He found it relaxing to stay inside playing games while listening to the rain come down. James smiles to himself as he remembers a favorite teacher, Mr. D. "I liked him cuz he was strict but he taught us a lot about insects. We learned about cocoons and stuff. That was my really cool years. First and second grade were the only good years I had at school."

When James was in the third grade, his brother was killed. He told me this and then disappeared into his own head for a moment. After a short pause, James said: 
I was getting suspended and fighting a lot, but I was still going to school every day. Third grade I got suspended every day. If I wasn't in class, I was in the office for something. It was just always something. I always had issues with school ever since third grade.

At the end of third grade, James was sent to live with his grandmother in a city almost 100 miles away.

In fourth grade, James tested into a gifted and talented program at the elementary school in his grandmother's neighborhood. He has fond memories of that year but as he got older, he began to rebel against his grandmother's rules. When he was 12 , he stole a car and drove the 100 miles back home to the neighborhood where he was born. James enrolled in a new middle school and was arrested for the first time in seventh grade. After his release, he was enrolled in another new middle school but rarely attended. James tells me:

It was cool for a minute. I was doing cool. They wanted me to play sports and stuff, but wasn't really into basketball and stuff. I felt like my year as a basketball player and shit was over. Come on, I was getting older. So I just stopped going to school altogether.

James was 13 years old when he decided he was too old to worry about attending school and dropped out. 
More than most other students, James is savvy about system and jaded about his prospects. He knows that his presence in the institution creates "job security" for the prison staff and teachers who work behind bars. Making a distinction between juvenile halls (county-run facilities) and the California Youth Authority (CYA, a state-run juvenile facility), James told me:

Cuz all they see—all they see you as is a paper. That's what they think. You're a career criminal even at a young age. They think you belong in prison or you're gonna end up in prison. They think like CYA would be good for you cuz it's locked down. You can't run and you-they feel like these places are supposed to help you, but somewhat to me it make you worser.

Cuz you're in here fightin', dealin' with different attitudes every day. It makes your temper probably—probably not this place, but I'm thinking CYA and all of that, the pen [penitentiary], that makes you worser cuz all you're doin' is fightin' and you're fightin' every day, every other day. You're fighting for your respect and you're fighting for your life, whatever.

It's different. It's like you experience new things in there. I got a lotta brothers that's in there. They tell me juvenile hall are better. Some tell me there [CYA] is better. You get more freedom there. You know what I'm sayin', but you gotta 
fight. You're gonna have to fight if you go there. No way you ain't gonna fight if you go to CYA.

It's like it makes you worse if you get a bid or you come out and you just-you were always like that in there, so you get out on the outs, you're just like - you know what I mean? You got that demeanor, so it's like-that's what they turn you into. Some people say they go there and get out. To me, if you go theresome of the people can change their life, but you gonna see a lot of stuff in there make you not wanna go back, where it's like you just—don't get it. I got a lotta old friends or my old partners, that's older than me, they been to YA. My uncle been to YA. He went to prison from YA. He ended up in prison doing life. My other partner, he been to the $\mathrm{Y}$ and he ended up first shootin'. It ain't cool at all in these institutions.

I mean we all need discipline. That's the whole point of it, but it's like that don't help with some people. Some of us it don't help. It's just to get us off the streets, from hurting other people or hurting ourselves even more. That's all I can say. That's how I see it. 
James can see - perhaps more than many of his peers - that the deck is stacked against him. I asked him if he sees education as a way out. He thought for a moment and slowly shook his head. After a thoughtful pause, he told me:

I mean I ain't gonna lie. The life I'm living, I know there's only two ways it gonna end up: dead or in jail. It's my choice in life.

It is what it is. I see how they is, but that ain't what I wanna do. If I can do somethin' to-you feel me—keep me goin' a legit way, without having to steal, rob or kill for it, then I'm all for it. If I could find a way that's gonna escape me and get me money—not selling dope or hittin' houses or somethin'—if it's cutting hair, and that's what I'm trying to learn, do that cuz you're a self-made person when you cut hair.

If a lot of us could find something different then we would, but most people don't really know nothing. Most of the people from the Eighties are not--I don't know. Most of the people I know, all they know is to sell drugs. That's all they was doin' growin' up. That's the only way. They ain't never had a job. That's the only thing you know. If that's the only thing you know how to get money then-you feel me - then you're gonna do it forever till you die or you're in jail. 
I wanna be free though. I ask-don't you wanna be free, even though-I mean people say sometime they be wantin' to go to jail or they wanna die, but just try to make somethin' outta life. There's always somethin' you could do. You got reasons on this earth. I don't know my reason for being here. I'm still tryin' to figure it out.

James is a thoughtful person who posed many interesting and unanswerable questions. It seems as though he has decided that school is for other people but that the path he is chosen does not require an education. Perhaps James is right. If education is based on a social contract between society and students, what happens when the social contract is broken?

For students who still believe in the social contact of education, there is an incentive to participate in schooling. Through the stories of Dominique, Juan and Ahmed whose narratives introduced each theme from the study, we can see what happens when students continue to believe in the contract. Through the story of James, we can see what happens when the student no longer has faith in the contract.

\section{Summary of the Findings}

The three themes of positive early school experiences, school disengagement in middle and high school, and academic reengagement in prison school capture the experiences of students attending school behind bars and address the study's research questions about how students make meaning of those experiences. Within each of the 
themes were strands which detailed how the theme was voiced through the students' experiences.

The data suggest that positive early school experiences were nearly ubiquitous among the students and were formative in shaping their early orientation toward school. Students told stories about their first day of school and learning how to write their names. For young people with older siblings or cousins, there was an excitement about joining their family at school. Students found that when they made mistakes as young children, school was still a welcoming place. The teachers would talk with them about what was wrong and would help them with coping strategies. Students described getting the opportunity to color, to talk, or just a quiet place to sit. For young people with unstable or abusive homes, school even became a refuge.

The findings indicate that the second theme, school disengagement in middle and high school, was characterized by increasingly harsh school discipline, exclusion, and detachment. Again, this finding was common across nearly all of the students. They described coming to school high or using drugs while at school; many students engaged in this behavior as a result of loss and trauma that was unrecognized or unaddressed. In addition, gang involvement played a significant role in many young people's detachment form school. Drugs, gangs, and other behaviors led to suspensions, expulsions, and other forms of exclusion for the students. In a vicious 
reinforcing cycle, the students who needed the stabilizing influence of school the most were able to access it the least.

The data also reveal that academic reengagement in prison school is possible for some students. For those young people who are so far removed from education that the potential benefits of school seem remote, prison school is too little and too late. For some students, however, reconnecting with teachers and with learning can lead to a reengagement in school. However, the weak academic program must be addressed for students to maintain this engagement. They must have confidence that the credits and diplomas they are earning while incarcerated are worthwhile and could set them on the path to higher education. Further, prison schools have an obligation to provide students with an education that is at least equal to what they would receive at a high school on the outside.

Taken together, the three themes paint a compelling picture of the educational trajectory for students in prison schools and the importance of maintaining positive connections to school across the trajectory. The current system of exclusion wherein students are removed from their schools and communities to be warehoused and educated in institutions runs contrary to what this study tells us about the needs of young people. The findings presented here demonstrate numerous opportunities for keeping young people engaged in school and for reengaging them when they become disconnected. Recommendations for doing so are presented in Chapter Five. 


\section{Chapter Five: Discussion and Implications}

Many things we need can wait. The child cannot. Now is the time his bones are formed, his mind developed. To him we cannot say tomorrow, his name is today.

$\sim$ Gabriela Mistral

\section{Introduction}

While juvenile prisons were not designed for learning, they are still called upon to educate 100,000 students each day. This study deepens our understanding of students' experiences in the school-to-prison pipeline through the stories of the students themselves. The primary questions guiding this research are: How do incarcerated students describe their educational experiences leading up to and during incarceration? How do incarcerated students make meaning of their educational experiences behind bars? The stories of young people, told in their own words, can show us how to disrupt the flow of adolescents through the pipeline and create juvenile justice schools that help all students succeed academically.

The data collected for this study came from phenomenological interviews with students which followed a standardized, open-ended protocol developed based on a review of the literature and themes discovered during the pilot study described earlier. Interview One consisted of an educational history during which I asked the students about their educational experiences up until the time when they became incarcerated. Interview Two consisted of the details of their current experience during which I asked students about their educational experiences while incarcerated. Interview Three 
consisted of reflections on the meaning of their past and present educational experiences and their own reflections on learning. Using this research design, I was able to draw out students' experiences as they walked through their memories of schools, teachers, and education.

The three themes of positive early school experiences, school disengagement in middle and high school, and academic reengagement in prison school answer the study's research questions about students' experiences and how students make meaning of those experiences. The first theme, positive early school experiences, was characterized by student excitement in learning and positive relationships with teachers. The second theme, school disengagement in middle and high school, was characterized by school discipline, exclusion, and disconnectedness. The third theme, academic reengagement in prison school, was characterized by reestablishing positive relationships with teachers and feeling a new engagement in learning. For many students, their educational trajectory was cyclical. The themes from their early elementary experience are repeated in prison school. Some students, however, were unable or unwilling to continue participating in formal education. In summary, the findings of this study both add to and deepen the existing literature about the school-toprison pipeline. The findings also bring life and texture to existing quantitative findings from which the experiences of students are largely absent (Balfanz et al., 2003; Baltodano et al., 2005; Foley, 2001; Tesoro et al., 2014; Wang et al., 2005). 


\section{Interpretation of Findings}

The findings of this study both support and augment the existing literature about students' experiences in the school-to-prison pipeline. First, findings on the importance of positive student-teacher relationships are discussed. Then, the impact of adverse childhood experiences on learning and engagement are presented. Next, the impact of exclusionary school discipline policies on students' educational trajectories are explored. Finally, the interconnected relationship between neglected, urban schools and prison schools is explored through the lens of student meaning-making.

Overall, these findings give voice to how students experience the school-toprison pipeline. Every attempt was made to present the findings in the students' own words and to allow them to represent their own reality. This is a departure from traditional research about the school-to-prison pipeline through which narratives are filtered by researchers or in which student narratives are entirely absent. Allowing students to tell their stories is not only an attempt to humanize research about the pipeline but also a first step in working with young people to address inequities in the pipeline. As Brandon told us at the opening of Chapter Four, "Even if they [teachers] had just a little sense of what it was like, what the kids was goin' through when they was out, maybe they'd act different and treat 'em different, but they just treat 'em as another person that committed a crime." Expanding on this idea, there are many people in addition to teachers who would benefit from knowing "what the kids was goin' through 
when they was out." Educational researchers, juvenile justice advocates, and policymakers would all benefit from learning about the young people who are often the focus on well-intentioned but poorly-conceived policy efforts. The discussion that follows is a step in that direction.

\section{The Importance of Student-Teacher Relationships}

The importance of student-teacher relationships is a key theme that emerged across the students' educational trajectory. Students who began their education with positive teacher relationships but found those relationships to be increasingly strained throughout their secondary school years were still able to reconnect with teachers behind bars. These findings build on existing work that demonstrates the importance of positive student-teacher relationships especially for those students who are struggling in school. Research has demonstrated that when students feel a strong personal connection with their teacher, they are likely to show greater engagement in learning, to have more positive classroom behavior, and to achieve at higher levels academically (Hamre and Pianta, 2001; Klem and Connell, 2004; Rimm-Kaufman \& Sandilos, 2011). For example, Brandon shared that Ms. Thompson was his favorite teacher because she would push him to do his work. As a result of their personal connection, Brandon would work harder in her class and earned the grades to prove it.

Positive student-teacher relationships have also been shown to improve behavioral outcomes for all students including those at-risk for behavioral problems 
(Crosnoe et al., 2004; Decker et al., 2007). Many of the young people in the study described situations where a teacher helped them to deal with behavior issues in the classroom. Juan, for example, shared the story of his favorite teacher Ms. Lora who would allow him to draw when he became angry in class. Because of the trusting relationship that Juan had developed with Ms. Lora, he was willing to share his problems with her and she approached him with kindness and compassion. Juan's story is one of many examples of teachers who helped students when they were dealing with difficult situations that led to problematic behavior in the classroom.

Many young people described a circular path that began with school excitement in their early years to school detachment in the middle grades and back to school engagement in prison school. Helping students to maintain positive student-teacher relationships across all grade levels and in the midst of difficult life circumstances would go a long way toward mitigating some of disengagement that many students experienced. Before young people reach prison schools, schools on the outside should be employing as many strategies as possible to avoid losing students and to keep students connected to school. Though the literature focuses on positive student-teacher relationships, students in the study mentioned positive relationships with many adults including coaches, administrators, and counselors. All of these positive relationships have to potential to help students maintain their connection to schooling. 
The findings of this study indicate that positive student-teacher relationships can be reestablished even if they have been broken over the educational trajectory. Though students often became disconnected from school during middle and high school, they remembered the positive relationships from their past. This gave them a foundation to build on when reestablishing these relationships in prison school. For example, Angelo shared that the teachers in juvenile hall are dependable and he can count on their support. For young people attending school in a juvenile justice educational setting, building positive relationships with teachers may be essential to reengaging in school and staying educationally engaged after they leave juvenile hall.

\section{The Impact of ACEs on Learning and Engagement}

Though this study focused on the educational experiences of the young people, the findings also give voice to the complex lives that many students in the juvenile justice system have led prior to their incarceration. The students in the study shared stories about being abused by family members; about being homeless and sleeping in family shelters; about seeing cousins shot and killed; about the murders of their fathers and brothers; about being jumped into gangs; about being compelled to sell drugs; and about being beaten by the police. The young people's willingness, and often eagerness, to share their stories may reflect the lack of opportunities that they have to process their experiences. While these traumatic events were not the center of this study, they provide important context to the students' ability to engage in school. Even for the 
students who may have led a life relatively free from trauma, juvenile incarceration is itself a traumatic experience. To be separated from friends, family, and community at a time when the adolescent is dealing with one of the most difficult circumstances of his or her life is incredibly difficult. In spite of the knowledge that trauma and abuse are common among incarcerated adolescents (Forrest et al. 2000; Holman \& Ziedenberg, 2006) there are few services for young people behind bars.

The research on ACEs, adverse childhood experiences, has shown that childhood traumatic events have a profound impact on learning. Adverse childhood experiences are experiences that harm children's developing brains so profoundly that they result in a wide range of short- and long-term effects. While discussing school, families, friends, and communities, many young people mentioned traumatic events from their childhood. The most common ACE discussed was the death of an immediate family member - most often the student's father. Students in the study also shared their experiences with various forms of abuse and neglect, household substance abuse, mental illness, violent treatment toward their mother, and having incarcerated household members. Approximately $80 \%$ of students in the study referred to at least one adverse childhood experience while several referenced many. This data confirms the work of Dierkhising et al. (2013) who found that $90 \%$ juvenile justice-involved youth reported multiple traumas. Further, these findings also echo the work of Baglivio 
et al. (2014) who found that incarcerated adolescents were four times more likely to report four or more ACEs than their non-incarcerated peers.

Further, the impact of ACEs on cognition and learning has shown that early traumatic stress can negatively impact brain development and the cognitive processes which underlie learning (Bücker et al., 2012; Burke et al., 2011; Carrion \& Wong, 2012; Perfect et al., 2016; Scott et al., 2013). As ACE scores increase, the risk for learning and behavior problems in school including low academic achievement increase (Burke et al., 2011). Addressing the impacts of ACEs in schools for incarcerated young people is a complex task. Recognizing and addressing the interplay between trauma, learning, and incarceration is essential for educators in prison schools.

\section{The Impact of Exclusionary School Discipline Policies}

One way that this study deepens our understanding of students' experiences in the school-to-prison pipeline is by personalizing the impact of exclusionary school discipline policies. All students in the study discussed school discipline including referrals, detentions, suspensions, and expulsions. All of these disciplinary consequences were ultimately shown to be variations on the same theme - exclusion. Students with behavioral issues were routinely removed from class. Research has shown that discipline policies that push students out of school routinely push them into the juvenile justice system (Advancement Project, 2005; Rios, 2011; Wald \& Losen, 2003). 
A study by Balfanz et al. (2013) found that students who were suspended just once in ninth grade were twice as likely to drop out of high school. Additional research found that suspended students are at greater risk for involvement in the juvenile justice system (NAACP Legal Defense Fund, 2005; Wald \& Losen, 2003). This finding was echoed by the findings of this study. Many students discussed out-of-school suspensions and expulsions as the driving force in their eventual departure from school. From students who extended short suspensions by several days (or weeks) to students who missed months of school while waiting for expulsion hearings to students who decided not to return to school after completing their punishments, this study found a variety of ways that exclusionary school discipline policies kept young people out of school.

Even when young people did return the school, they often did so with the stigma of their punishment. They often returned to school ankle-monitoring devices as a condition of their probation and were required to meet with probation officers on their school campus. These practices sometimes resulted in a slow decline away from school. Sometimes, students would just stop showing up to class. For example, Donte told me about being arrested at school in front of his friends and tells me that he could never attend that school again because he is too embarrassed. This finding shows how exclusionary school discipline policies negatively impact young people and their 
educational trajectory. Creating appropriate alternatives to exclusionary school discipline will be discussed in the recommendations below.

\section{Summary of the Findings: Making Meaning}

This study set out to uncover how incarcerated students describe their educational experiences leading up to and during incarceration and to understand how students make meaning of these experiences. In doing so, this study also sought to better understand the underlying social contract of education and what happens when that contract is broken. In American society, education has three purposes - to control, to socialize, and to sort (Noguera, 2003).

Some young people in the study knew, from an early age, that the social benefits of education were not available to them. Young people who realized that the social contract of education had been broken and who decided that they would no longer participate were subject to increasingly harsh sanctions. First, they were excluded from class. This typically took the form of office referrals, detention, and tracking. If this sanction was not severe enough to encourage conformity, students were excluded from the school. This usually came in the form of suspensions, expulsions, independent studies programs, and continuation school assignments. If this did not work, students were then excluded from community. They were sent to sterile facilities with euphemistic names such as boys' camp, training school, or group home. If this final sanction was insufficient to gain the students' compliance, they were completely 
excluded from society. Through the machinations of the juvenile justice system, they were warehoused in juvenile detention facilities. How ironic that we use the word justice to describe this system.

The findings of this study reveal the roles that both students and schools play in violating the social contract of education. Adolescents who commit crimes are no less deserving of understanding and kindness than younger students who act out in subtler ways. Many incarcerated young people are hurt and need resources to help them heal along with supportive environments and positive relationships with adults. As Dominique explained to me:

I have really connected with some of the teachers and they make it seem like they love their job because they know what we go through. They know our situations and they mainly just come in here and they just love on us. One teacher, she comes in here and she doesn't see these are girls who committed crimes and so they're in juvenile hall. She sees it as they have problems and they need someone to love on them, you know? Cuz some of us never got loved on enough when we were little so just, everybody needs someone to love on 'em. There is something poignant about Dominque's remarks. In addition to the social processes of education articulated above, schools are also a place that young people rely on for a sense of safety and community. There is an opportunity for schools to provide the love and stability that some young people do not receive at home. 
Students like Dominque need such a school or they will suffer permanent educational marginalization.

For those interested in interrupting the flow of students through the school-toprison pipeline, the stories of the students provide clear points of intervention. Many students discussed the transition from elementary to middle school as a turning point in their educational trajectories. According to Sergio, middle school offered more distractions than elementary school:

You had to deal with more problems and like more distractions towards your school and studies and homework and all that type of stuff when you get into middle school. It was just like—older kids and the things I was doing. I smoked cigarettes and like for me, smoke weed. A lot of times they would offer it to me. Yeah, that's what kind of got me off track in middle school.

Considering ways to ease the transition from elementary to middle school would be an impactful intervention for many young people. For students already attending middle and high school, reducing exclusionary approaches to discipline would help keep some of the most vulnerable young people in the classroom instead of on the streets. For young people who are already attending school in juvenile hall, they need multiple opportunities to form positive student-teacher relationships. Learning about the various experiences of students as they move along a path toward juvenile incarceration can give educators and policymakers a better understanding of how to disrupt that path. 


\section{Implications for Social Justice Leadership}

While calls for juvenile justice reform are growing (Alexander, 2012; Bernstein, 2014), this dialogue has focused on diverting students from institutions without addressing the needs of those who are still there. It is urgently important to improve the education of young people in juvenile prisons while also working to dismantle the harmful and inequitable juvenile justice system. Social justice leaders are called to take action against unjust policies. Sander et al. (2011) contend that the first step in the process is to listen to the concerns of youth. This study provides a step in that direction by bringing the voices of young people into the literature.

This study also builds on the work of Shields (2010) who also calls for leadership which questions the notions of justice and democracy, critiques inequitable practices and addresses both the individual and the public good; this type of leadership is referred to as transformative. Some educational leaders might argue that considering the needs of students and being mindful of inequitable practices is the purview of all "good leaders" and not just transformative leaders. Theoharis (2007) would take exception to this and argues that social justice leadership is more than just "good" leadership. Instead, it is leadership that is focused on creating more just and equitable systems for marginalized students. In all structures, systems, policies, and decisions, a social justice leader is called to consider who is helped and who is harmed at each step along the way. The juvenile justice educational system has the potential to harm but 
also has the potential to reengage students in learning. As the findings demonstrate, many students can take advantage of the uncomplicated learning environment and connections with teachers. Educational leaders who are working with young people at any point in the school-to-prison pipeline can and should advocate for the needs of those students.

While considering the social and emotional needs of students, educational leaders must also attend the students' academic needs. In addition to their role as organizational managers, school administrators are expected to be instructional leaders (Horng \& Loeb, 2010). This is a challenge when working with a population as academically-diverse as a youth prison. Students may be incarcerated for one week, one month, one year, or longer. Student records are often delayed and it is difficult to appropriately place students in classes. Serving students with special needs may be a challenge. However, considering the needs of diverse populations and designing instruction to meet their needs will continue to be a skill expected of all educational leaders going forward. Resolving the tension that is created when working within an unjust system is a learned skill but one worth mastering. Dismantling harmful systems - failing schools and youth prisons - is not easy work but it is imperative if we are to address the harm caused by both systems. While dismantling the system is important, it is also necessary to address the needs of those currently attending school behind bars. 


\section{Implications for Educational Equity}

While this study did not explicitly address race, most of the students interviewed for the study were Black or Latino. Young people of color are disproportionately impacted by the school-to-prison pipeline and are overrepresented in the juvenile justice system (Advancement Project, 2005). Recent data show that while youth of color comprise 38 percent of the total US youth population, they comprise nearly 70 percent of youth who are incarcerated (Burns Institute, 2013). Thus, the achievement differences observed among students of color are often concentrated in prison schools. For educators concerned with issues of equity, the prison school is a setting which needs urgent attention.

The negative consequences of poor academic achievement and the negative consequences of youth incarceration are interrelated; both experiences prime students for difficulties throughout their life trajectory. This relationship is documented in the growing body of literature related to the school-to-prison pipeline (Alexander, 2012; Winn, 2011). School failure and youth incarceration both contribute to higher rates of unemployment and lower lifetime earnings (Balfanz et al., 2003; Kirsch et al., 2007). Both lead to poorer health outcomes for students (McKinsey, 2009). Both have enormous economic costs for society (Balfanz et al., 2003; Darling-Hammond, 2010; McKinsey, 2009). Until the educational and social issues contributing to the school-toprison pipeline are addressed, the flow of students through the pipeline will continue 
with unimpeded force. Addressing the factors that contribute to juvenile incarceration while also improving prison schools has the potential to significantly impact educational equity.

\section{Implications for Policy and Practice}

The findings of this study suggest changes to policy and practice which may be implemented to positively impact the educational trajectory and academic outcomes for young people in the school-to-prison pipeline. Two suggestions for changing outcomes for students are discussed below.

\section{Reduce Exclusionary Discipline Policies}

If educators and policymakers are to stop the flow of students through the school-to-prison pipeline, a necessary first step is to keep students in school and engaged in their learning. Reducing exclusionary discipline policies is an important policy step for all schools. As discussed during the literature review in Chapter Two, research has shown that alternatives to suspension and expulsion reduce the risk of dropping out of school and becoming involved in the juvenile justice system (Advancement Project, 2005; Balfanz et al., 2003; Balfanz et al., 2013). Further, recent research shows that, in California, lower district suspension rates have been correlated with higher academic achievement (Losen, Keith, Hodson, Martinez, and Belway, 2015). This research contradicts the often held belief that suspending fewer students 
would lead to more chaotic classrooms. In fact, keeping all students in class while providing thoughtful alternatives to suspension boosts achievement across the school. Further, the findings of this study demonstrate that exclusion from school is a key factor in students' disengagement from learning. Many young people described being suspended or expelled from school multiple times. As a result, some students missed months of school while waiting for expulsion hearings or did not return to school once their punishment had ended. Some students were not allowed to return to the school they were excluded from and were funneled into continuation schools or independent studies programs. All of these students eventually landed in juvenile hall. Policies which only allow for suspension, expulsion, and school exclusion as a punishment of last resort after alternative forms of discipline have been implemented are important for reducing the number of young people attending school behind bars.

\section{Individualized Learning Plans for Incarcerated Students}

While students attending school in juvenile hall have a wide variety of educational needs, students in this study all received the same educational program. Students who had already taken and passed algebra were placed into algebra classes. Students ranging in age from 14 to 18 were placed into the same general science class. Young people with special needs were placed in general education classes with no differentiation or support for their learning differences. Juvenile hall schools need to assess young people at intake and design Individual Learning Plans (ILPs) based on 
their individual needs. Unlike Individualized Education Plan (IEPs) that are legal documents prepared for children with disabilities, ILPs would be created for all students.

Instead of waiting for school transcripts to arrive, students would be given standardized assessments as soon as they arrive in the prison in order to determine their educational needs. Based on the results of the assessment, students would meet with a schoolwide teaching team to co-design an ILP. Students with special needs would also receive a mandated IEP. Instead of assigning students to a classroom based on the severity of their crime, students would be sent to classes based on their educational needs. Instead of organizing the school around the typical high school model, prison schools must discard semester-based confinements along with age and grade cohorts to develop personalized and purposeful educational experiences.

Each student's ILP would be based on his or her academics needs, built around his or her interests, and broken into short learning modules. Students' interests and abilities would be used to arrange cross-age classes and workgroups. Student learning would be accelerated by building on young people's strengths and passions while also addressing academic deficiencies. Remediation would be developmentally-appropriate (no more childish worksheets for older adolescents) and would be self-paced. In this model, students would become co-designers of their own schooling through the refinement of their Individualized Learning Plan. All students would meet weekly with 
their advisor teacher in one-on-one sessions to set and monitor personal goals. The advisor teacher would serve as a both an academic guide and a mentor for each student as they move through this new way to learn. Through continuous feedback, students engage in modules of instruction, independent studies, and real-world project challenges. Further, this model supports the development of positive teacher relationships.

At the end of each module, students meet with their advisor teacher to review the work they have produced. Instead of awarding credits at the end of the semester, the teacher awards grades and course credit at the end of each module so the student can quickly accumulate meaningful credits toward graduation. Students may use various methods to demonstrate their understanding and build a portfolio of work which they can take with them upon release.

This design addresses many of the deficiencies and challenges of the educational program that the students in the study described. Many students talked about the long delay in getting their transcripts from the high schools they had already attended. Through the use of computer-based assessments that deliver immediate results, students can begin school as soon as they arrive. Most instruction that the young people described was direct instruction with an emphasis basic skills. By combining remediation with independent studies and student-directed work, this new design allows students to progress rapidly over short intervals. Further, in this new design, students 
are treated as students instead of inmates. They are given the freedom and the latitude to act as learners so that they may come to see themselves as such.

Finally, this design addresses the wide range of special education needs among incarcerated students. Up to half of all incarcerated students have a form of learning disability (Foley, 2001; Leone \& Weinberg, 2010; Annamma, 2014). This design allows for differentiation for all students in all subjects. Teachers work closely with students to diagnose and support learning differences instead of ignoring students' special education needs. Many of the issues centered on the weak academic program could be addressed by creating Individualized Learning Plans for all students and using their confinement as an opportunity to accelerate their learning.

\section{Recommendations for Further Study}

This study focused on students' experiences in juvenile hall schools. While an examination of student records would have a useful way to verify students' educational histories, the restrictions of the site prevented this. One area for future research would be to combine student records with student interviews to develop a more detailed account of students' educational trajectories' and progress through school.

Although this study employed teacher interviews and classroom observations to assist in collecting student data, the primary focus is on students. A recommendation for future research would be a study of teacher experiences in juvenile hall schools with an eye toward improving instructional practices. Combing student and teacher 
experiences would be interesting step in creating more academically rigorous prison schools.

\section{Limitations}

This study adds to a growing body of research that qualitatively examines the impact of the school to prison pipeline. It builds on the literature demonstrating poor academic outcomes for students attending such schools and expands on the literature by bringing in the voices of students. However, this study examines the educational experiences of students attending school at one juvenile justice educational facility. The results may not generalizable to all juvenile justice educational facilities as they vary greatly across jurisdictions. Also, only a subset of students at the facility were interested in participating in interviews. This may impact the study by introducing sampling bias. In addition, while the average length of stay in the institution at the time of interview was approximately five months, many students had multiple incarcerations in multiple institutions. This may have impacted their overall impressions of juvenile justice education. Finally, while classroom observations and teacher interviews were used to supplement the student interviews, students' educational histories were not verified through their academic records and may have been subject to recall bias.

\section{Reflections on the Research Process}

Completing my dissertation was the most important learning experience of my educational career. Choosing a problem of practice to study and learning as much as 
possible about that problem is a challenging and exciting journey. After years of reading research conducted by others, I set out to contribute to that body of knowledge. Even when it was difficult, I appreciated the opportunity to learn and grown as a researcher, as an educator, and as a person. Delving into, this topic of research proved to be more emotionally demanding than I expected. I truly came to understand and appreciate the impact of vicarious trauma and the role of self-care during this study. Conducting research in a juvenile justice setting was difficult. I wrote many data memos during this time and an excerpt from one summarizes my feelings about conducting research in the facility.

\section{Walking Through Doors}

Today, I visited the prison to interview students. To reach the students who are attending school in the detention facility, I must first take a journey which always ties my stomach in knots. After I park my car, I carefully check my pockets. I cannot take a purse or backpack into the facility so I carry my driver's license in my back pocket along with my car key. In my hands, I have a folder with consent forms and letters explaining my study plus a moleskin notebook and a pen. Spiral notebooks are prohibited. These items plus my digital recorder are all I take with me. These items are all subject to search as am I.

After I walk through the front doors of the facility, I go through the metal detectors. I usually need to remove my shoes and earrings before I can walk through 
without triggering the alarm. My items take a short ride through the $\mathrm{x}$-ray machine. After clearing security, I walk to the Administration Department. I must have a visitation form, submitted by the school principal and approved by the chief of probation, on file in Administration each time I visit. Each day requires a new form. In Administration, I exchange my driver's license for a visitor's badge and sign into the visitor's log. With my badge affixed in a highly visible location, I walk down the hallway and through a set of double doors. I make a right turn, walk up two sets of concrete stairs, and through another set of double doors. I make a left turn and walk down another hallway and through yet another set of double doors. This is the moment that the knots in my stomach are the worst. Though I am not sure why, I feel afraid.

I enter the visiting room reception area and push the button for sally port door 1. I wait for staff in the control room to peer at me through the camera. Once they see my visitor's badge, they open sally port door 1 . The sally port doors are heavy and I need two hands to push them open. I enter the sally port and push the button for door 2 . It will not open until after door 1 closes. I wait. The control room opens door 2 . I enter the next sally port and push button for door 3 . I wait. The control room opens the door. I enter control room reception and sign into another visitor's log. I wait for the control room to open door 4. I push it open with both hands and enter the detention center.

Here, all of the units are arranged along an impossibly long corridor. There are no windows. Fluorescent lights glow overhead. The corridor smells of disinfectant and 
cafeteria food. The doors are arranged numerically and I reach the unit soon. I push the button for the unit staff to open the first door. The door slides horizontally with a metallic clang. I enter the unit sally port and wait for the unit staff to open the second door. Once inside the unit, I greet the unit staff and give them the names of the students who I will interview today. They unlock the door of the interview room and I settle in while I wait for them to get the first student. This is when the knot in my stomach finally begins to loosen.

I have tried to understand the reasons for my apprehension as I enter the institution. I have visited several times and know my way around. I have met many staff while there and most are friendly. Although some of the students have been convicted of serious crimes, I do not fear for my safety. The students do not feel dangerous to me. In fact, they are like teenagers everywhere. They are funny and smart and sassy and rebellious and serious and introspective and ridiculous and sweet. The building, however, has a personality of its own. It is a living, breathing, pulsating thing. It smells like Lysol and feels like broken children. Yes, the building feels like broken children. There is an oft-repeated platitude - hurt people hurt people. It is true. The pain of the young people inside the prison swirls through the air like the pepper spray. There is a fine mist of sadness covering everything. It makes me want to hug my own children. It makes me want to cry. It makes me want to flee. Instead, I settle into the hard plastic chair in the interview room and I ask questions. I try to understand a small 
slice of the students' lives. Sometimes, they give very little and our time together is short. Sometimes, they seem to have been waiting their entire lives to tell their story. Their stories tumble out in a torrent of words. I am grateful each time.

\section{Conclusion}

In summary, the findings illuminate both the experiences of students in the school-to-prison pipeline and demonstrate how students make meaning of these experiences. These results add to the growing body of research about student outcomes in the school-to-prison pipeline by bringing the voices of young people into the literature. There are times when their voices are broken, unpolished, or unsure. However, it is important that whenever possible we learn about a phenomenon directly from those most impacted by it. During my student interviews, few students asked about the nature of my research but JaMarcus was quite curious. He asked, "I was wondering what is this for? I don't really get the real meaning of this." Using my plainest words, I explained the study to him. He thought about it for a while and told me, "Make sure people know we're here. I know they forget. Remind them about us. There's a school here and kids here. Don't let 'em forget." These findings are about remembering. There are schools in juvenile hall. Do not forget about them. 


\section{References}

Advancement Project. (2005). Education on lockdown: The schoolhouse to jailhouse track. Washington, DC. Retrieved from http://www.advancementproject.org/ resources/entry/education-on-lockdown-the-schoolhouse-to-jailhouse-track.

Alexander, M. (2012). The new Jim Crow: Mass incarceration in the age of colorblindness. New York, NY: The New Press.

Annamma, S. A. (2014). Disabling juvenile justice: Engaging the stories of incarcerated young women of color with disabilities. Remedial and Special Education, 35(5), $313-324$.

Anthony, E. K., Samples, M. D., de Kervor, D. N., Ituarte, S., Lee, C., \& Austin, M. J. (2010). Coming back home: The reintegration of formerly incarcerated youth with service implications. Children and Youth Services Review, 32(10), 12711277.

Anyon, J. (1980). Social class and the hidden curriculum of work. The Journal of Education, 162(1), 67-92.

Baglivio, M. T., Epps, N., Swartz, K., Huq, M. S., Sheer, A., \& Hardt, N. S. (2014). The prevalence of adverse childhood experiences (ACE) in the lives of juvenile offenders. Journal of Juvenile Justice, 3(2), 1.

Baglivio, M. T., \& Epps, N. (2015). The interrelatedness of adverse childhood experiences among high-risk juvenile offenders. Youth Violence and Juvenile 
Justice, 3(2), 1-23.

Bahena, S., Cooc, N., Currie-Rubin, R., Kuttner, P., \& Ng, M. (2012). Disrupting the school-to-prison pipeline. Cambridge, MA: Harvard Educational Review.

Balfanz, R., Byrnes, V., \& Fox, J. (2013). Sent home and put off-track: The antecedents, disproportionalities, and consequences of being suspended in the ninth grade. Center for Civil Rights Remedies and the Research-to-Practice Collaborative, National Conference on Race and Gender Disparities in Discipline. Retrieved from http://civilrightsproject.ucla.edu.

Balfanz, R., Spiridakis, K., Neild, R. C., \& Legters, N. (2003). High-poverty secondary schools and the juvenile justice system: How neither helps the other and how that could change. New Directions for Youth Development, (99), 71-89.

Baltodano, H. M., Harris, P. J., \& Rutherford, R. B. (2005). Academic achievement in juvenile corrections: Examining the impact of age, ethnicity and disability. Education and Treatment of Children, 28(4), 361-379.

Barile, J. P., Donohue, D. K., Anthony, E. R., Baker, A. M., Weaver, S. R., \& Henrich, C. C. (2012). Teacher-student relationship climate and school outcomes: Implications for educational policy initiatives. Journal of Youth and Adolescence, 41, 256-267.

Beger, R. R. (2003). The "worst of both worlds": School security and the disappearing fourth amendment rights of students. Criminal Justice Review, 28(2), 336-354. 
Bell, J. (2001). Education, delinquency, and incarceration. In W. Ayers, B. Dohrn, \& R. Ayers (Eds.), Zero tolerance: Resisting the drive for punishment in our schools (pp. 136-142). New York: New Press.

Bernstein, N. (2014). Burning down the house: The end of juvenile prison. New York, NY: The New Press.

Bücker, J., Kapczinski, F., Post, R., Ceresér, K. M., Szobot, C., Yatham, L. N., Kapczinkski, N.S., \& Kauer-Sant'Anna, M. (2012). Cognitive impairment in school-aged children with early trauma. Comprehensive Psychiatry, 53(6), 758764.

Burke, N. J., Hellman, J. L., Scott, B. G., Weems, C. F., \& Carrion, V. G. (2011). The impact of adverse childhood experiences on an urban pediatric population. Child Abuse \& Neglect, 35(6), 408-413.

Burns Institute for Juvenile Justice Fairness and Equity [Burns Institute] (2013). Unbalanced juvenile justice. Retrieved from http://data.burnsinstitute.org/about.

Butin, D. W. (2010). The education dissertation: A guide for practitioner scholars. Thousand Oaks, CA: Corwin Press.

Caldwell, J., \& Curtis, J. A. (2013). Incarceration nation: How educational programs in prisons "lockout" incarcerated juveniles. Journal of Education and Social Justice, 1(1), 51-60.

Carrion, V. G., \& Wong, S. S. (2012). Can traumatic stress alter the brain? 
Understanding the implications of early trauma on brain development and learning. Journal of Adolescent Health, 51(2), S23-S28.

Christle, C. A., Jolivette, K., \& Nelson, C. M. (2005). Breaking the school to prison pipeline: Identifying school risk and protective factors for youth delinquency. Exceptionality: A Special Education Journal, 13(2), 69-88.

Coalition for Juvenile Justice. (2001). Annual report: Abandoned in the back row. New lessons in education and delinquency prevention. Retrieved from http://www.juvjustice.org/sites/default/files/resource-files/resource_122_0.pd.

Creswell, J. W. (2008). Educational research: Planning, conduction, and evaluating quantitative and qualitative research (3rd ed.). Upper Saddle River, NJ: Pearson Education.

Creswell, J. W., \& Plano Clark, V. L. (2011). Designing and conducting mixed methods research. Washington, DC: Sage Publications.

Crosnoe, R., Johnson, M. K., \& Elder, G. H. (2004). Intergenerational bonding in school: The behavioral and contextual correlates of student-teacher relationships. Sociology of Education, 77(1), 60-81.

Curby, T. W., Rimm-Kaufman, S. E., \& Ponitz, C. C. (2009). Teacher-child interactions and children's achievement trajectories across kindergarten and first grade. Journal of Educational Psychology, 101(4), 912.

Darling-Hammond, L. (2010). The flat world and education: How America's 
commitment to equity will determine our future. New York: Teachers College Press.

Decker, D. M., Dona, D. P., \& Christenson, S. L. (2007). Behaviorally at-risk African American students: The importance of student-teacher relationships for student outcomes. Journal of School Psychology, 45(1), 83-109.

Dierkhising, C. B., Ko, S. J., Woods-Jaeger, B., Briggs, E. C., Lee, R., \& Pynoos, R. S. (2013). Trauma histories among justice-involved youth: Findings from the National Child Traumatic Stress Network. European Journal of Psychotraumatology, 4, 274-294.

Drakeford, W., \& Staples, J. M. (2006). Minority confinement in the juvenile justice system: Legal, social, and racial factors. Teaching Exceptional Children, 39(1), $52-58$.

Felitti, V. J., Anda, R. F., Nordenberg, D., Williamson, D. F., Spitz, A. M., Edwards, V., Koss, M.P., \& Marks, J. S. (1998). Relationship of childhood abuse and household dysfunction to many of the leading causes of death in adults: The Adverse Childhood Experiences (ACE) Study. American Journal of Preventive Medicine, 14(4), 245-258.

Foley, R. M. (2001). Academic characteristics of incarcerated youth and correctional educationally programs: A literature review. Journal of Emotional and Behavioral Disorders, 9(4), 248-259. 
Forrest, C. B., Tambor, E., Riley, A. W., Ensminger, M. E., \& Starfield, B. (2000). The health profile of incarcerated male youths. Pediatrics, 105(1), 286-291.

Foucault, M. (1977). The means of correct training. In Discipline and punish (pp. 189205). New York: Pantheon.

Fox, B. H., Perez, N., Cass, E., Baglivio, M. T., \& Epps, N. (2015). Trauma changes everything: Examining the relationship between adverse childhood experiences and serious, violent and chronic juvenile offenders. Child Abuse \& Neglect, 46, 163-173.

García, J., \& De Lissovoy, N. (2013). Doing school time: The hidden curriculum goes to prison. Journal for Critical Education Policy Studies, 11(4), 49-69.

Giroux, H., \& Penna, A. (1979). Social education in the classroom: The dynamics of the hidden curriculum. Theory \& Research in Social Education, 7(1), 21-42.

Grevstad, J. A. (2010). Adverse childhood experiences and juvenile justice. PowerPoint delivered to Washington State Family Policy Council June, 8, 2010.

Hamre, B. K., \& Pianta, R. C. (2001). Early teacher-child relationships and the trajectory of children's school outcomes through eighth grade. Child Development, 72(2), 625-638.

Harris, K. D. (2014). Juvenile justice in California, 2013. California Department of Justice. Retrieved from http://oag.ca.gov/sites/all/files/agweb/pdfs/cjsc/ publications/misc/ jj11/preface.pdf. 
Holman, B., \& Ziedenberg, J. (2006). The dangers of detention: The impact of incarcerating youth in detention and other secure facilities. Washington, DC: Justice Policy Institute. Retrieved from http://www.justicepolicy.org/ research/1978.

Inderbitzin, M. (2005). Growing up behind bars: An ethnographic study of adolescent inmates in a cottage for violent offenders. Journal of Offender Rehabilitation, $42(3), 1-22$.

Jeffers, A. R. (2010). Early academic experiences of recently incarcerated African American males (Doctoral dissertation). University of Southern California.

Justice Policy Institute (2009). The costs of confinement: Why good juvenile justice policies make good fiscal sense. Retrieved from http://www.justicepolicy.org/ images/upload/09_05_repcostsofconfinement_ij_ps.pdf.

Juvenile Justice Educational Enhancement Program [JJEEP] (2005). 2004 Annual Report to the Florida Department of Education. Tallahassee, FL: Florida Department of Education.

Kakar, S. (2006). Understanding the causes of disproportionate minority contact: Results of focus group discussions. Journal of Criminal Justice, 34(4), 369-381.

Katsiyannis, A., Ryan, J. B., Zhang, D., \& Spann, A. (2008). Juvenile delinquency and recidivism: The impact of academic achievement. Reading \& Writing Quarterly, 24(2), 177-196. 
Kirsch, I., Braun, H., Yamamoto, K., \& Sum, A. (2007). America's perfect storm: Three forces changing our nation's future. Princeton, NJ: Educational Testing Service.

Klem, A. M., \& Connell, J. P. (2004). Relationships matter: Linking teacher support to student engagement and achievement. Journal of School Health, 74(7), 262-273.

Ladson-Billings, G. (1994) The dreamkeepers: Successful teachers of African American children San Francisco: Jossey-Bass.

Ladson-Billings, G. (1995). Toward a theory of culturally relevant pedagogy. American Educational Research Journal, 32(3), 465-491.

Leone, P. E., \& Weinberg, L. A. (2010). Addressing the unmet educational needs of children and youth in the juvenile justice and child welfare systems.

Washington, DC: Georgetown University, Center for Juvenile Justice Reform. Retrieved from http://cjjr.georgetown.edu/pdfs/ed/edpaper.pdf.

Losen, D., Hodson, C., Keith, I. I., Michael, A., Morrison, K., \& Belway, S. (2015). Closing the school discipline gap in California: Signs of progress. Los Angeles, CA: The Center for Civil Rights Remedies at The Civil Rights Project. Retrieved from http://civilrightsproject.ucla.edu/

McInerney, M., \& McKlindon, A. Unlocking the Door to Learning: Trauma-Informed Classrooms \& Transformational Schools. Education Law Center. Retrieved from http://www. elc-pa. org/wp-content/uploads/2015/06/Trauma-Informed-inSchools-Classrooms-FINAL-December2014-2. pdf. 
McKinsey \& Company. (2009). The economic impact of the achievement gap in American schools: Summary of findings. New York: Social Sector Office. Retrieved from http://mckinseyonsociety .com/the-economic-impact-of-theachievement-gap-in-americas-schools.

Mendel, R. A. (2011). No place for kids: The case for reducing juvenile incarceration. Baltimore, MD: The Anne E. Casey Foundation. Retrieved from http://www.aecf.org/resources/no-place-for-kids-full-report/.

Miles, M. B., Huberman, A. M. \& Saldaña. J. (2014). Qualitative data analysis: A methods sourcebook (3rd ed.). Thousand Oaks, CA: Sage.

NAACP Legal Defense and Educational Fund. (2005). Dismantling the school-toprison pipeline. Washington, DC. Retrieved from http://www.naacpldf.org/publication/dismantling-school-prison-pipeline.

Noguera, P. A. (1995). Preventing and producing violence: A critical analysis of responses to school violence. Harvard Educational Review, 65(2), 189-213.

Noguera, P. A. (2003). Schools, prisons, and social implications of punishment: Rethinking disciplinary practices. Theory Into Practice, 42(4), 341-350.

Office of Juvenile Justice and Delinquency Prevention. (2010). Juveniles on probation: Overview. Retrieved from http://ojjdp.ncjrs.gov/ojstatbb/probation/overview.html.

Office of Juvenile Justice and Delinquency Prevention (n.d.) Glossary. Retrieved from 
http://www.ojjdp.gov/ojstatbb/glossary.html .

Paris, D., \& Winn, M. T. (2013). Humanizing research: Decolonizing qualitative inquiry with youth and communities. Washington DC: Sage.

Perfect, M. M., Turley, M. R., Carlson, J. S., Yohanna, J., \& Saint Gilles, M. P. (2016). School-related outcomes of traumatic event exposure and traumatic stress symptoms in students: A systematic review of research from 1990 to 2015. School Mental Health, 8(1), 7-43.

Raible, J., \& Irizarry, J. G. (2010). Redirectin the teacher's gaze: Teacher education, youth surveillance and the school-to-prison pipeline. Teaching and Teacher Education, 26(5), 1196-1203.

Rimm-Kaufman, S., \& Sandilos, L. (2011). Improving students' relationships with teachers to provide essential supports for learning. Teacher's Modules. Retrieved from http://www.apa.org/education/k12/relationships.aspx.

Rios, V. M. (2011). Punished: Policing the lives of Black and Latino boys. New York, NY: New York University Press.

Rudasill, K. M., Reio, T. G., Stipanovic, N., \& Taylor, J. E. (2010). A longitudinal study of student-teacher relationship quality, difficult temperament, and risky behavior from childhood to early adolescence. Journal of School Psychology, $48(5), 389-412$.

Saldaña, J. (2011). Fundamentals of qualitative research. New York: Oxford 
University Press.

Sander, J. B., Sharkey, J. D., Olivarri, R., Tanigawa, D. a., \& Mauseth, T. (2010). A qualitative study of juvenile offenders, student engagement, and interpersonal relationships: Implications for research directions and preventionist approaches. Journal of Educational and Psychological Consultation, 20(4), 288-315.

Scott, B. G., Burke, N. J., Weems, C. F., Hellman, J. L., \& Carrión, V. G. (2013). The interrelation of adverse childhood experiences within an at-risk pediatric sample. Journal of Child \& Adolescent Trauma, 6(3), 217-229.

Seidman, I. (2013). Interviewing as qualitative research: A guide for researchers in education and the social sciences. New York, NY: Teachers College Press.

Sickmund, M., Sladky, T. J., \& Kang, W. (2004). Census of juveniles in residential placement [databook]. Washington, DC: US Department of Justice.

Tesoro, A., Thompson, K. C., \& Morris, R. J. (2014). Racial differences in academic achievement among juvenile offenders. Learning and Individual Differences, $36,207-212$.

United States Department of Education Office for Civil Rights. (2014). Civil rights data collection: Data snapshot: School discipline. Washington, DC. Retrieved from https://www2.ed.gov/about/offices/list/ocr/docs/crdc-discipline-snapshot.pdf.

Wald, J., \& Losen, D. J. (2003). Defining and redirecting a school-to-prison pipeline. New Directions for Youth Development, (99), 9-15. 
Wang, X., Blomberg, T. G., \& Li, S. D. (2005). Comparison of the educational deficiencies of delinquent and nondelinquent students. Evaluation Review, 29(4), 291-312.

Winn, M. T. (2011). Girl time. New York, NY: Teachers College Press.

Wordes, M., \& Jones, S. M. (1998). Trends in juvenile detention and steps toward reform. Crime \& Delinquency, 44(4), 544-560.

Young, E. (2010). Challenges to conceptualizing and actualizing culturally relevant pedagogy: How viable is the theory in classroom practice? Journal of Teacher Education, 61(3), 248-260.

Young, M. V., Phillips, R. S., \& Nasir, N. I. S. (2010). Schooling in a youth prison. Journal of Correctional Education (61)3, 203-222.

Zamora, D. (2005). Levels of academic achievement and further delinquency among detained youth. Southwest Journal of Criminal Justice, 2(1), 42-53. 


\section{Appendix A \\ Operational Definitions of Key Terms}

In this study, many terms unique to the field of juvenile justice are used. In some cases, there is an equivalent term in the adult criminal justice system with which the reader may be more familiar. For the purposes of this dissertation, the following definitions are provided:

- Adjudication: When juvenile justice officials decide if the youth has committed the act for which he or she is charged (Drakeford \& Staples, 2006). In adult criminal court, the term adjudicated is analogous to convicted and indicates that the court has found the youth guilty (Office of Juvenile Justice and Delinquency Prevention, n.d.).

- Detention: A form of secure custody of youth who have been arrested and are being held while awaiting trial. Detention centers are the juvenile justice system's version of jail. Some youth are confined to detention centers because they have violated condition of their probation or parole. Some are detained while awaiting their final disposition such as being sentenced to a community program or being transferred to a juvenile correctional facility (Holman and Ziedenberg, 2006).

- Disposition: When a youth is subject to a definite action or treatment plan in regards to a particular case. Disposition options typically include waiver to 
adult court, placement, probation, or dismissal (Office of Juvenile Justice and Delinquency Prevention, n.d.).

- Intake: When juvenile justice officials decide whether to formally process the case, informally process the case, divert the youth to another program, or dismiss the case (Drakeford \& Staples, 2006).

- Juvenile justice facility/juvenile detention facility/youth prison: In this dissertation, these terms are used interchangeably to denote a state-operated or county-operated juvenile detention facility, juvenile correctional facility, juvenile hall, juvenile prison camp, or other government-run facility where minors who have been arrested are confined.

- Juvenile justice education facility/juvenile justice school/prison school/court school: In this dissertation, these terms are used interchangeably to denote a secondary school program operated in a government-run juvenile justice facility (see above).

- Status offense: A crime that is only illegal for minors but not for adults (Office of Juvenile Justice and Delinquency Prevention, n.d.). Examples include truancy, curfew violations, and consuming alcohol. 


\section{Appendix B}

\section{San Francisco State University Institutional Review Board Approval}

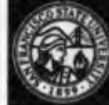

SAN FRANCISCO

STATE UNIVERSITY

OFFICE OF RESEARCH AND SPONSORED PROGRAMS HUMAN AND ANIMAL PROTECTIONS

INSTITUTIONAL REVIEW BOARD

Date: July 27,2015

To: Janine Saunders

Re: Educational Experience of Incarcerated Youth

The Institutional Review Board (IRB) at San Francisco State University has reviewed and approved the use of human subjects in the above protocol. You may proceed with your research as described in your protocol and as modified in any subsequent correspondence. Please honor your own discipline's professional code of conduct.

Protocol Number: H15-25

Approval Date: July 23, $2015 \quad$ Non-Exempt Full Committee Review Original IRB Committee Date: July 15, 2015

Expiration Date: This approval expires on July 14, 2016.

If the project will continue, it must be renewed before the expiration date. Please allow at least six weeks for processing the renewal application. Data cannot be used in the research if collected after the expiration date, before the protocol has been renewed.

Completion: Upon completion of the project, a Study Completion Form must be submitted to the IRB. Renewal and completion forms are found on the web site under Forms and Templates.

Adverse Event Reporting: All unanticipated or serious adverse events must be reported to the IRB within ten working days.

Modifications: Prior IRB approval is required before implementing any changes in any of the approved documents. Data cannot be used in the research if collected before any changes are approved.

Recordkeeping: You must retain all signed consent forms for at least 3 years after all research activity is completed, including data analysis.

Questions: Please contact ORSP - Human and Animal Protections and the Institutional Review Board at (415) 338-1093, or at protocol@sfsu.edu

Sincerely,

Institutional Review Board

CALIFORNIA STATE UNIVERSITY: Bakernfield, Channel lolanda, Chico, Dominguez Hillo, East Bay, Fresno, Fullerton, Humboldr, Loung Beach, Lou Angeles,

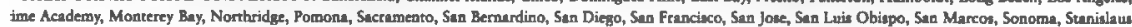


Appendix C

Recruitment Letter for Student Interviews

Hello, my name is Janine Saunders. I am a graduate student at San Francisco State University in the Graduate College of Education. I am conducting research about incarcerated students' experiences in school in [county name redacted], and I am inviting you to participate because you are currently enrolled in court school at [name of school redacted].

Participation in this research includes participating in an interview about your educational experiences in juvenile hall. If you agree to participate, I will interview you at a time convenient for you. The interview will take about 30 minutes, and I will audio record the interview to make sure I understand what you have said. If I need to clarify your statements, I will contact you within one month to conduct a second interview. The second interview will also take about 30 minutes.

If you agree to participate in this research and are chosen for an interview, you will be notified verbally by your teacher of the date and time of your interview.

If you have any questions or would like to participate in the research, I can be reached at (415) 323-6463 or jsaunde2@sfsu.edu. 
Appendix D

Recruitment Letter for Teacher Interviews and Observations

Hello, my name is Janine Saunders. I am a graduate student at San Francisco State University in the Graduate College of Education. I am conducting research about incarcerated students' experiences in school in [county name redacted], and I am inviting you to participate because you currently teach at [school name redacted].

Participation in this research includes participating in an observation of at least one class period. If you agree to participate, I will observe your class at a time convenient for you. The class period observation will take about 60 minutes, and I will take field notes during the observation. Following the observation, I will interview you at a time convenient for you. The interview will take about 30 minutes, and I will audio record the interview to make sure I understand what you have said. If I need to clarify your statements, I will contact you within one month.

If you have any questions or would like to participate in the research, I can be reached at (415) 323-6463 or jsaunde2@sfsu.edu. 


\author{
Appendix E \\ Minor Assent/Informed Consent to Participate in Interviews
}

\title{
Purpose of Research
}

Hello, my name is Janine Saunders. I am a graduate student at San Francisco State University in the Graduate College of Education. I am conducting research about incarcerated students' experiences in school in [county name redacted], and I am inviting you to participate because you are currently enrolled in court school at [school name redacted].

\section{Research Procedures}

Participation in this research includes participating in an interview about your educational experiences in juvenile hall. If you agree to participate, I will interview you at a time convenient for you. The interview will take about 30 minutes, and I will audio record the interview to make sure I understand what you have said. If I need to clarify your statements, I will contact you within one month to conduct a second interview. The second interview will also take about 30 minutes.

\section{Risks}

There is a risk of loss of privacy. However, no names or identities will be used in any published reports of the research. Only the facility advisor and I will have access to the research data. There is also a risk of discomfort or anxiety due to the nature of the questions asked; however, you can answer only those questions you choose to answer, and can stop participation in the interview at any time.

\section{Confidentiality}

To protect your privacy, all research data will be stored in a device with full disk encryption and password-protection. All data will be kept in Professor Jamal Cook's office at San Francisco State University in Burk Hall 521. I will not use your name or any other identifying information in the research reports. After three years, all written data will be destroyed and all electronic data will be de-identified and retained for possible use with research consistent with the purposes of this study.

It is important for you to know that I am a mandated reporter. As a mandated reporter, I am subject to the California Child Abuse and Neglect Reporting Act. This means that I must make a report if I suspect, or if you tell me, that you are are being hurt or abused or if you tell me that you have hurt or abused someone else. This includes if I think you may hurt yourself. 


\section{Benefits and Compensation}

There are no direct benefits to you for participating in this research. There will be no compensation for participating in this research.

\section{Costs}

There will be no cost to you for participating in this research.

\section{Assent/Consent}

You have been given a copy of this assent/consent to keep. If you have any questions about the research you may contact me at (415) 323-6463 or jsaunde2@sfsu.edu; or you may contact my faculty advisor, Professor Cooks, at jamalc@sfsu.edu; or Human and Animal Protections at protocol@sfsu.edu or 415-338-1093.

Please note that participation in research is voluntary. You may answer only those questions you want to answer, and you may stop participating at any time with no penalty. Your decision whether or not to participate in this research will have no bearing on your disposition in the juvenile justice system or on your educational status.

Participant's Name

Participant's Signature Date

Researcher's Signature Date 


\section{Appendix F \\ Parent/Guardian Permission}

\section{Purpose of Research}

Hello, my name is Janine Saunders. I am a graduate student at San Francisco State University in the Graduate College of Education. I am conducting research about incarcerated students' experiences in school in [county name redacted], and I am inviting your child to participate because he/she is currently enrolled in court school at [school name redacted].

\section{Research Procedures}

If you agree to let your child participate in this research, the following will occur:

I will interview your child at [school name redacted] during the weekday at a time convenient for him/her. I will ask questions about his/her educational experiences while incarcerated. The interview will take about 30 minutes, and I will audio record the interview to make sure I understand what he/she has said. If I need to clarify his/her statements, I will contact him/her within one month to conduct a second interview. The second interview will also take about 30 minutes.

\section{Risks}

There is a risk of loss of privacy. However, no names or identities will be used in any published reports of the research. Only the faculty advisor and I will have access to the research data. There is also a risk of discomfort or anxiety due to the nature of the questions asked; however, your child can answer only those questions he/she chooses to answer, and can stop participation in the interview at any time.

\section{Confidentiality}

To protect your child's privacy, all research data will be stored in a device with full disk encryption and password-protection. All data will be kept in Professor Jamal Cook's office at San Francisco State University in Burk Hall 521. I will not use your child's name or any other identifying information in the research reports. After three years, all written data will be destroyed and all electronic data will be de-identified and retained for possible use with research consistent with the purposes of this study.

It is important for you to know that I am a mandated reporter. As a mandated reporter, I am subject to the California Child Abuse and Neglect Reporting Act. This means that I must make a report if I suspect, or if your child tells me, he/she is being hurt or abused 
or if your child tells me that he/she has hurt or abused someone else. This includes if I think your child may hurt him/herself.

\section{Benefits and Compensation}

There are no direct benefits to you or your child for participating in this research. There will be no compensation for participating in this research.

\section{Alternatives}

Your child is free to choose not to participate in this research study.

\section{Costs}

There will be no cost to you or your child for participating in this research.

\section{Questions}

If you have any questions about the research you may contact me at (415) 323-6463 or jsaunde2@sfsu.edu or you may contact my advisor, Professor Cooks, at jamalc@sfsu.edu. Questions about your child's rights as a study participant, or comments or concerns about the study may be addressed to Human and Animal Protections at protocol@sfsu.edu or 415-338-1093.

\section{Consent}

You have been given a copy of this consent to keep. Please note that participation in research is voluntary. You are free to decline to have your child participate in this research. You may withdraw your child's participation at any time without penalty. Your decision whether or not to participate in this research will have no bearing on your child's disposition in the juvenile justice system or on your child's educational status.

\section{Child's Name}

Parent/Guardian Name

Parent/Guardian Signature Date

Researcher's Signature Date 
Appendix G

Teacher Consent to Participate in Interviews and Observations

\section{Purpose of Research}

Hello, my name is Janine Saunders. I am a graduate student at San Francisco State University in the Graduate College of Education. I am conducting research about incarcerated students' experiences in school in [county name redacted], and I am inviting you to participate because you currently teach at [school name redacted].

\section{Research Procedures}

Participation in this research includes participating in an observation of at least one class period and includes one interview. If you agree to participate, I will observe you while teaching at a time convenient for you. The class period observation will take about 60 minutes, and I will take field notes during the observation. Following the observation, I will interview you at a time convenient for you. The interview will take about 30 minutes, and I will audiotape the interview to make sure I understand what you have said. If I need to clarify your statements, I will contact you within one month.

\section{Risks}

There is a risk of loss of privacy. However, no names or identities will be used in any published reports of the research. Only the faculty advisor and I will have access to the research data.

\section{Confidentiality}

To protect your privacy, all research data will be stored in a device with full disk encryption and password-protection. I will not use your name or any other identifying information in the research reports. After three years, all written data will be destroyed and all electronic data will be de-identified and retained for possible use with research consistent with the purposes of this study.

\section{Benefits and Compensation}

There are no direct benefits to you for participating in this research. There will be no compensation for participating in this research.

\section{Alternatives}

You are free to choose not to participate in this research study.

\section{Costs}

There will be no cost to you for participating in this research. 


\section{Questions}

If you have any questions about the research you may contact me at (415) 323-6463 or jsaunde2@sfsu.edu; or you may contact my faculty advisor, Professor Cooks, at jamalc@sfsu.edu; or Human and Animal Protections at protocol@sfsu.edu or 415-3381093.

\section{Consent}

You have been given a copy of this consent to keep. Please note that participation in research is voluntary. You may answer only those questions you want to answer, and you may stop participating at any time with no penalty.

Participant's Name

Participant's Signature Date

Researcher's Signature Date 
Appendix $\mathrm{H}$

\section{Student Interview Protocol}

The purpose of this research is to learn more about your schooling experiences in juvenile hall. I am a currently a graduate student at San Francisco State University and I am conducting this research for a class project. If you agree to participate in this project, you will be interviewed for approximately 30 minutes.

No names or identities will be used in any published reports of the research. The questions asked may make you feel uncomfortable or anxious; you can answer only those questions you choose and can stop the interview at any time. Only my faculty advisor, Professor Jamal Cooks, and I will have access to the research data. No other students and no professors will receive any identifying information including your name. We will not be discussing the facility in which you are incarcerated or the reason(s) for your incarceration.

Please provide only the information that directly answers the question and no additional information. You are free to end the interview at any time or skip any questions you do not want to answer.

\section{First Interview}

1. Tell me about yourself.

1b. Do you remember your very first day of school? Can you tell me about it?

2. What do you recall most about elementary school?

3. What do you recall most about middle school?

4. Tell me about the school you were attending right before you came here.

\section{Second Interview}

5. Tell me about your experiences in school here.

$5 \mathrm{~b}$. Walk me through a whole day at school here.

6. What do you enjoy most about school here?

7. What do you enjoy least about school here?

8. What, if any, academic support do you receive from teachers here?

9. How do you think the teachers feel about their job here?

10. How do you think the other adults feel about their job here?

11. If you have problems here, are they with the school work or with the people around you?

\section{Third Interview}


12. Does school in juvenile hall prepare you for the real world? If yes, how?

13. What do you think is the purpose of school in the hall?

14. What advice would you give to a student just arrested who is about to begin school in the hall?

15. Do you see yourself as a learner? If yes, say more about that.

16. What do you think people need to know about school here? 


\section{Appendix I}

\section{Teacher Interview Protocol}

The purpose of this research is to learn more about students' schooling experiences while in juvenile hall. I am a currently a graduate student at San Francisco State University and I am conducting this research for a class project. If you agree to participate in this project, you will be interviewed for approximately 30 minutes following a classroom observation.

No names or identities will be used in any published reports of the research. Only my faculty advisor, Professor Jamal Cooks, and I will have access to the research data. No other students and no professors will receive any identifying information including your name.

Please provide only the information that directly answers the question and no additional information. You are free to end the interview at any time.

1. Tell me about yourself.

2. How long have you taught here?

3. Tell me about your experiences teaching here.

4. What do you enjoy most about teaching here?

5. What do you enjoy least about teaching here?

6. Tell me about the academic support that you provide to students.

7. How do you feel about your job here?

8. How do you think other teachers feel about their job here?

9. How do you think the other adults feel about their job here?

10. Who helps you when you have challenges here?

11. Does school in juvenile hall prepare students for the real world? If yes, how?

12. What do you think is the purpose of school in the hall?

13. What advice would you give to a student just arrested who is about to begin school in the hall?

14. Tell me about your teaching philosophy.

15. What do you think people need to know about teaching here? 